\title{
Molybdenum-100 Targets for Cyclotron Production of Technetium-99m
}

\author{
by
}

Gabriel J. Surette

\begin{abstract}
A thesis submitted to
the Faculty of Graduate and Postdoctoral Affairs in partial fulfillment of the requirements for the degree of

Master of Applied Science

in

Mechanical Engineering
\end{abstract}

Ottawa-Carleton Institute for Mechanical and Aerospace Engineering Department of Mechanical and Aerospace Engineering Carleton University Ottawa, Ontario, Canada
(C) 2015

Gabriel J. Surette 


\section{Abstract}

A process for manufacturing targets for technetium- $99 \mathrm{~m}$ production, via ${ }^{100} \mathrm{Mo}(\mathrm{p}$, $2 \mathrm{n})^{99 \mathrm{~m}} \mathrm{Tc}$, is presented. Targets consist of a thin layer of molybdenum-100 pressed into a copper heat sink complete with water cooling channels and O-rings. These targets are designed to be irradiated in cyclotrons at hospitals and regional pharmacies around the world to replace fission produced ${ }^{99} \mathrm{Mo}$.

The iterations and tests leading to the final target design and processing procedures are presented. Physical descriptions of the targets are given, followed by the procedure for manufacture, and process improvements for large-scale production.

The importance of ${ }^{99 \mathrm{~m}} \mathrm{Tc}$ as a diagnostic imaging tool is presented, with references to instability of current sources and recent shortages, which have had led to world-wide efforts to develop non-reactor produced isotopes. 


\section{Acknowledgements}

First and foremost, I would like to thank my supervisor, Dr. Glenn McRae, for giving me the opportunity to work on this project and pushing me to succeed. Glenn was patient throughout this work, but emphasized the importance of deadlines and given requirements. Meetings with Glenn and his students are enjoyable.

Scott Langille, Curtis St. Louis, and Paul Keeping played a pivotal role in the production of targets. They gave novel ideas, helping hands, and humour from the beginning of the project, right until the end.

The Science Technology Centre, specifically, I would like to thank Graham Beard, Ron Roy, and Steve Tremblay. Not only is the level of their work top notch, they also had insight when developing new parts and accommodated this project with amazing lead time when deadlines were looming.

Alex Proctor, Kevin Sangster, and Ian Lloy of the Mechanical \& Aerospace Engineering Machine Shop allowed me access to the shop in my first year at Carleton, and every year since. They increased my practical knowledge, which helps for designing components and experiments.

Thanks to the Civil and Environmental Engineering lab, supervised by Stanley Conley, keeper of the MTS press. The MTS press was available within short notice, and the 
friendly staff would take time from their work to turn on the hydraulic pumps so we could press targets, lots of targets.

Best Theratronics Limited and Advanced Systems Designs Incorporated also supported the project in numerous ways, including: contributing ideas at team meetings, organizing machine shop time, and gold plating copper blanks. Dr. Lidia Matei required these targets for her radiochemistry experiments so she would push for progress and help answer the many questions I had. William Gelbart has been in the targetry business for over thirty years and was irreplaceable during the design of elliptical targets.

Family and friends, they are the most important people of all. I have been blessed with four older siblings, a pile of cousins, and an even larger group of friends. I can't list all of you by name, but every bit of support you provided made this project a success. I was once told this is the kind of thing that makes parents proud. 


\section{Table of Contents}

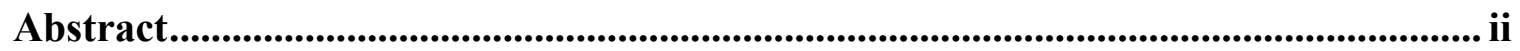

Acknowledgements ............................................................................................................................. iii

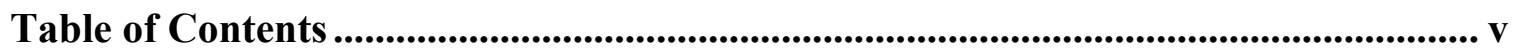

List of Tables ................................................................................................................................ viii

List of Figures........................................................................................................................... ix

List of Appendices......................................................................................................................... xi

List of Abbreviations .................................................................................................................. xii

1 Chapter: Introduction .............................................................................................. 1

$1.1 \quad$ Diagnostic Imaging using SPECT ……………………………………………....

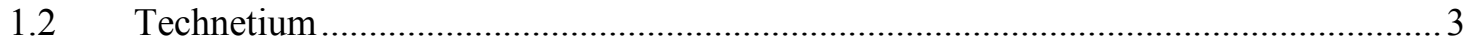

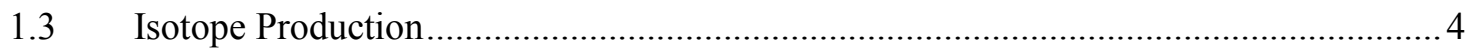

1.3.1 Linear Accelerator Pros and Cons..........................................................................

1.3.2 Cyclotron Pros and Cons...................................................................................

1.3.3 Competitive Target Designs .................................................................................

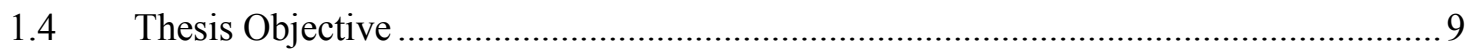

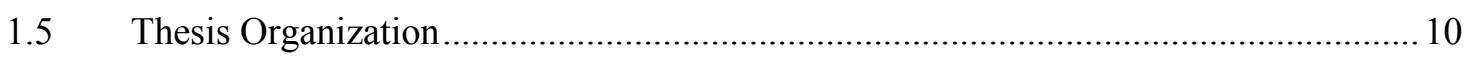

2 Chapter: Target Iterations and Developments ......................................................... 11

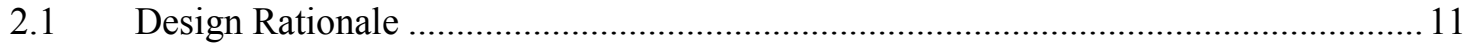

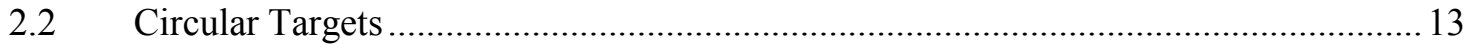

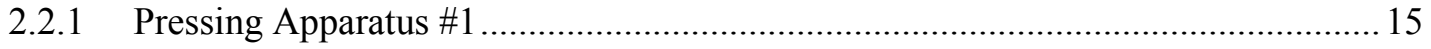

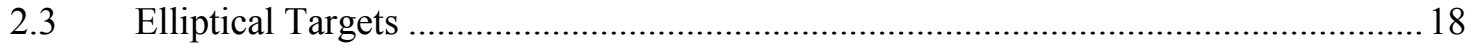

2.3.1 Pressing Apparatus \#2 ………………………………………………………... 19

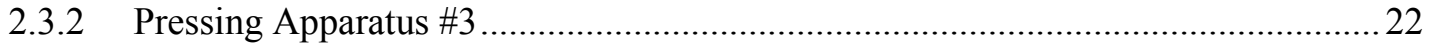




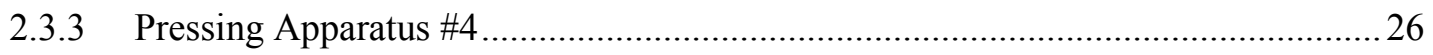

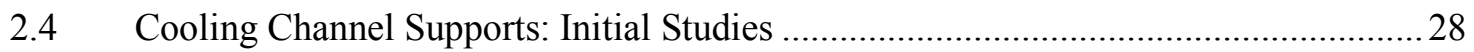

3 Chapter: Target Design and Procedure for Manufacture ................................... 30

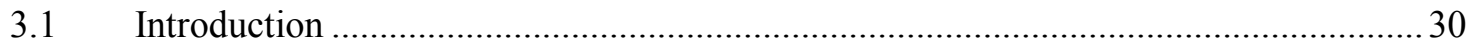

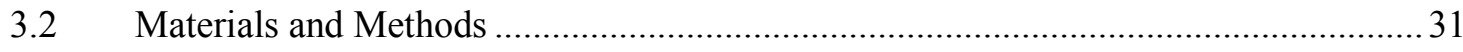

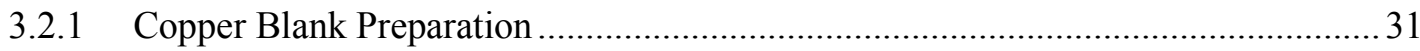

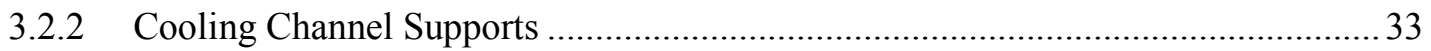

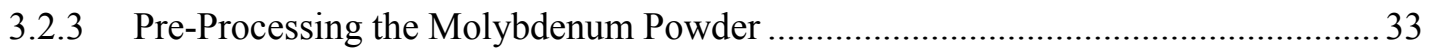

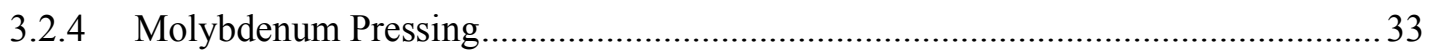

3.2.4.1 Apparatus for Pressing an Elliptical Target................................................. 34

3.2.4.2 Procedure for Pressing an Elliptical Target................................................... 35

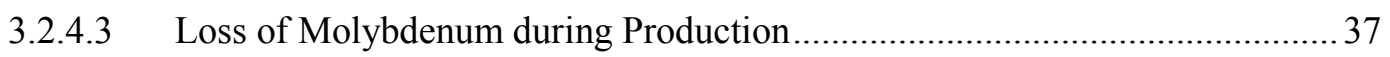

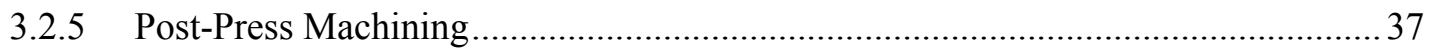

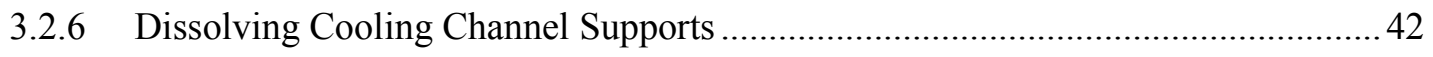

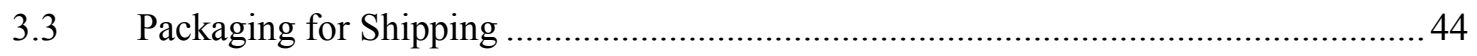

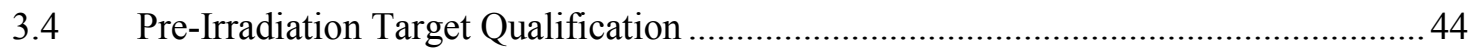

4 Chapter: Testing and Irradiation of Circular Targets............................................ 46

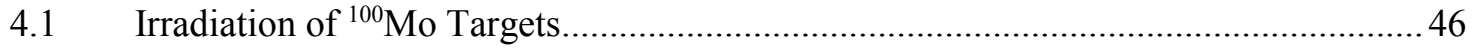

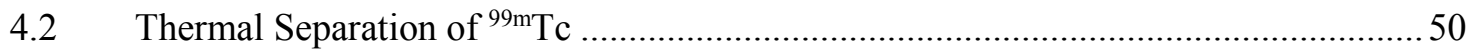

5 Chapter: Large Scale Production and Future Considerations ........................... 52

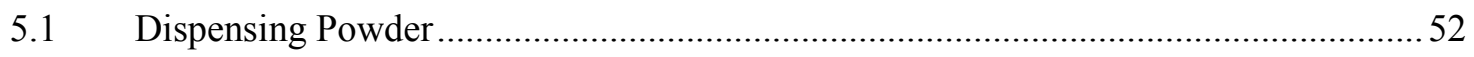

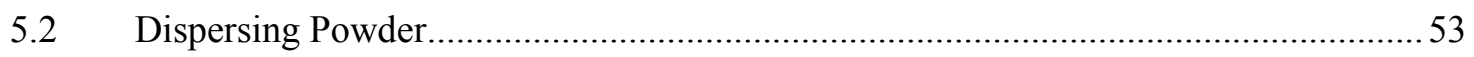

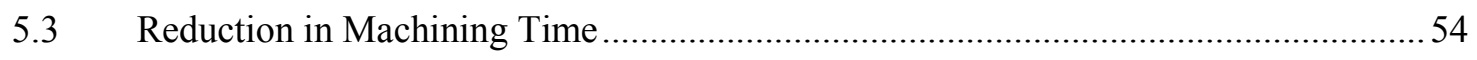

6 Chapter: Conclusions ....................................................................................... 56

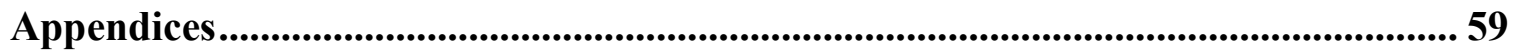


Appendix A Engineering Drawings of Components

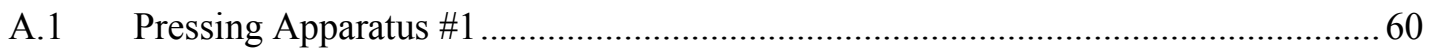

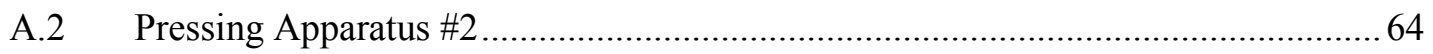

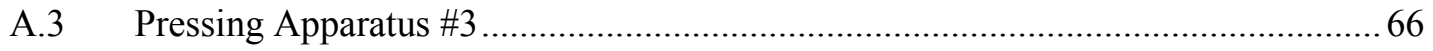

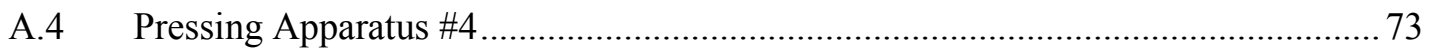

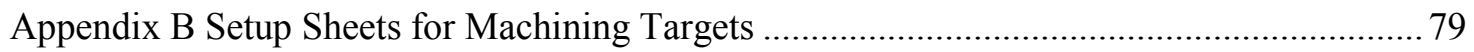

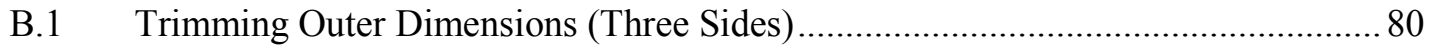

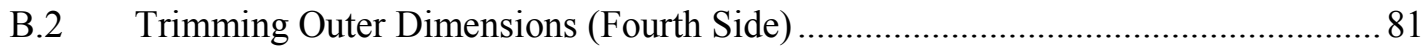

B.3 Target Thickness and Water Side O-ring Groove ................................................ 82

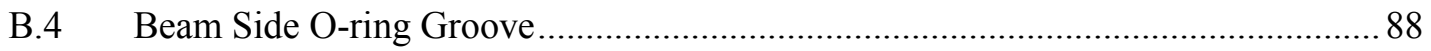

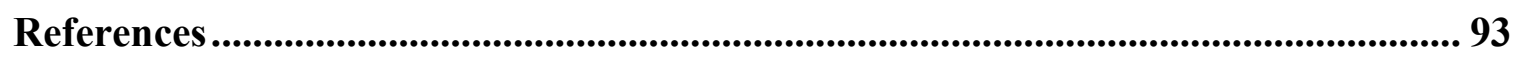




\section{List of Tables}

Table 1: Summary of data for circular ${ }^{100}$ Mo targets.............................................. 18

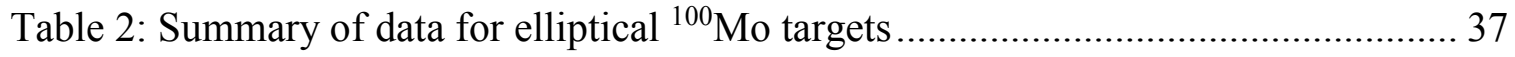

Table 3: Isotopic distribution of Mo-100 target material............................................. 49 


\section{List of Figures}

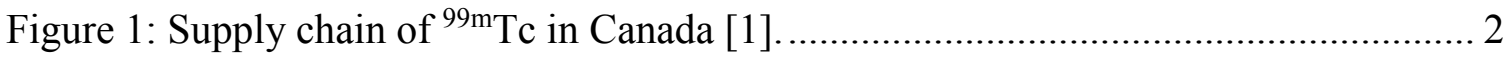

Figure 2: Breakdown of the medical uses of Tc-99m [6] .......................................... 3

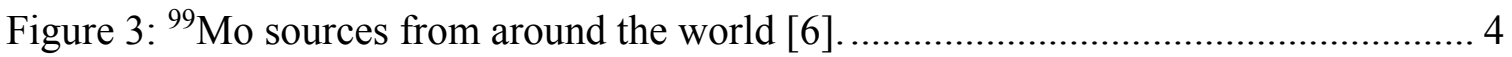

Figure 4: Schematic of elliptical target in beam line................................................... 12

Figure 5: SEM image of the cross section of a circular target....................................... 17

Figure 6: Rendered image of an elliptical target. Dimensions: $65 \mathrm{~mm}$ x $30 \mathrm{~mm}$ x $2.8 \mathrm{~mm}$.

Figure 7: Copper blank with pressing apparatus \#2.................................................. 20

Figure 8: SEM image of cross section of an elliptical target, with a dense $60 \mu \mathrm{m}$

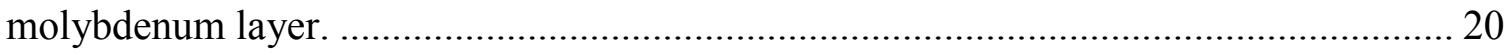

Figure 9: Elliptical targets proof of concept: water side (left) and beam side (right)....... 21

Figure 10: SEM image of cross section of elliptical target manufactured with manual press and apparatus \#3. The molybdenum is not fully dense. .......................................... 24

Figure 11: Lower Mold \#4 and Cooling Channel Support \#2 with a copper blank.......... 26

Figure 12: Lower Mold \#4 and Cooling Channel Support \#2 ........................................ 27

Figure 13: Slitting saw (50.8 mm diameter) and jig for cutting cooling channels into a

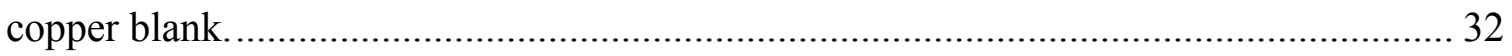

Figure 14: Three-pin jig for cutting outer dimensions of elliptical targets...................... 38

Figure 15: Clamping sequence for machining outer dimensions of an elliptical target.

Three sides can be machined while clamped in the left configuration; the final side is

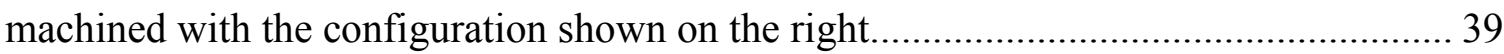

Figure 16: Two-piece jig attached to vice jaws, used to clamp a target. .......................... 40 
Figure 17: Finished O-ring groove on water side of an elliptical target.......

Figure 18: An elliptical target with molybdenum covered, awaiting beam side O-ring

groove.

Figure 19: Dissolving cooling channel supports from an elliptical target supported in beaker.

Figure 20: Beam side of a finished elliptical ${ }^{100}$ Mo target......................................... 43

Figure 21: Water side of a finished elliptical ${ }^{100}$ Mo target. ........................................ 43

Figure 22: Circular ${ }^{100} \mathrm{Mo}$ target (24 mm diameter) before (left) and after (right) irradiation [21]. 47

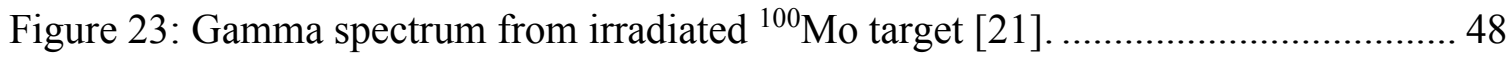

Figure 24: Thermal Separation Unit with mixture of $\mathrm{H}_{2} \mathrm{O}_{2}$ and dissolved target. 51 


\section{List of Appendices}

Appendix A: Engineering Drawings of Components ..............................................59

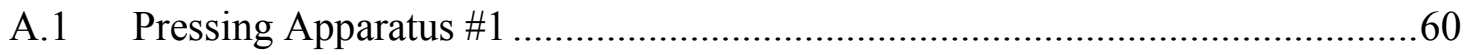

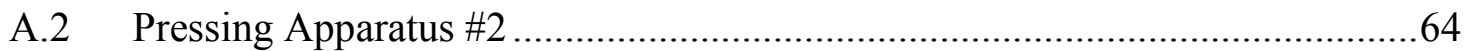

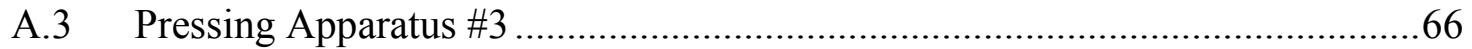

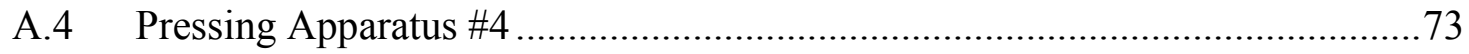

Appendix B: Setup Sheets for Machining Targets .......................................................79

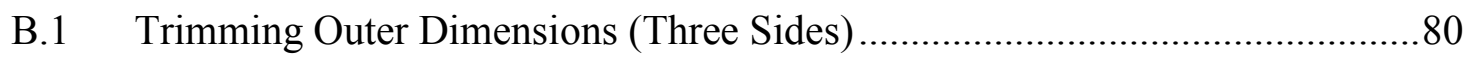

B.2 Trimming Outer Dimensions (Fourth Side) ............................................. 81

B.3 Target Thickness and Water Side O-ring Groove .........................................82

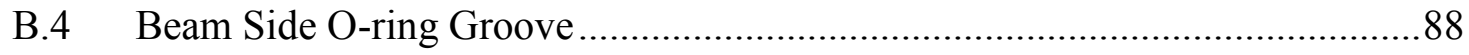




\section{List of Abbreviations}

\begin{tabular}{|c|c|}
\hline AECL & Atomic Energy of Canada Limited \\
\hline $\mathrm{Al}$ & Aluminum \\
\hline ASD-Inc. & Advanced Systems Designs Incorporated \\
\hline $\mathrm{Bq}$ & Becquerel \\
\hline BR2 & Belgian Reactor 2 \\
\hline BTL & Best Theratronics Limited \\
\hline CAD & Computer Aided Design \\
\hline $\mathrm{Ci}$ & Curie \\
\hline CLS & Canadian Light Source \\
\hline $\mathrm{Cu}$ & Copper \\
\hline EOB & End of Bombardment \\
\hline $\mathrm{H}_{2} \mathrm{O}_{2}$ & Hydrogen Peroxide \\
\hline $\mathrm{HCl}$ & Hydrochloric acid \\
\hline HFR & High Flux Reactor \\
\hline ITAP & Isotope Technology Acceleration Program \\
\hline M42 & $\begin{array}{l}\text { Tool steel with composition C: } 1.10 \text {; Si: } 0.50 \text {; Mn: } 0.20 \text {; Cr: } 3.90 \text {; Mo: } \\
\text { 9.20; W: } 1.40 ; \text { Co: } 7.80 \text {; V: } 1.00\end{array}$ \\
\hline MAPLE & Multi-purpose Applied Physics Lattice Experiment \\
\hline $\mathrm{MeV}$ & Mega electron Volt \\
\hline Mo & Molybdenum \\
\hline MTS & Material Test System \\
\hline $\mathrm{Na}^{99 \mathrm{~m}} \mathrm{TcO}_{4}$ & Sodium Pertechnetate \\
\hline NIPNE & National Institute for Physics and Nuclear Engineering \\
\hline NISP & Non-reactor-based Isotope Supply Contribution Program \\
\hline NRU & National Research Universal \\
\hline PET & Positron Emission Tomography \\
\hline PIPE & Prairie Isotope Production Enterprise \\
\hline SAFARI & South African Fundamental Atomic Research Installation \\
\hline SEM & Scanning Electron Microscope \\
\hline SPECT & Single Photon Emission Computed Tomography \\
\hline SRIM & Stopping and Range of Ions in Matter \\
\hline STC & Science Technology Centre \\
\hline Tc & Technetium \\
\hline TRIM & TRansport of Ions in Matter \\
\hline $\mathrm{U}$ & Uranium \\
\hline
\end{tabular}




\section{Chapter: Introduction}

The purpose of this project was to develop a process for manufacturing medical isotope targets, which will be irradiated with protons in cyclotrons at hospitals and regional pharmacies around the world. Currently, the vast majority of medical isotopes used in diagnostic imaging are supplied by nuclear reactors. In Canada, the National Research Universal (NRU) reactor in Chalk River produces medical isotopes, which are shipped to MDS Nordion in Ottawa, and subsequently shipped internationally [1]. The supply chain of technetium-99m $\left({ }^{99 m} \mathrm{Tc}\right)$ in Canada is shown in Figure 1. With the shutdown of the NRU reactor scheduled for March 31, 2018 [2], many Canadian companies and universities are taking advantage of government sponsored programs in order to be at the forefront of non-reactor produced isotopes. In collaboration with Best Theratronics Limited, Carleton University developed a ${ }^{100}$ Mo target which is used to produce the most commonly used medical isotope, ${ }^{99 \mathrm{~m}} \mathrm{Tc}$. The importance of ${ }^{99 \mathrm{~m}} \mathrm{Tc}$ becomes apparent when looking at the statistics of its usage; it is used worldwide in more than 30 million procedures each year, and its use is expected to increase by one or two percent each year for the next twenty years [3]. Reliable sources for medical isotopes are essential for the health and welfare of Canadians, and the ability to produce isotopes on-site at hospitals will both increase access to the isotopes, and reduce shipment requirements. 

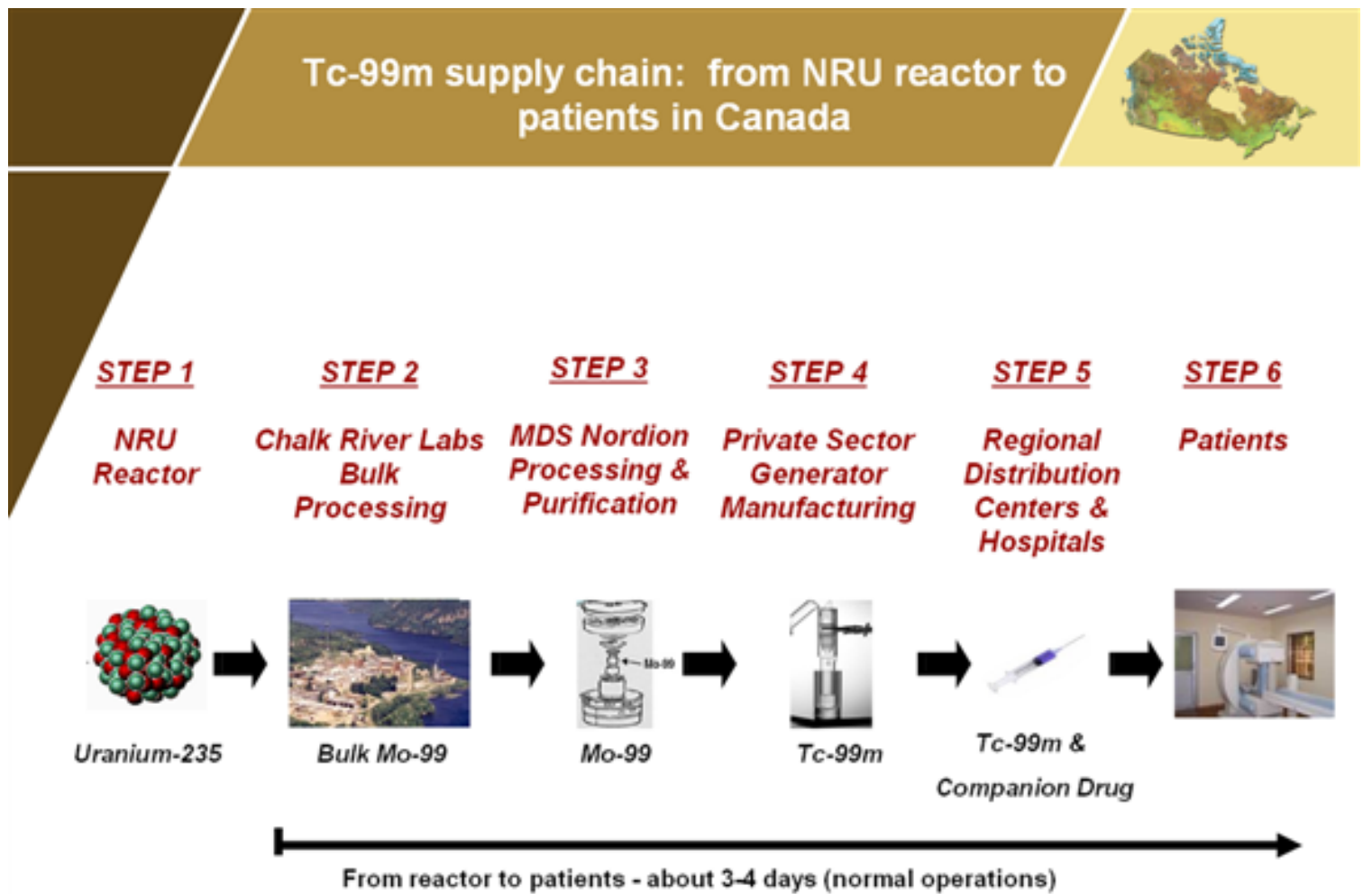

17. Natural Resources Resecurces naturelles

Canadä

Figure 1: Supply chain of ${ }^{99 \mathrm{~m}} \mathrm{Tc}$ in Canada [1].

\subsection{Diagnostic Imaging using SPECT}

Single Photon Emission Computed Tomography (SPECT) is a widely used diagnostic nuclear imaging technique. SPECT scanners provide images of organ function that are used to diagnose tumours, infection, and neurological disorders [4]. The physiological images are developed based on the detection of energy transmitted from a radioactive pharmaceutical administered to the patient, usually intravenously [5]. The radiopharmaceutical employed is determined by what part of the body is under study. Pharmaceuticals are designed to collect in specific organs. The radioactive isotope emitting electromagnetic radiation in the form of gamma rays, is attached to specific 
molecules as a radiopharmaceutical compound, and used in medical imaging. A gamma camera detects the gamma rays from the organ being studied [5]. A computer is used in conjunction with the gamma camera to produce a tomographical image of the radiopharmaceutical in the organ. Technetium- $99 \mathrm{~m}$ is the dominant radionuclide for SPECT imaging, and can be attached to over 20 compounds [6]. A breakdown of the uses for ${ }^{99 \mathrm{~m}} \mathrm{Tc}$ as a medical isotope is shown in Figure 2.

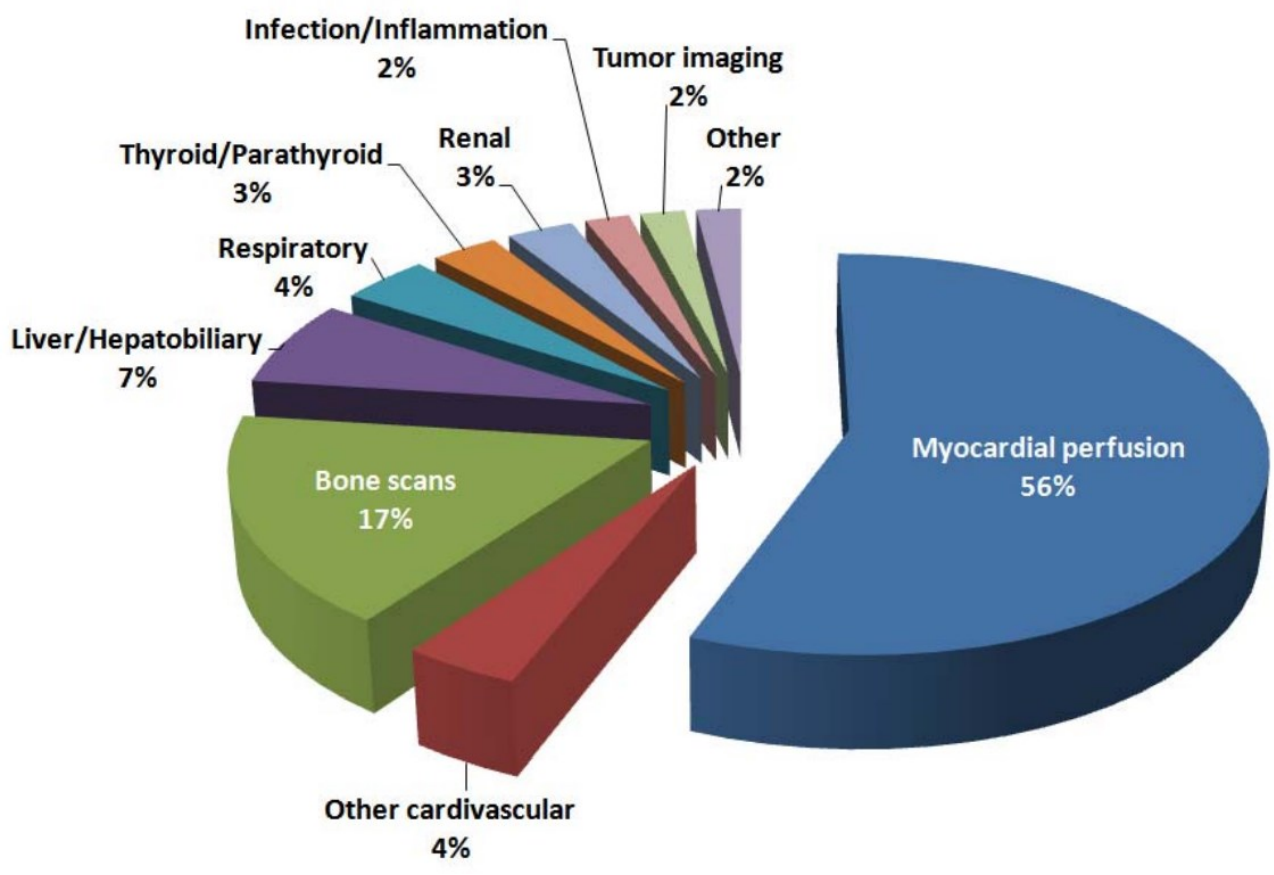

Figure 2: Breakdown of the medical uses of Tc-99m [6].

\subsection{Technetium}

Technetium was the first element to be artificially created, and was done so by Italian physicists in 1937 [7]. Perrier and Segrè discovered technetium by examining a molybdenum sample which had been bombarded by deuterons from the Berkeley cyclotron [8]. There are twenty-two isotopes of technetium, however, the most 
commonly sought isotope is ${ }^{99 \mathrm{~m}} \mathrm{Tc}\left(\mathrm{T}_{1 / 2}=6.02\right.$ hours $)$, a meta-stable isomer of ${ }^{99} \mathrm{Tc}[9]$. The importance of ${ }^{99 \mathrm{~m}} \mathrm{Tc}$ as a medical isotope for diagnostic imaging has been known since the early 1960's, when it was used at Brookhaven Medical Department in a thyroid physiology study [10]. Technetium-99m is a desirable isotope for diagnostic imaging because its short half-life of 6 hours limits radiation exposure to patients, and the 140 $\mathrm{keV}$ gamma rays emitted are easily detected by a gamma camera [9]. Worldwide, approximately $80 \%$ of all diagnostic imaging procedures involve ${ }^{99 \mathrm{~m}} \mathrm{Tc}[3]$.

\subsection{Isotope Production}

Historically, ${ }^{99 \mathrm{~m}} \mathrm{Tc}$ has been produced from beta decay of ${ }^{99} \mathrm{Mo}$, which is a fission product of uranium. Five nuclear reactors, including NRU in Chalk River, Canada, supply $95 \%$ of the world's ${ }^{99}$ Mo [6]. A breakdown of ${ }^{99}$ Mo sources is shown in Figure 3. Chalk River generally produces between $30 \%$ and $40 \%$ of the required world supply of ${ }^{99}$ Mo [6].
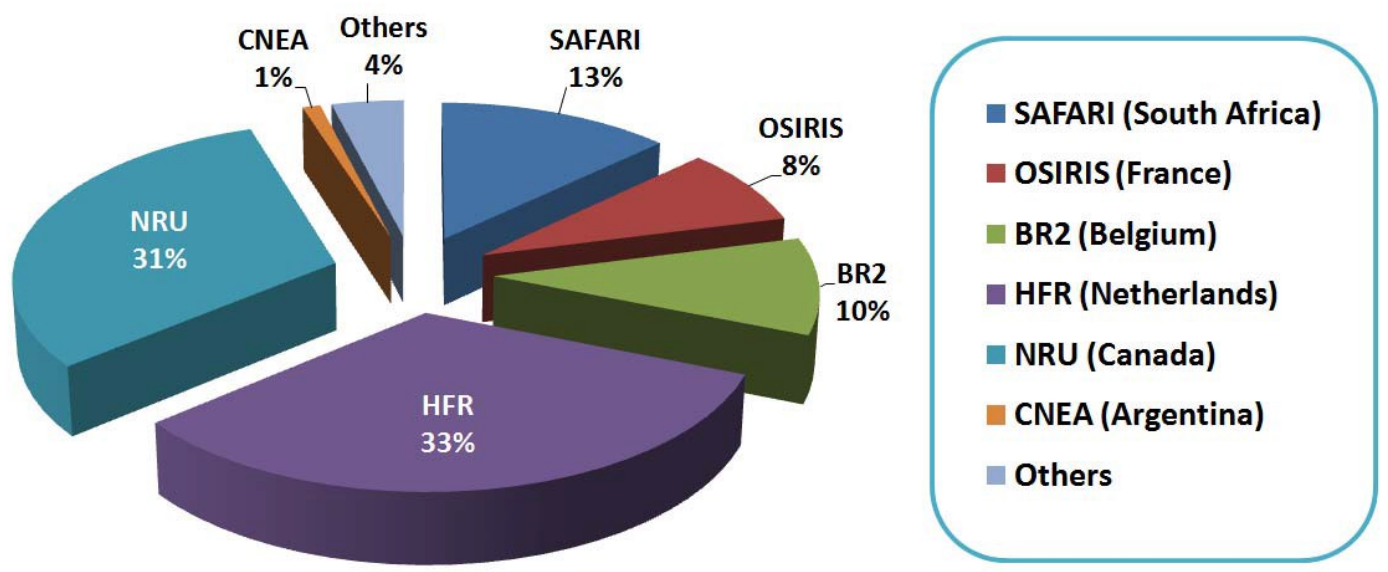

Figure 3: ${ }^{99}$ Mo sources from around the world [6]. 
Molybdenum-99 is produced by irradiating highly enriched uranium targets: ${ }^{235} \mathrm{U}(\mathrm{n}$, F) ${ }^{99}$ Mo. Isomers with atomic mass 99 amu account for six percent of the fission products [11].

Production of ${ }^{99 \mathrm{~m}} \mathrm{Tc}$ from fission ${ }^{99} \mathrm{Mo}$ has been the preferred method because of available reactor infrastructure and, hence, other methods were not commercialized. Unfortunately, the current reactors used to produce ${ }^{99} \mathrm{Mo}$ are old and are scheduled for imminent shutdown. The project between Atomic Energy of Canada Limited (AECL) and MDS Nordion to replace NRU with MAPLE 1 and MAPLE 2 was cancelled in 2008 [6]. The reactors would have been capable of producing $100 \%$ of the world's required ${ }^{99}$ Mo [12]. Non-reactor based methods to produce ${ }^{99}$ Mo were not considered for commercial production because it was assumed the MAPLE reactors would provide a robust supply.

An example of non-reactor produced ${ }^{99 \mathrm{~m}} \mathrm{Tc}$ was demonstrated in 1971 when Beaver and Hupf bombarded a ${ }^{100}$ Mo target with protons from a medical cyclotron, resulting in the emission of two neutrons, via ${ }^{100} \mathrm{Mo}(\mathrm{p}, 2 \mathrm{n}){ }^{99 \mathrm{~m}} \mathrm{Tc}$ [13]. Little attention was given to this method until NRU experienced unexpected shutdowns in 2007 and 2009. The reactor shutdowns caused world-wide isotope shortages, exemplified by journal articles and news headlines locally and internationally. Articles were titled: "Medical isotope shortage reaches crisis level" (Nature [14]), "Isotope shortage looms after reactor shutdown," (Toronto Star, [15]), and "Medical isotope shortage concerns in US" (Royal Society of Chemistry [16]). 
The fragility of the ${ }^{99 \mathrm{~m}} \mathrm{Tc}$ supply was further exposed when the Canadian government announced a halt of reactor based isotope production in 2016, later revised to 2018 [2]. Simultaneously, the Canadian government promised a secure supply of ${ }^{99 \mathrm{~m}} \mathrm{Tc}$ for Canadians when NRU halts production. This promise was accompanied by government sponsored research programs such as Non-reactor-based Isotope Supply Contribution Program (NISP - \$35 million) [17], and Canada’s Isotope Technology Acceleration Program (ITAP - \$25 million), [18]. The purpose of these programs was to "support collaboration among academic, private and public sector partners to develop non-reactorbased technologies, particularly linear accelerators and cyclotrons, to produce a more diverse and reliable supply of Tc-99m in the medium to long term [18]."

Several Canadian companies, enterprises, and universities, including TRIUMF on the University of British Columbia campus [19], the University of Alberta [11], Canadian Light Source (CLS), and Prairie Isotope Production Enterprise (PIPE) have been concurrently trying to produce medical isotope targets for use in particle accelerators. Apart from direct production of ${ }^{99 \mathrm{~m}} \mathrm{Tc}$ with a cyclotron, linear accelerators are used for ${ }^{100} \mathrm{Mo}(\gamma, \mathrm{n}){ }^{99} \mathrm{Mo}$, and photo-fission of ${ }^{238} \mathrm{U}[6]$. Details of these methods and predictions of how Canada will produce the required ${ }^{99 \mathrm{~m}} \mathrm{Tc}$ are found in the "Report of the Expert Review Panel on Medical Isotope Production" [6]. Canada uses 4 TBq (110 Ci) for $5,500{ }^{99 \mathrm{~m}} \mathrm{Tc}$ scans every day, which requires $8 \mathrm{TBq}(220 \mathrm{Ci})$ at the start of each day to compensate for the six hour half-life decay [12]. A novel method of nuclear diagnostic imaging called neutron-activated Single Photon Emission Computed Tomography (nSPECT) is also being assessed as an alternative to injecting radioactive isotopes [20]. 


\subsubsection{Linear Accelerator Pros and Cons}

Electron accelerators are used to bombard ${ }^{100}$ Mo targets, which causes the ${ }^{100} \mathrm{Mo}(\gamma$, n) ${ }^{99}$ Mo reaction [12]. Linear accelerators require enriched molybdenum targets, and produce ${ }^{99} \mathrm{Mo}$, which is loaded into ${ }^{99 \mathrm{~m}} \mathrm{Tc}$ generators; a proven technology currently used for reactor produced ${ }^{99} \mathrm{Mo}$. The half-life of ${ }^{99} \mathrm{Mo}$ is more than ten times that of ${ }^{99 \mathrm{~m}} \mathrm{Tc}$, so a central location can produce and ship the ${ }^{99} \mathrm{Mo}$, in accord with the current supply chain, Figure 1. Few linear accelerators exist in Canada for this purpose, whereas cyclotrons already exist in hospitals and pharmacies.

\subsubsection{Cyclotron Pros and Cons}

Technetium-99m can be produced in hospitals and regional pharmacies with the same cyclotron technology currently used for making Positron Emission Tomography (PET) isotopes, although time on cyclotrons would have to be divided between these competing technologies. Cyclotrons directly produce ${ }^{99 \mathrm{~m}} \mathrm{Tc}$ via ${ }^{100} \mathrm{Mo}(\mathrm{p}, 2 \mathrm{n}){ }^{99 \mathrm{~m}} \mathrm{Tc}$ reaction and will not require the traditional generator; however, methods to separate and purify the ${ }^{99 \mathrm{~m}} \mathrm{Tc}$ are in the research and development stage and will require licensing before they can be commercialized. In addition, targets need to be designed, which is the objective of this thesis.

\subsubsection{Competitive Target Designs}

Methods proposed for large-scale target manufacturing include: electrophoretic deposition [19], pressing and sintering [11], electroplating, and carburization. Plasma spraying was investigated, but customized equipment to reduce wasteful overspray 
became too costly for the process to be feasible [21]. Regardless of manufacturing procedure, targets must dissipate heat during irradiation, and higher thermally conductive substrates allow higher power proton beam lines, which yield more ${ }^{99 \mathrm{~m}} \mathrm{Tc}$.

Manufacturing ${ }^{100}$ Mo targets via electrophoretic deposition [19] involves high temperature sintering, which necessitated a material with a high melting temperature, such as tantalum. Tantalum has poor thermal conductivity relative to copper, and therefore cannot dissipate as much heat during irradiation. In the electrophoretic deposition process, ${ }^{100}$ Mo powder is initially refined in three stages by heating it as a mixture with $\mathrm{H}_{2} \mathrm{O}_{2}$, in a partial hydrogen environment. The refined powder is then mixed with a polar organic solvent and a binder, and a potential of $1200 \mathrm{~V}$ is applied between an anode and cathode for up to 30 minutes to cause deposition of binder and ${ }^{100}$ Mo onto the cathode. Targets are then sintered in an argon environment for several hours at temperatures between $1200^{\circ} \mathrm{C}$ and $1900^{\circ} \mathrm{C}$, and still only achieve $85 \%$ theoretical density [19].

The pressing and sintering manufacturing process [11] has advantages compared with the electrophoretic deposition method, and an aluminum substrate is used for its higher thermal conductivity relative to tantalum. In the process, molybdenum sheets are pressed and then sintered at $1600^{\circ} \mathrm{C}$ in a hydrogen rich environment. The sheets are subsequently bonded to an aluminum substrate by application of compressive force and heat, for an hour in an evacuated atmosphere [11]. 
Targets manufactured with procedures presented in this thesis are advantageous over other target designs, because fully dense molybdenum is bonded to a copper substrate with compressive force alone. Copper has higher thermal conductivity than tantalum and aluminum; therefore, more heat can be dissipated by the target, allowing higher beam power, thereby increasing production of ${ }^{99 \mathrm{~m}} \mathrm{Tc}$.

\subsection{Thesis Objective}

The objective of this thesis was to produce a robust target comprised of a thin layer of ${ }^{100}$ Mo bonded to a copper heat sink subject to the following requirements:

- Demonstrate a target produces ${ }^{99 \mathrm{~m}} \mathrm{Tc}$ when irradiated in a cyclotron with protons and is commercially viable.

- Target must be capable of withstanding irradiation induced heat $(6 \mathrm{~kW})$ for up to six hours. In the event that the target fails during irradiation, radioactive material could move throughout the cyclotron, which would require expensive downtime and decontamination.

- Loss of ${ }^{100} \mathrm{Mo}$ was to be less than $5 \%$ during production. The ${ }^{100} \mathrm{Mo}$ costs about $\$ 2000 / g$ (ISOFLEX, USA), so waste must be minimal.

- O-rings for the target were to be specified; one to seal the proton beam side and hold a medium vacuum $\left(10^{-7} \mathrm{~atm}\right)$, the other to seal the cooling channels through which water is pumped.

- The molybdenum layer was to be greater than $95 \%$ of the theoretical density, with a thickness of about $60 \mu \mathrm{m}$ for elliptical targets and $230 \mu \mathrm{m}$ for circular targets. 
- Geometric tolerances on the target needed to be consistent with the tolerances of the target holder on the cyclotron.

\subsection{Thesis Organization}

This thesis is organized into six chapters. The introduction chapter is followed by Chapter 2, in which the rationale for target design and specifications are described. Initial iterations and target development are also discussed. Chapter 3 presents the final procedure used for production of targets. Steps for transforming a copper blank into a target ready for irradiation are explained, with specific information provided on the materials and methods required. The fourth chapter is devoted to results from irradiation

of circular ${ }^{100} \mathrm{Mo}$ targets and ${ }^{99 \mathrm{~m}} \mathrm{Tc}$ obtained from the targets. The fifth chapter discusses experiments conducted to increase the production rate of targets. Future considerations pertaining to mass production of targets are discussed. The concluding chapter reviews how the requirements for the objective of the thesis were met. 


\section{Chapter: Target Iterations and Developments}

This chapter discusses iterations undertaken to meet the requirements of Section 1.4. The rationale for the preliminary designs and the final target manufacturing procedure are given. Descriptions of various apparatus developed to meet the requirements are presented.

\subsection{Design Rationale}

The target was designed to be irradiated with a $15 \mathrm{MeV}$ proton beam. The thickness of the molybdenum layer was chosen such that the energy of the beam would be reduced to $10 \mathrm{MeV}$ as it exits the layer. In the $15 \mathrm{MeV}$ to $10 \mathrm{MeV}$ energy range, both meta-stable and ground state ${ }^{99} \mathrm{Tc}$ are produced [11]. Only the meta-stable ${ }^{99 \mathrm{~m}} \mathrm{Tc}$ is desired, as the ground state ${ }^{99} \mathrm{Tc}$ does not emit gamma radiation and is an additional chemical load to the patient. Target thickness optimizes the ratio of ${ }^{99 \mathrm{~m}} \mathrm{Tc}$ to ${ }^{99} \mathrm{Tc}$ production.

Molybdenum thickness was based on results obtained by simulations made with "Stopping and Range of Ions in Matter" (SRIM [22]) software, which calculates the range of energetic particles (protons) in matter (molybdenum). The range of a $10 \mathrm{MeV}$ proton in molybdenum was subtracted from the range of a $15 \mathrm{MeV}$ proton, to provide the desired thickness, which was a $230 \mu \mathrm{m}$ molybdenum layer at normal incidence. Two types of targets were manufactured: circular targets, Section 2.2, and elliptical targets, Section 2.3. Circular targets are irradiated at normal incidence, and therefore require a $230 \mu \mathrm{m}$ molybdenum layer. Elliptical targets are irradiated at a grazing angle of $15^{\circ}\left(75^{\circ}\right.$ angle of incidence), so the corresponding thickness is $60 \mu \mathrm{m}(230 \mu \mathrm{m} \cos (75))$. 
Figure 4 illustrates the grazing angle at which the elliptical targets are irradiated by the cyclotron beam.

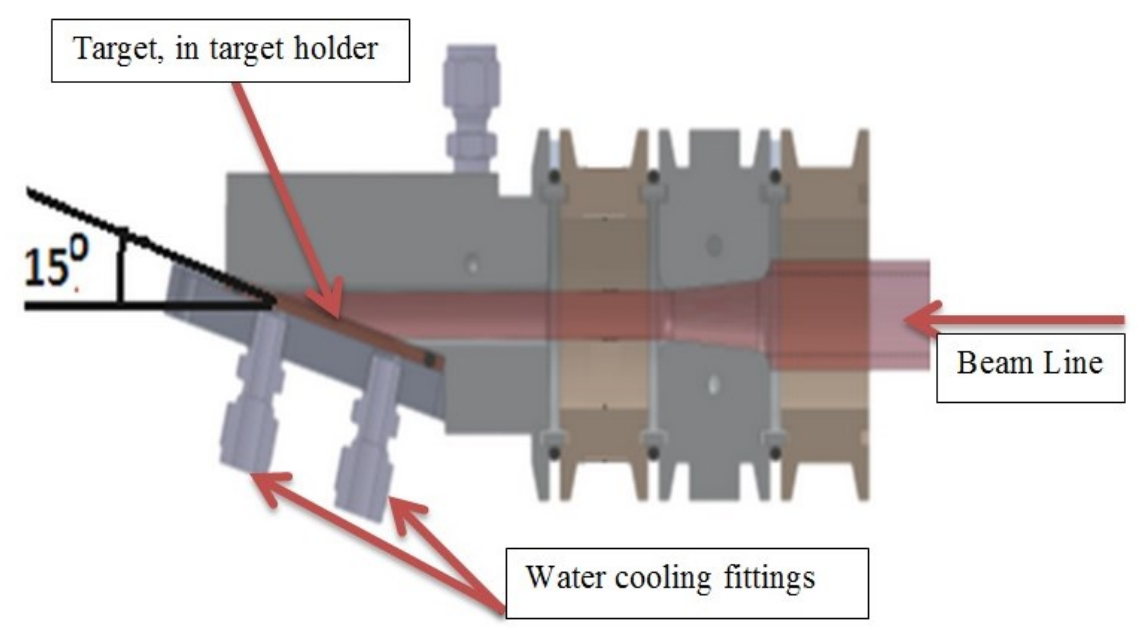

Figure 4: Schematic of elliptical target in beam line.

Kinetic energy from protons hitting a target is converted into thermal energy, which must be removed via water cooling. Thermal simulation conducted by ASD-Inc. [23] has shown that during irradiation with $6 \mathrm{~kW}$, water cooling at a rate of $8 \mathrm{~L} / \mathrm{min}$ will maintain the molybdenum below $260^{\circ} \mathrm{C}$, which is the temperature at which any oxides inadvertently generated in situ could volatilize and contaminate the target holder and cyclotron [21]. The elliptical shape reduces the heat flux associated with high current sources because of its increased area compared with a circular target. During irradiation, the short axis of the ellipse will be at right angles to the beam; the projection of the molybdenum target on a plane perpendicular to the beam matches the circular Gaussian beam profile [21]. 
Production and activity of ${ }^{99 \mathrm{~m}} \mathrm{Tc}$ can be modeled using standard rate equations [24]. Production rate of the isotope is:

$$
P_{\mathrm{Tc}-99 \mathrm{~m}}=\Phi \sigma N_{\mathrm{Mo}}
$$

Where $\Phi$ is the proton flux (number of protons per $\mathrm{cm}^{2} \mathrm{~s}$ ), and $\sigma$ is the cross section $\left(\mathrm{cm}^{2}\right.$ per proton), and $N$ is the number of target nuclei. The net rate at which radioactive nuclei are produced can be described by:

$$
\frac{d N_{\mathrm{Tc}-99 \mathrm{~m}}}{d t}=P_{\mathrm{Tc}-99 \mathrm{~m}}-\lambda N_{\mathrm{Tc}-99 \mathrm{~m}}
$$

Where $\lambda$ is the decay constant for ${ }^{99 \mathrm{~m}} \mathrm{Tc}\left(\mathrm{s}^{-1}\right)$. At $\mathrm{t}=0, N_{\mathrm{Tc}-99 \mathrm{~m}}(0)=0$, and the solution for (2) is:

$$
N_{\mathrm{Tc}-99 \mathrm{~m}}(t)=\frac{\Phi \sigma N_{M o}}{\Phi \sigma+\lambda}\left(e^{-\Phi \sigma t}-e^{-\lambda t}\right)
$$

For ${ }^{99 \mathrm{~m}} \mathrm{Tc}$ production, $\Phi \sigma$ is much less than $\lambda$, so the activity, $A_{\mathrm{Tc}-99 \mathrm{~m}}=\lambda N_{\mathrm{Tc}-99 \mathrm{~m}}$, of the sample can be approximated with:

$$
A_{\mathrm{Tc}-99 \mathrm{~m}}=P_{\mathrm{Tc}-99 \mathrm{~m}}\left(1-e^{-\lambda t}\right)
$$

For a six hour irradiation of a ${ }^{100}$ Mo target in a typical cyclotron, approximately 1 in 10,000 nuclei are converted to ${ }^{99 \mathrm{~m}} \mathrm{Tc}$ nuclei.

\subsection{Circular Targets}

The goal was to produce a molybdenum sheet attached to a copper heat sink. Initially, thin molybdenum sheets were pressed from natural molybdenum $\left({ }^{\mathrm{nat}} \mathrm{Mo}\right)$ powder with the 
intent to attach them to a substrate afterwards. Manufacturing of the sheets began with a $500 \mathrm{kN}$ Material Testing System (MTS 810) and upper and lower platens made of M42 steel, hardened to approximately $62 \mathrm{RC}$ [25]. Various forces were applied by the MTS until ${ }^{\text {nat }}$ Mo sheets could be produced and handled without crumbling. These thin sheets of natMo were then placed onto copper disks, and pressed by the MTS. Frequently, the thin sheets would fracture during pressing into the copper; the molybdenum sheets did not always survive a second pressing. Thin sheets of molybdenum were also pressed into copper powder with enough force to compress the powder into a dense metal. The contact between the molybdenum and the copper was incomplete, and thus not suitable for dissipation of high temperatures.

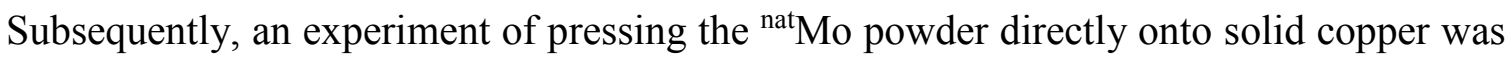
conducted successfully. Both copper sheets and copper disks were tested, and it was determined that although the disks deformed more than the sheet, they yielded a more robust layer of molybdenum. It was hypothesized that the deformation was related to how well the molybdenum adhered to the copper disks. After this initial success, BTL provided preliminary requirements for circular targets: the circular targets were to be comprised of a copper disk $24.0 \mathrm{~mm}(+0.0 \mathrm{~mm},-0.2 \mathrm{~mm})$ in diameter and $1.6 \mathrm{~mm}$ thick, with a $10 \mathrm{~mm}$ diameter sheet of Mo in the centre. Requirements for the Mo sheet were an areal density of $60 \mathrm{mg} / \mathrm{cm}^{2} \pm 20 \%$. Total loss of molybdenum during production was to be less than $5 \%$. The first pressing apparatus was developed to meet the given requirements. 


\subsubsection{Pressing Apparatus \#1}

The MTS press, circular die and circular washer were used with platens, Appendix A.1, to make circular natural molybdenum targets. The circular die was made of M42 steel, hardened to $62 \mathrm{RC}$ [25]. The circular washers were made of stainless steel. A circular washer was centred on the copper disk, and a measured amount of ${ }^{\text {nat }}$ Mo powder placed in the opening of the washer. The circular die would then be placed on top of the powder inside of the washer, and the whole assembly placed between the platens held in the press. Force was applied by the press to create a robust layer of molybdenum. After pressing, the target's dimensions increased in diameter and reduced in thickness. In order to meet the specification of a $24 \mathrm{~mm}$ diameter target, copper disks with an initial diameter of $22.5 \mathrm{~mm}$ were used.

Initially, the circular washer and copper disk were aligned manually by hand and eye, but this proved to be difficult. To overcome the alignment issue, a semi-circular jig was fabricated and used, Appendix A.1: Circular Target Jig. This target jig was used to align the copper disk, the circular washer and the circular die until a $1 \mathrm{kN}$ preload was applied by the press. After the preload was applied, the circular target jig was removed from the pressing apparatus, and the full force applied by the press. The force required to make a $24 \mathrm{~mm}$ target was fine-tuned by examining the diameter of the copper disk relative to the circular washer as the force from the press increased; when the diameters became equal, the press was stopped, and the load removed. The fitment between the circular die and circular washer allowed $\sim 5 \%$ of the molybdenum powder to move up between the two 
components during pressing. This powder was collected during removal of the target from the apparatus.

Apparatus \#1 was used to prepare ${ }^{100} \mathrm{Mo}$ targets for test irradiation at National Institute for Physics and Nuclear Engineering (NIPNE), in Bucharest, Romania. For these tests, at normal incidence, the required areal density of molybdenum is $238 \mathrm{mg} / \mathrm{cm}^{2}$, see Section 2.1. Before the enriched molybdenum powder was used, natural molybdenum targets were manufactured with different forces to validate the procedure. A cross-section image of a target was taken with a scanning electron microscope (SEM), see Figure 5. The SEM image showed that the molybdenum layer had a thickness of $230 \mu \mathrm{m}$. Based on the volume and mass of the molybdenum, the density of the layer met the specification, see Section 1.4. Apparatus \#1 was used to produce two ${ }^{100}$ Mo targets on April 16, 2014. Each of the targets had $199 \mathrm{mg}$ of ${ }^{100} \mathrm{Mo}$ and was pressed with $350 \mathrm{kN}$. The results obtained after irradiation at NIPNE are presented in Section 4.1. 


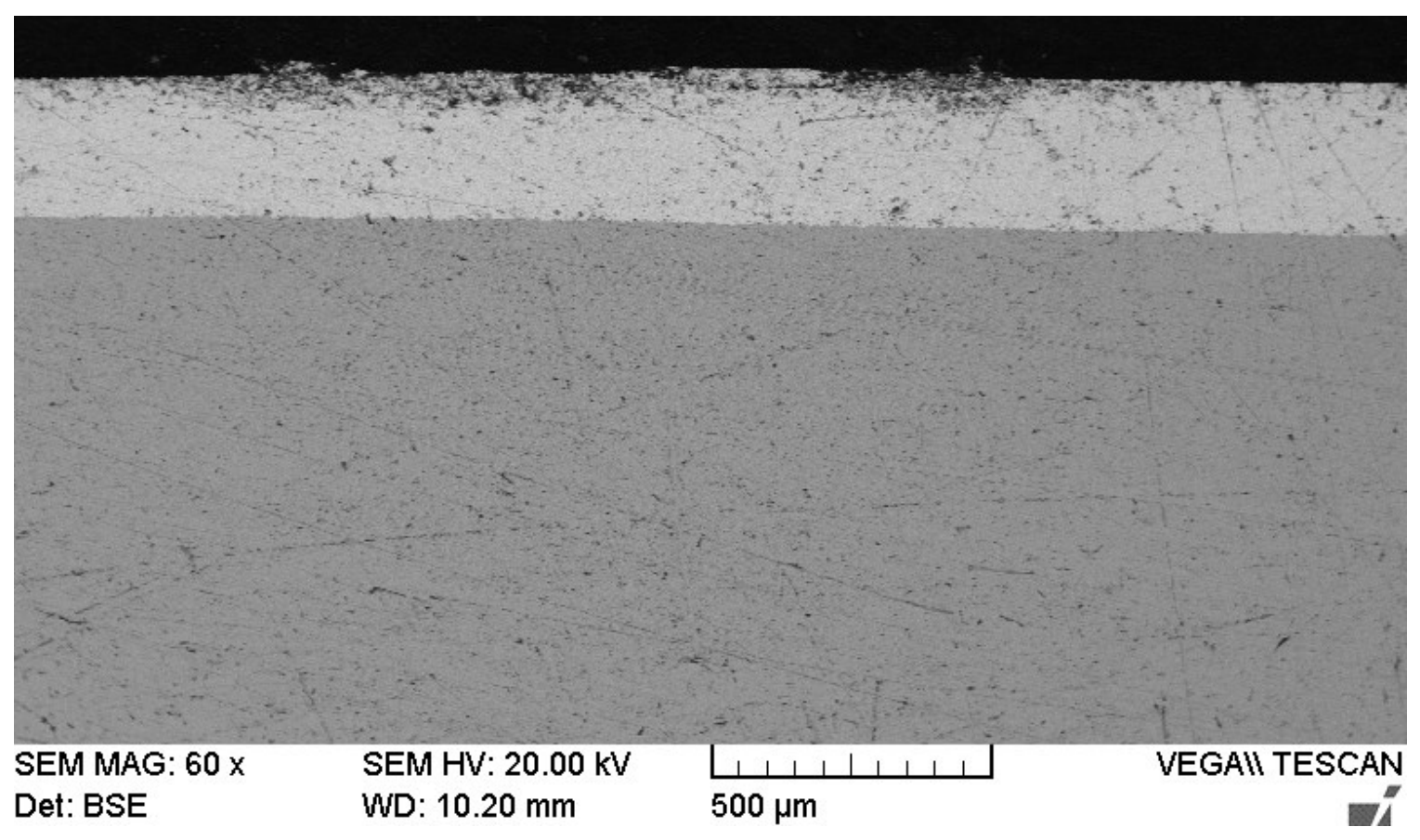

Figure 5: SEM image of the cross section of a circular target.

Two more circular ${ }^{100}$ Mo targets were produced on April 8, 2015 for a second test irradiation at NIPNE. The previous targets were not flat, and it was specified that the targets for the second test were to be flat, without rough edges or burrs. Before an attempt was made to produce two circular ${ }^{100}$ Mo targets, a batch of natural molybdenum targets was pressed. The force used to press the natural molybdenum targets was varied, keeping the mass of molybdenum constant, to determine the force required to produce a $24 \mathrm{~mm}$ diameter target. For example: when $380 \mathrm{kN}$ and $213.0 \mathrm{mg}$ of Mo was used, the resulting diameter of the target was $23.68 \mathrm{~mm} \pm 0.10 \mathrm{~mm}$; when $430 \mathrm{kN}$ and $214.4 \mathrm{mg}$ Mo was used, the resulting diameter of the target was $24.0 \mathrm{~mm} \pm 0.05 \mathrm{~mm}$. Five natural molybdenum targets were made before the ${ }^{100}$ Mo targets. Two ${ }^{100}$ Mo targets were pressed with the parameters shown in Table 1. 
Table 1: Summary of data for circular ${ }^{100}$ Mo targets

\begin{tabular}{|c|c|c|c|c|c|c|}
\hline $\begin{array}{l}\text { Target } \\
\text { Number }\end{array}$ & $\begin{array}{l}\text { Mass Cu } \\
\text { Blank (g) }\end{array}$ & $\begin{array}{l}\text { Mass Mo } \\
\text { Initial (g) }\end{array}$ & $\begin{array}{c}\text { Final Mass } \\
\text { Target (g) }\end{array}$ & $\begin{array}{c}\text { Mass Mo on } \\
\text { Target (g) }\end{array}$ & $\begin{array}{c}\text { Applied } \\
\text { Force (kN) }\end{array}$ & $\begin{array}{l}\text { Diameter } \\
\text { (mm) }\end{array}$ \\
\hline $1-1$ & 5.6870 & 0.2156 & 5.8799 & 0.1929 & 420 & $\begin{array}{r}24.10 \\
\pm 0.10\end{array}$ \\
\hline $1-2$ & 5.6785 & 0.2178 & 5.8745 & 0.1960 & 410 & $\begin{array}{r}24.20 \\
\pm 0.20\end{array}$ \\
\hline
\end{tabular}

A fine file was used to reduce the diameter of the ${ }^{100}$ Mo targets and to improve their roundness so the $24 \mathrm{~mm}+0.0 \mathrm{~mm},-0.2 \mathrm{~mm}$ tolerance was achieved. The thickness of the targets was found to be $1.45 \mathrm{~mm} \pm 0.05 \mathrm{~mm}$. Differences between the particle size of the

${ }^{100}$ Mo and the ${ }^{\text {nat }}$ Mo powders effected the change in diameter of the copper disks after pressing. During the experiments with the natural molybdenum to determine the force, targets pressed with $430 \mathrm{kN}$ expanded to $24.0 \mathrm{~mm} \pm 0.05$, whereas, the ${ }^{100}$ Mo targets had larger diameters despite similar conditions, see Table 1. The natural molybdenum had a smaller particle size, which also resulted in a smoother surface finish.

\subsection{Elliptical Targets}

Elliptical targets are required for high power irradiation, see Section 2.1. Molybdenum in the shape of an ellipse $38.6 \mathrm{~mm} \times 10 \mathrm{~mm}$ was pressed into a copper blank. Originally, the copper blank had dimensions $55 \mathrm{~mm}$ x $20 \mathrm{~mm}$ x $2.8 \mathrm{~mm}$, with a single O-ring groove around its perimeter. During the course of this project, the target design was changed to include O-rings on both sides and the dimensions became $65 \mathrm{~mm}$ x $30 \mathrm{~mm}$ x $2.8 \mathrm{~mm}$, 
with $9.1 \mathrm{~mm}$ radius on the four corners. A rendered image of the beam side of an elliptical target, without O-ring grooves, is shown in Figure 6.

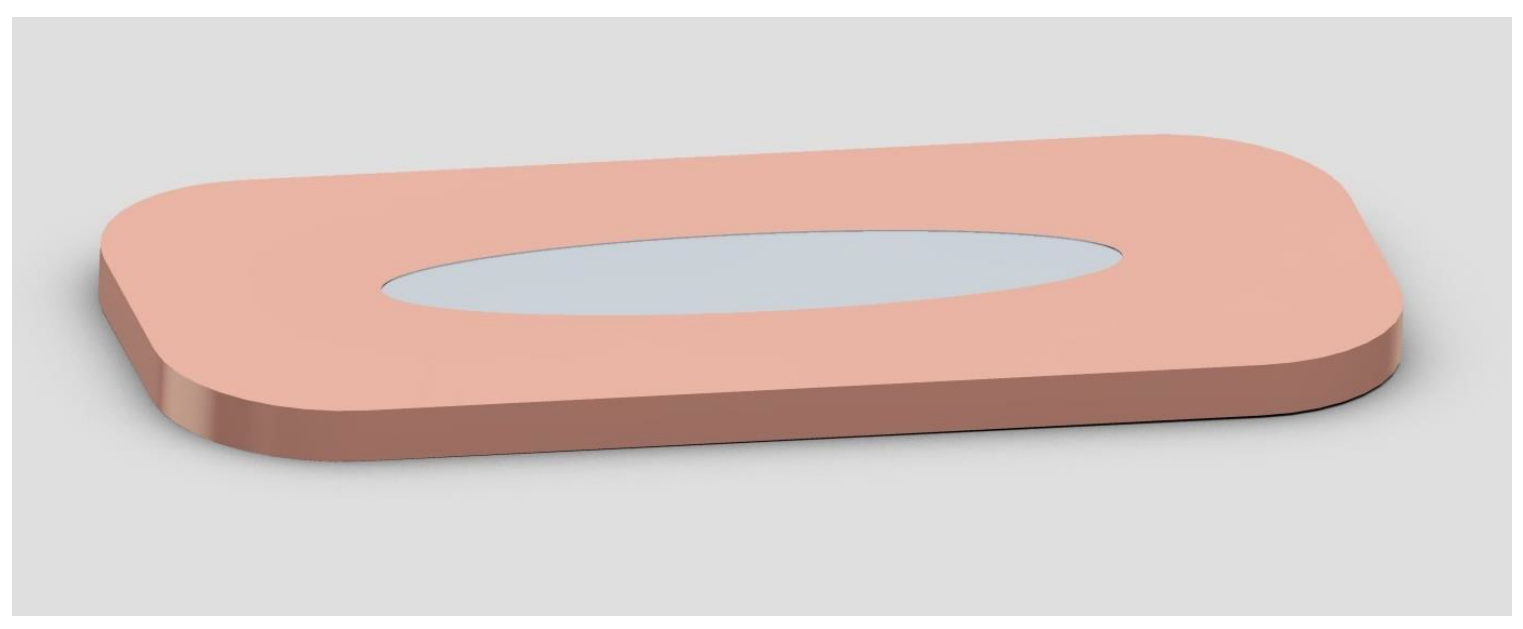

Figure 6: Rendered image of an elliptical target. Dimensions: $65 \mathrm{~mm} \times 30 \mathrm{~mm}$ x $2.8 \mathrm{~mm}$.

\subsubsection{Pressing Apparatus \#2}

Pictures of the components of apparatus \#2 are shown below in Figure 7, and the engineering drawings are in Appendix A.2. The elliptical washer has the same dimensions as the $65 \mathrm{~mm} \times 30 \mathrm{~mm}$ copper blank, and the two components were fixed together with Scotch tape. Molybdenum powder was dispersed onto the blank through the opening of the washer. The elliptical die was made of hardened M42 steel, and transferred the force from the platens to the molybdenum contained in the washer. This apparatus produced robust molybdenum layers when the load from the MTS was applied at $1 \mathrm{~mm} / \mathrm{s}$. 

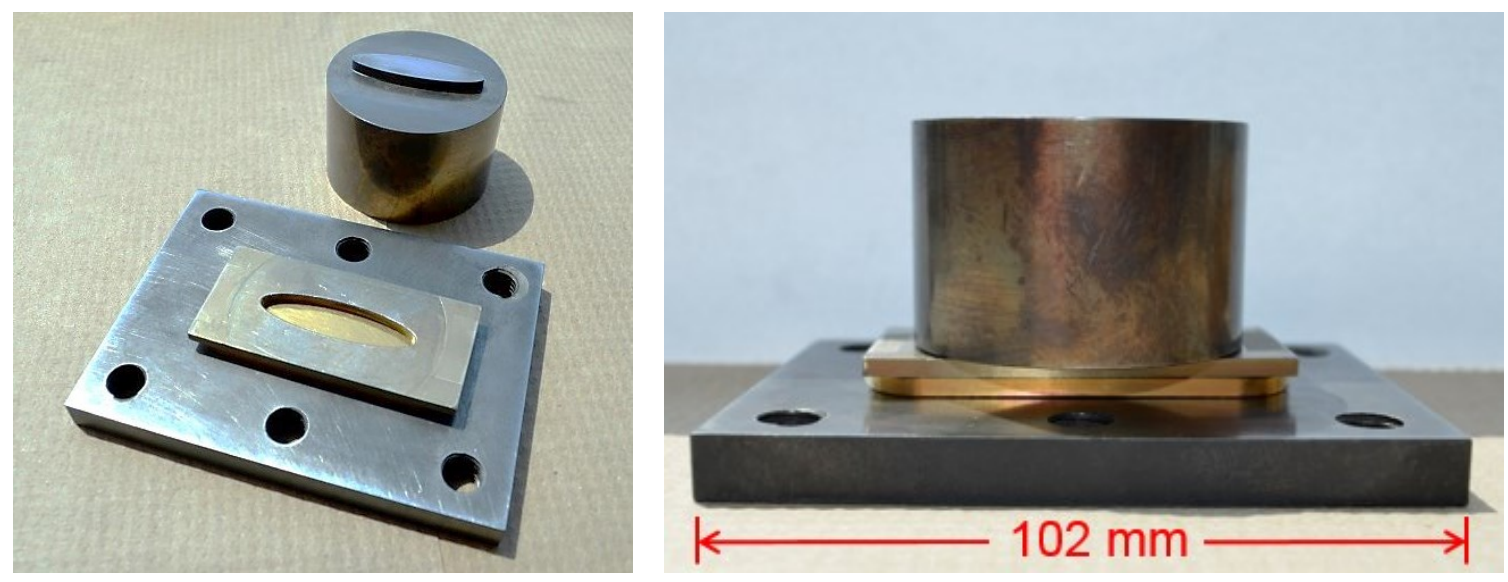

Figure 7: Copper blank with pressing apparatus \#2.

A target manufactured with apparatus \#2 was sectioned and examined with a SEM, Figure 8.

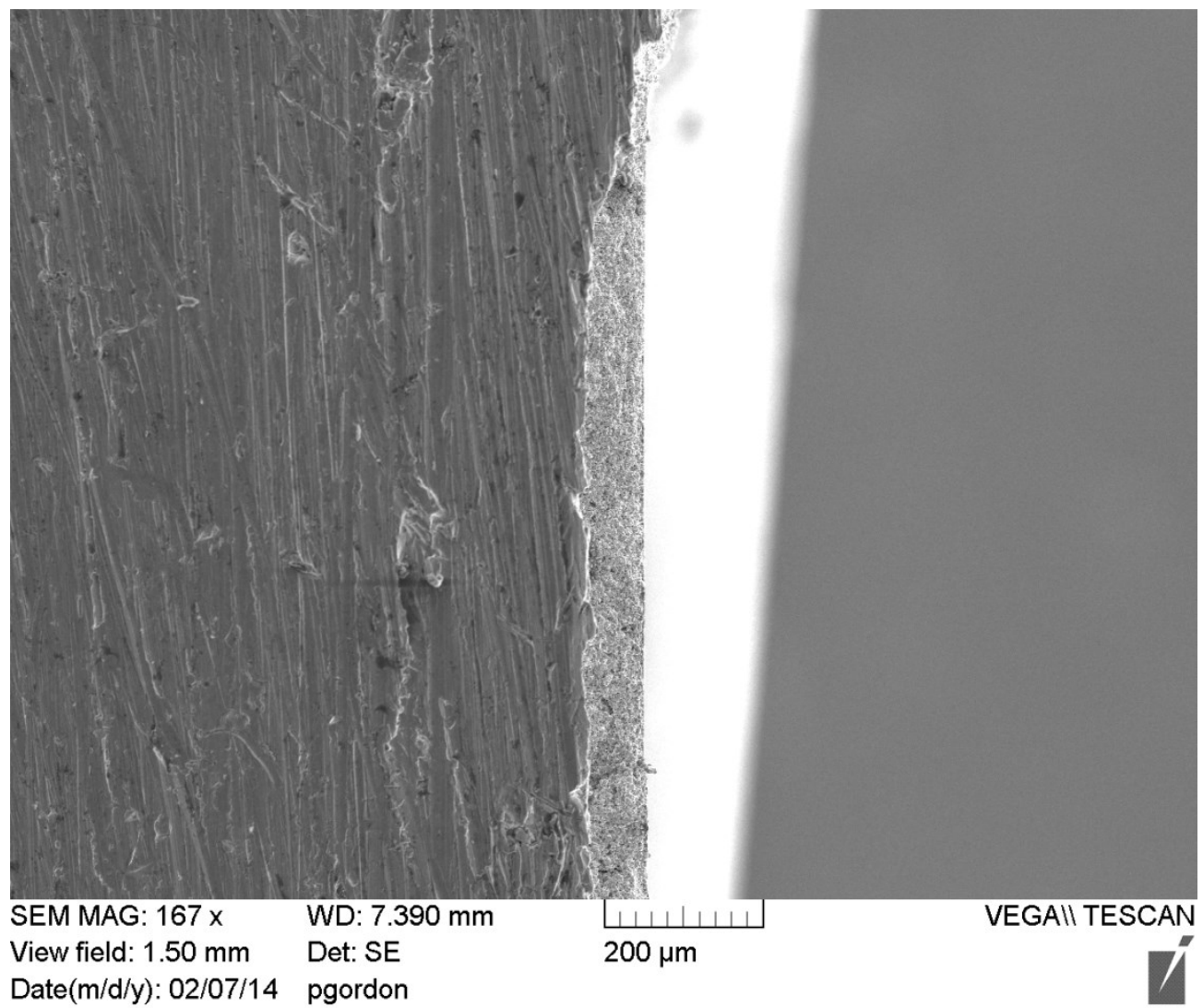

Figure 8: SEM image of cross section of an elliptical target, with a dense $60 \mu \mathrm{m}$ molybdenum layer. 
The water side and the beam side of a proof of concept target are shown in Figure 9. During this initial development of targets, dovetail O-ring grooves for both faces of the targets were designed to have $25 \%$ void space, and provide $25 \%$ squeeze, and $5 \%$ stretch to the O-ring [26]. Dovetail grooves secure the O-rings better than conventional grooves, and dovetail cutters were purchased from Harvey Tool (part number: 23814). A channel must be rough cut with an end mill before the dovetail cutter is used. The first iteration of grooves was designed for sizes \#131 and \#125 O-rings. After targets were machined with the dovetail cutter, seven cooling channels were machined with an end mill.
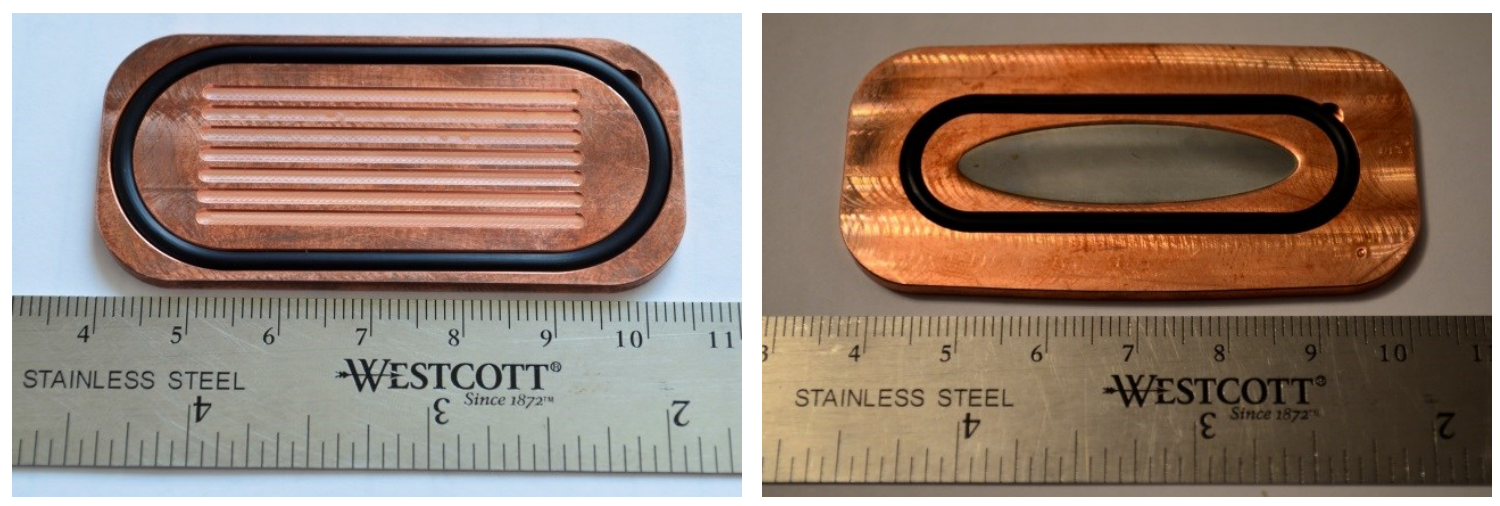

Figure 9: Elliptical targets proof of concept: water side (left) and beam side (right).

Figure 9 shows that in general, elliptical targets can be manufactured; however, the first iteration of O-ring grooves and cooling channels would not meet the requirement of being able to dissipate heat from high power irradiation $(6 \mathrm{~kW})$. Deeper cooling channels were required to cool the target, which meant the beam side O-ring groove had to be moved outwards to avoid meeting the cooling channels below. Moving the beam side Oring further outwards has an additional benefit of lowering the operating temperature of the O-ring. The water side O-ring groove had to be moved inwards to avoid overlap with 
the beam side O-ring. The drop hole for the dovetail cutter was moved from the outside of the groove to the inside of the groove on the water side. These updated features were used in the development of apparatus \#3.

\subsubsection{Pressing Apparatus \#3}

Revised features for the next iteration of targets included O-rings with smaller crosssectional diameters, and deeper cooling channels. The O-ring grooves were designed for sizes \#027 and \#029 O-rings. The cooling channels became $0.70 \mathrm{~mm}$ wide and $2.1 \mathrm{~mm}$ deep. A new dovetail cutter, (Harvey Tool: 23806), and a slitting saw were used for postpress machining of targets.

The third pressing apparatus was designed so that the beam side O-ring groove could be rough cut into the copper blank to save post-press machining time. A groove on the beam side of a copper blank (Copper Blank \#3, Appendix A.3) was machined to the same dimensions as the rough cut groove used for the dovetail cutter. Apparatus \#3, comprised of a lower mold, top mold, elliptical die, and copper blank, was assembled such that the copper blank was in the pocket of the lower mold and the top mold supported the rough cut groove in the copper while being pressed, Appendix A.3. Unfortunately, pressing deformed the rough cut groove and resulted in the groove being too large for the dovetail cutter to cut the specified groove. 
Alternatives to the MTS press were investigated with apparatus \#3. A manual press with Enerpac components was used to produce the first targets from apparatus \#3, in its annealed state. The cylinder was an $\mathrm{RCH} 603$, the pump was a two-stage P-80, the line was Series E6, and the gauge was Model GF-8135. Although a press of this type could be a viable option for target production, the available press had deformed platens and did not work well. This setup did not press the elliptical die squarely into the top mold, deformed the top of the die, and altered the overall geometry of the apparatus. The overall dimensions of the die were re-machined to be square; however, the elliptical protrusion was modified by hand. The die was difficult to remove from the top mold, and the fitment of the elliptical protrusion in the top mold was fine-tuned using 320 grit emery paper. Only half of the targets manufactured using the manual press were satisfactory, the other half had cracks in the molybdenum, and the layer appeared powdery and not fully dense. One of the successful targets was sectioned with a slow speed diamond saw and mounted in Bakelite for SEM imaging. The mounted sample was polished with progressively finer paper until 600 grit was used. An image from the SEM is Figure 10. 


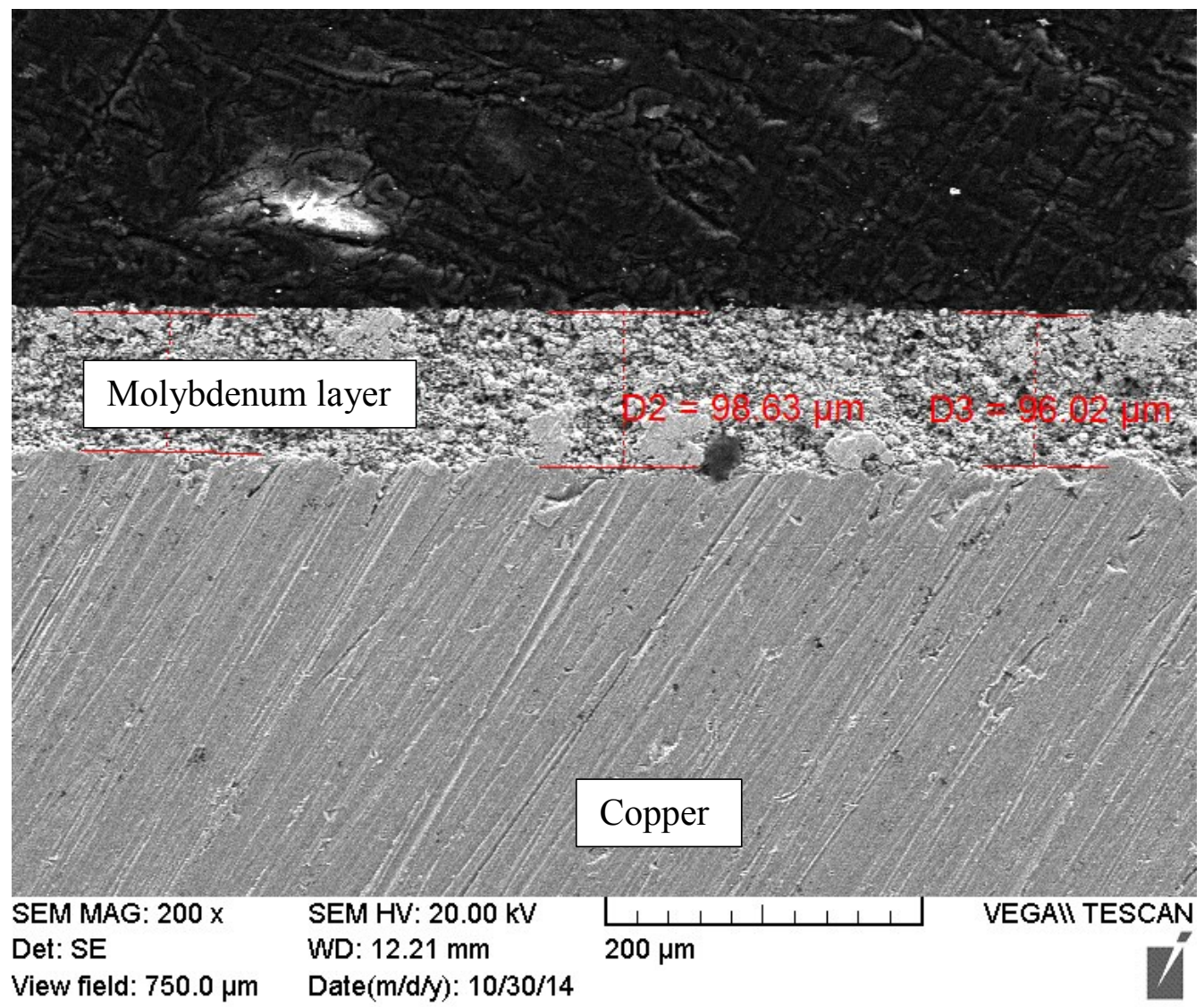

Figure 10: SEM image of cross section of elliptical target manufactured with manual press and apparatus \#3. The molybdenum is not fully dense.

Suggestions for improving the apparatus included: heat treatment for increased hardness, using a thicker lower mold and a thinner top mold, and incorporating alignment pins so the die is constrained to the top mold in all directions except the pressing direction. The top mold and elliptical die were hardened to approximately $65 \mathrm{RC}[25]$ and were used to manufacture a batch of targets. Molybdenum was consistently powdery with the hardened components, even when $610 \mathrm{kN}$ was used. All of the targets had a defect in the same corner, suggesting that there was deformation in the die and the apparatus was compromised. It was thought the top mold should be more like the elliptical washer in apparatus \#2, which had more elastic deformation during pressing, and thus allowed the 
copper to flow. The top mold was annealed by bringing it up to $825^{\circ} \mathrm{C}$ and allowing it to furnace cool until $600^{\circ} \mathrm{C}$ was reached. After the furnace cooled to $600^{\circ} \mathrm{C}$, the furnace door was opened and the top mold was allowed to air cool. A hardness of $28 \mathrm{RC}$ was achieved by this process. The softened top mold and hardened elliptical die \#2 were machined square and to have the die protrude $0.381 \mathrm{~mm}$ from the top mold. These components were used to press six targets, three of which survived post-press machining. The targets were considered a failure if the molybdenum cracked.

Subsequently, efforts were made to find a method for machining targets without cracking the molybdenum. Targets from both the manual and MTS presses were used for development of the post-press machining procedure. One of the developments was to cover the molybdenum with an elliptical shaped shim and Captain tape to protect the molybdenum from chips and coolant during machining. A $70 \mathrm{~mm}$ diameter slitting saw was used in both conventional milling and climb-milling methods, with no noticeable difference in eliminating cracks from the molybdenum. Targets which had cracked molybdenum were inspected after the molybdenum was removed and witness marks from the slitting saw were visible on the beam side. The marks were a result of downward force from the slitting saw on the thin copper between the bottom of cooling channels and molybdenum. As an alternative to the slitting saw, an end mill was used to machine the cooling channels, but was not successful either. These target failures, as a result of postpress machining the cooling channels, necessitated using copper blanks with premachined channels and apparatus \#4. 


\subsubsection{Pressing Apparatus \#4}

Apparatus \#4 was designed to support a copper blank with pre-machined cooling channels during pressing. Refer to Appendix A.4 for engineering drawings, and Figure 11 and Figure 12 for images of apparatus \#4. The cooling channel support and lower mold were constructed of M42 steel and designed to support nine cooling channels machined in a copper blank. The design of the copper blank was revised to have wider cooling channels, $0.79 \mathrm{~mm}$ instead of $0.70 \mathrm{~mm}$, because of tools available. Likewise, the radius in the bottom of the channels was changed by use of a $51 \mathrm{~mm}$ diameter slitting saw.

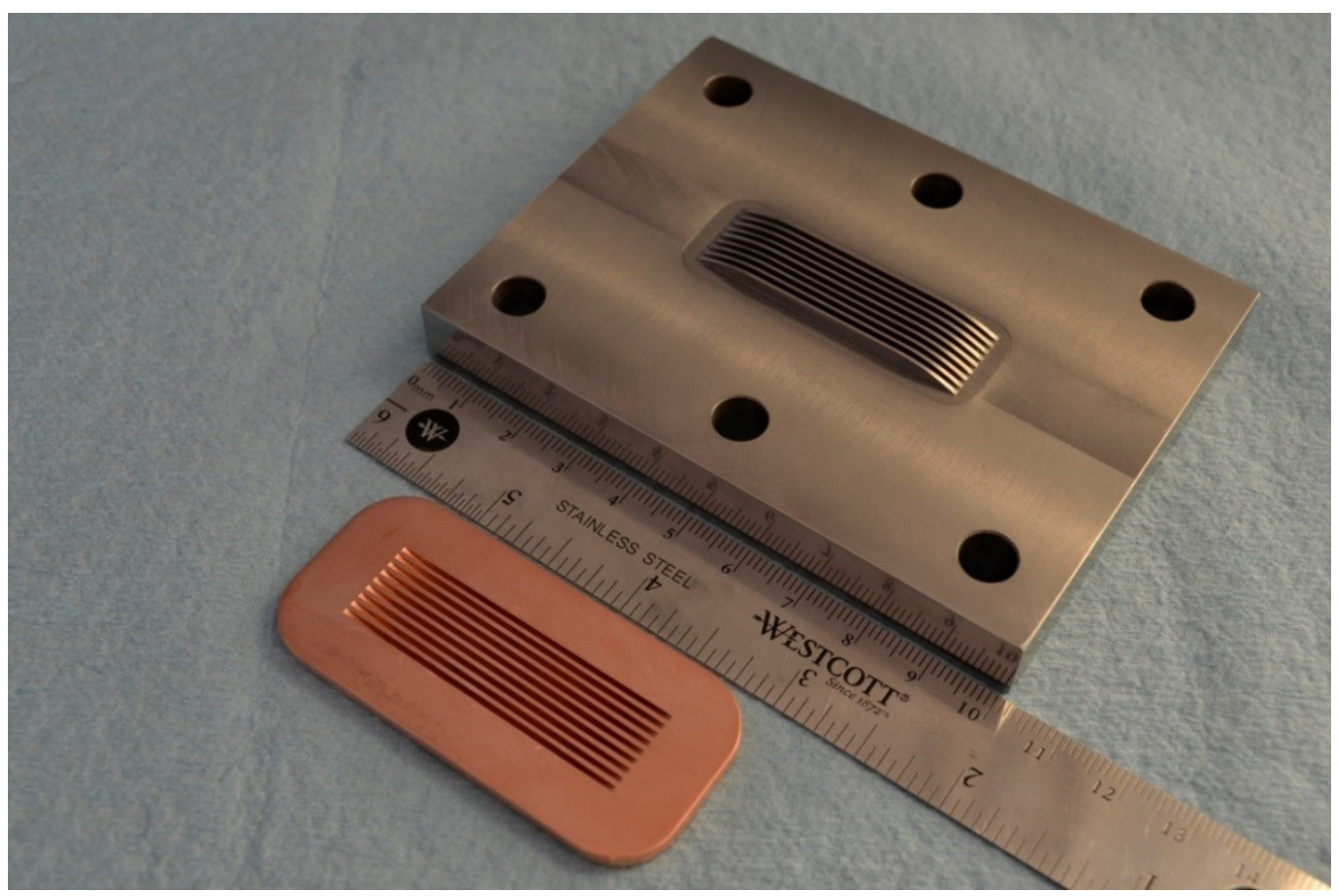

Figure 11: Lower Mold \#4 and Cooling Channel Support \#2 with a copper blank. 


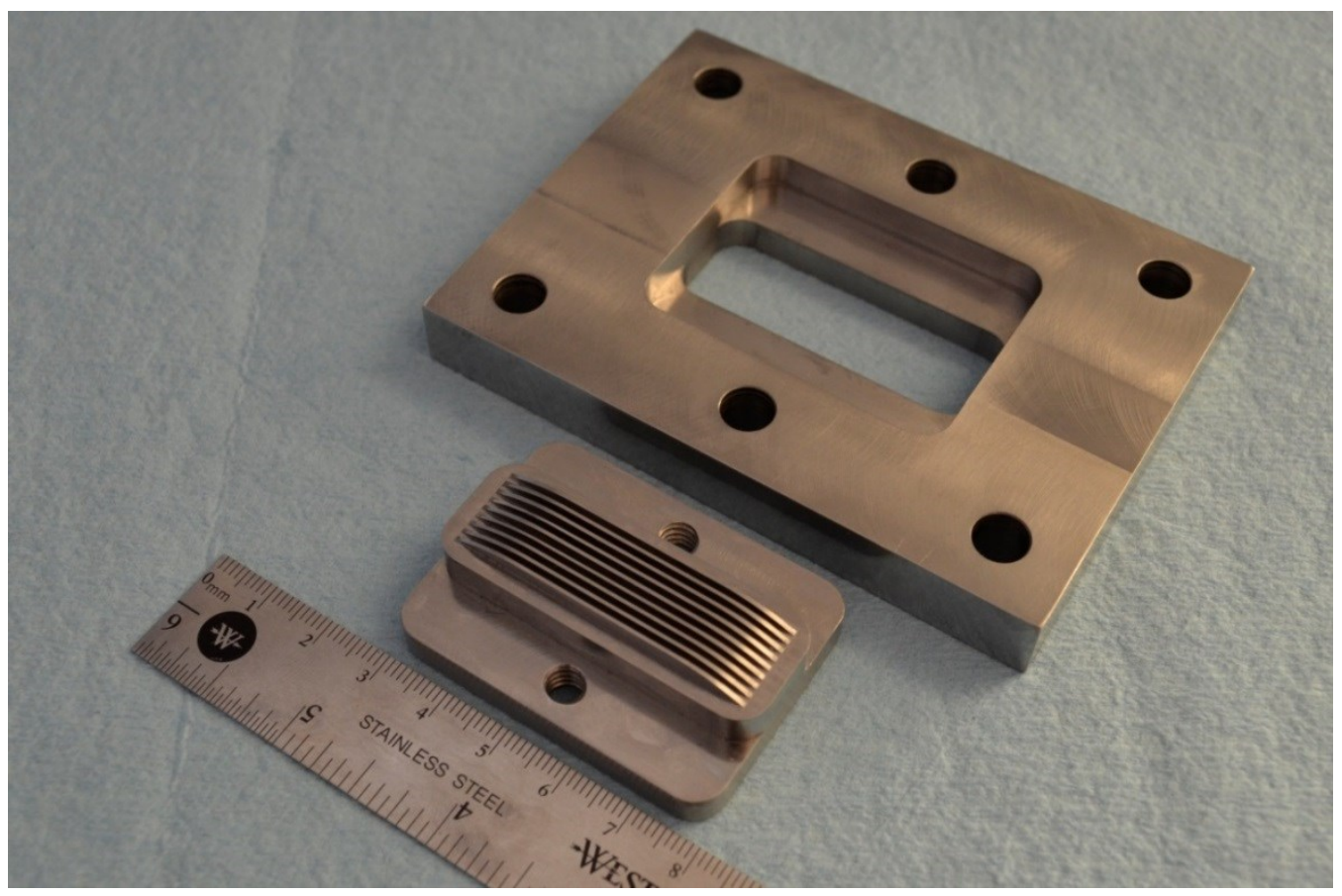

Figure 12: Lower Mold \#4 and Cooling Channel Support \#2.

The cooling channel support and lower mold \#4 received a vacuum heat treatment with triple temper, resulting in a hardness of $66 \mathrm{RC}$ [25]. The elliptical die and elliptical washer from apparatus $\# 2$ were used to press a copper blank, with nine cooling channels pre-machined, supported by the cooling channel support and lower mold. When the target was removed from the support, the centre three fins of the cooling channel support remained intact, but the other six sheared off and became lodged in the cooling channels. The cooling channel support was too hard and the fins too thin to withstand the deformation induced by the applied load of $400 \mathrm{kN}$. Another steel cooling channel support was not produced, and alternative methods were investigated.

A consequence of a target with the cooling channels pre-machined was an overlap between the outermost channels and the O-ring groove after pressing. The interference 
resulted in the two outermost channels being eliminated from the design, and copper blanks were produced with only seven channels.

\subsection{Cooling Channel Supports: Initial Studies}

Target failures occurred during machining of the cooling channels. Machining outer dimensions and O-ring grooves did not result in the molybdenum cracking. It was therefore decided to have the cooling channels machined before pressing. If the channels were not supported, however, they would deform beyond useful and the molybdenum would be less dense compared with a target pressed using a solid copper blank. Several materials were inserted into the cooling channels to find one which could withstand the extreme pressure, and was easily removed from the channels after pressing.

Poly Filla ${ }^{\circledR}$ was the first compound used to support the cooling channels during pressing and reduced the deformation of the cooling channels, but was difficult to remove. Next, a homemade ceramic powder consisting of $65 \%$ alumina $\left(\mathrm{Al}_{2} \mathrm{O}_{3}\right), 20 \%$ zirconium silicate $(\mathrm{ZrSiO} 4$, Acros $), 10 \%$ sodium hydrogen phosphate $\left(\mathrm{Na}_{2} \mathrm{HPO}_{4}, \mathrm{BDH}\right)$, and $5 \%$ sugar was used [27]. The ceramic had more shrinkage than Poly Filla ${ }^{\circledR}$ and did not completely fill the channels upon drying. Portland cement had similar shrinkage to the ceramic powder, and also resulted in cooling channels being incompletely filled and deformed during pressing. Cerrolow, a low melting temperature alloy, was also investigated. The alloy was melted onto the blank, but did not readily flow into the channels due to high surface tension. Soap was used to reduce the surface tension of the channels, but the alloy did not fill the channels. 
Finally, aluminum strips cut from sheet metal were used to support the cooling channels. A target was pressed using a copper blank with aluminum filling the cooling channels. The cooling channels did not collapse, but bowed towards the outer edges, much like the copper itself. To dissolve the aluminum, the target was rested on top of a Petri dish, with the channels facing the bottom. The dish and target were placed inside a large beaker and hydrochloric acid was poured into the Petri dish until the acid level was flush with the top of the target. With $37 \%(\mathrm{w} / \mathrm{w}) \mathrm{HCl}$ as the solvent, the aluminum was completely dissolved from the copper within half an hour. Three different concentrations, $12 \mathrm{M}, 1$ $\mathrm{M}$, and $0.1 \mathrm{M} \mathrm{HCl}$ were tested on aluminum strips in beakers. It was found that both the $12 \mathrm{M}$ and $1 \mathrm{M}$ worked to dissolve the aluminum strips overnight, but $0.1 \mathrm{M}$ had little effect on the strips. 


\section{Chapter: Target Design and Procedure for Manufacture}

The final specifications of the elliptical targets and steps to fulfill the operational requirements are presented in this chapter. General constraints on the target design, geometric tolerances, and suggested materials for the O-rings were provided by the industrial partner, BTL. A procedure for manufacturing elliptical targets is presented; this chapter explains how to transform the raw materials into a completed target, ready for irradiation.

Circular targets are manufactured with a procedure similar to what is presented in this chapter. The differences between the procedures are: circular targets require a circular die and circular washer, and do not require post-press machining. The procedure for circular target manufacturing is not included in this thesis.

\subsection{Introduction}

In addition to the objectives of Section 1.4, the following requirements were added:

- Cooling channels needed to have the full depth of $2.1 \mathrm{~mm}(0.083$ ”). Both the Oring grooves and the cooling channels were allowed to have small radii at the bottom.

- Target thickness tolerance was specified to be \pm 25 microns (0.001"). Outside dimensions were to be $\pm 0.1 \mathrm{~mm}(0.004 ")$.

- The O-ring materials known as EPDM or Ethylene-propylene rubber were recommended. 
An engineering drawing of the final copper blank used for target production is titled "Copper Blank with Seven Cooling Channels" and can be found in Appendix A.4. The copper blanks are pressed, and machined so the O-ring grooves meet the specifications of "Copper Blank with Dovetail Grooves \#4" in Appendix A.4. The targets have outside dimensions of $65 \mathrm{~mm}$ x $30 \mathrm{~mm}(2.56$ " x 1.18 ") with $9.1 \mathrm{~mm}(0.36$ ") radii on the four outside corners. Originally, a nine cooling channel target was proposed, but due to deformation of the channels during pressing, the two outermost channels interfered with the water side O-ring groove. A seven channel target was created, and the interference with the O-ring groove was eliminated. The O-ring grooves were designed using Creo and standard O-ring dimensions. The dovetail cross-section was drawn in the CAD model, and the contour line of the groove was altered until an appropriate perimeter was created. The inside perimeter of the O-ring is smaller than the mating surface of the groove in the copper, resulting in approximately five percent stretch of the O-ring.

\subsection{Materials and Methods}

This section outlines how a copper blank is transformed into a target. Details for the preparation of copper blanks, and the materials and equipment used to press the blanks into targets are given. The post-press machining steps are explained, along with the procedure for dissolving the aluminum cooling channel supports.

\subsubsection{Copper Blank Preparation}

Copper sheet was cut into blanks by a $\mathrm{CNC}$ milling machine at Best Theratronics Limited. The blanks had the proper length, width, and radius on corners, but excess 
material was left on the thickness. Thickness of the blanks was left as $3.2 \mathrm{~mm}(1 / 8$ ") to account for reduction in thickness during pressing, and so the water-side of the target could be made flat during post-press machining. The beam side of copper blanks was gold plated by Advanced Systems Designs Inc. The gold plating served to reduce oxidation of the copper during post-irradiation separation and purification. Batches of gold-plated blanks were received at Carleton, and sent to the Science Technology Centre to have the cooling channels machined. A CNC milling machine fitted with a slitting saw was used to cut the cooling channels into the copper blank, which was clamped in a pocket jig, gold side down, as shown in Figure 13. The slitting saw had a thickness of $0.79 \mathrm{~mm}(1 / 32$ ”), a diameter of $50.8 \mathrm{~mm}(2.0$ ”), and each channel was cut to full depth in a single pass. After the cooling channels were cut, the copper blanks fulfilled the specifications of "Copper Blank with Seven Cooling Channels" in Appendix A.4 and were ready to have the cooling channel supports inserted.

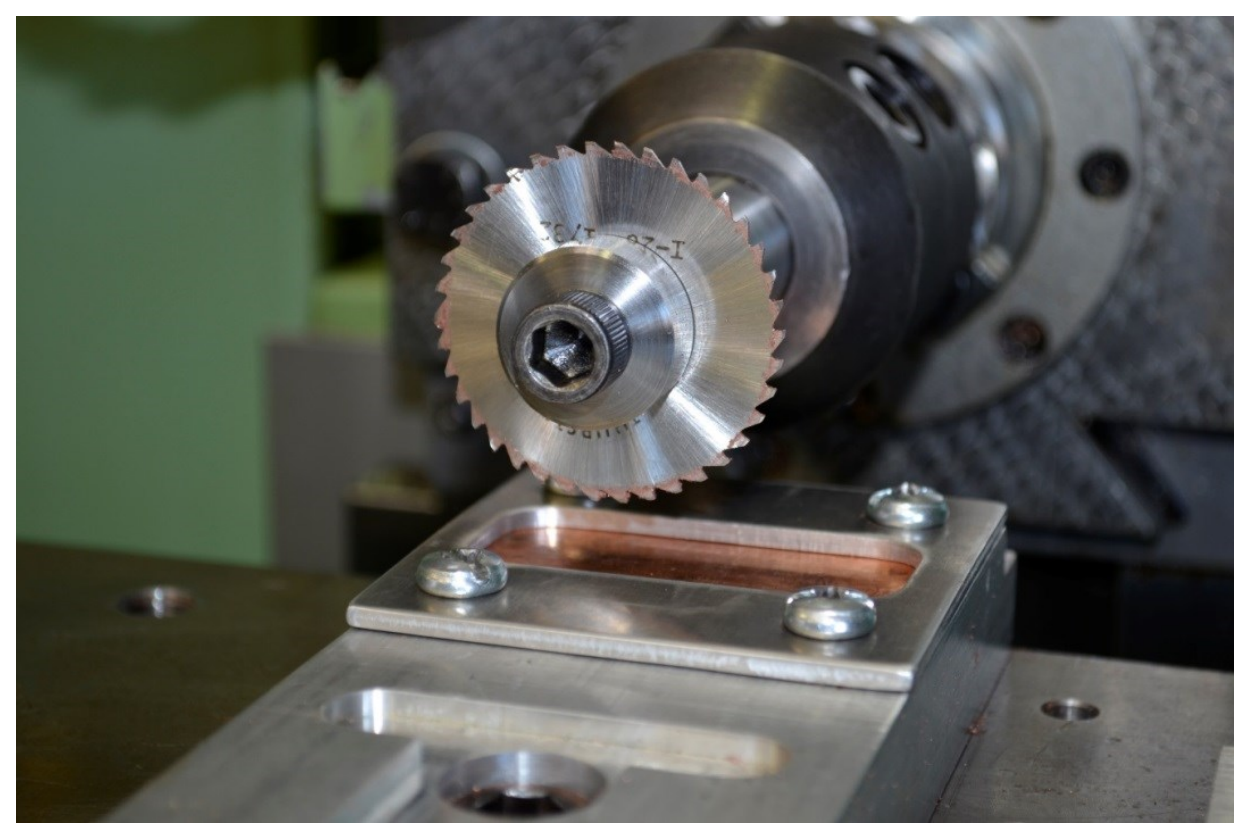

Figure 13: Slitting saw (50.8 $\mathbf{~ m m}$ diameter) and jig for cutting cooling channels into a copper blank. 


\subsubsection{Cooling Channel Supports}

Cooling channel supports consisted of aluminum strips cut from $0.79 \mathrm{~mm}(1 / 32$ ") sheet. The aluminum sheet was cut into long strips with a shear, each having a width of about $2.6 \mathrm{~mm}(0.10$ ”). These long strips were subsequently cut with side cutters into lengths of $43 \mathrm{~mm}$ (1.70"). After the shearing and cutting operations, the dimensions of the aluminum strips resembled the dimensions of the cooling channels; so that an aluminum strip fills the void of the cooling channel to prevent collapse during pressing. An aluminum strip was placed into each cooling channel using a pin punch and a hammer. Excess aluminum was removed with a file and made flush with the copper face using a surface plate and sandpaper.

\subsubsection{Pre-Processing the Molybdenum Powder}

The natural molybdenum powder used was Alfa Aesar, average particle size: 3-7 micron,

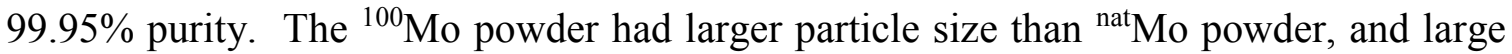
chunks were mixed in with the fine powder. Large chunks could be separated from the fine powder and crushed into smaller particles using a razor blade. The appearance of the pressed ${ }^{100}$ Mo after the large chunks were eliminated was similar to that of the natural molybdenum.

\subsubsection{Molybdenum Pressing}

This section describes the apparatus and procedure used to press ${ }^{100}$ Mo onto the goldplated copper blanks. Engineering drawings for components of the apparatus are found in Appendices. 


\subsubsection{Apparatus for Pressing an Elliptical Target}

- Elliptical die (Appendix A.2)

- Elliptical washer (Appendix A.2)

- Copper blanks (Appendix A.4)

- Two platens (Appendix A.1)

- Steel plate: $101.6 \mathrm{~mm}$ x $76.2 \mathrm{~mm}$ (4" x 3"); $12.7 \mathrm{~mm}$ thick (1/2")

- Scotch tape

- Permanent marker

- Small spatula

- Razor blade

- Petri dish

- Small beaker

- Nitrile gloves

- Safety glasses

- Molybdenum-100 powder: $99.03 \%$ (ISOFLEX, USA)

- Press: MTS $810500 \mathrm{kN}$ load frame

○ Load Unit: Model 318.50B

○ Load Cell: Model 661 23E-01 500 kN

- Controller: Flextest SE

- Control Software: Station Master V3.5C 1817

- Balance: Sartorius LE225D, precision 0.0001g 


\subsubsection{Procedure for Pressing an Elliptical Target}

Nitrile gloves and safety glasses were worn throughout the pressing process. The ${ }^{100} \mathrm{Mo}$ powder had inconsistent particle size, and large chunks were present in the original container. To eliminate the large chunks, approximately one gram of the ${ }^{100} \mathrm{Mo}$ was placed into a Petri dish, and the fine particles were separated from the chunks using a razor blade. The large chunks were then crushed with the razor blade, and added to the fine particles. Molybdenum for each target was taken from the Petri dish, and massed in a small beaker. The procedure was comprised of the following steps:

- The balance was leveled and zeroed.

- A copper blank was labelled using a permanent marker.

- Mass of the copper blank was determined using the balance and recorded.

- The elliptical washer was placed onto the steel plate, with the chamfered side of the opening facing downwards.

- The copper blank was centred on the elliptical washer, gold side against the washer, and taped into place.

- The copper blank and elliptical washer was flipped over, so the copper was resting on the steel plate, and the elliptical washer was top of the copper blank.

- $220 \pm 3 \mathrm{mg}$ of molybdenum powder was placed onto the copper blank through the opening of the elliptical washer using the small spatula.

- The molybdenum powder was spread to a uniform thickness on the copper blank using the small spatula.

- The MTS press was turned on, and programmed for a specific cycle. 
- Platens were secured into the upper and lower jaws of the MTS press.

- The steel plate holding the copper blank, elliptical washer, and evenly distributed molybdenum powder was placed on the centre of the lower platen.

- The elliptical die was carefully placed inside the opening of the elliptical washer.

- The program controlling the MTS press was started.

- The MTS closed at $1 \mathrm{~mm} / \mathrm{s}$ until $1 \mathrm{kN}$ was reached.

- The MTS pressed at $1 \mathrm{~mm} / \mathrm{s}$ until $400 \mathrm{kN}$ was reached.

- The MTS unloaded and opened.

- Elliptical die was removed from the elliptical washer and inspected for molybdenum powder or damage.

- Elliptical washer and target (which was the copper blank) were removed from the steel plate, and inspected.

- Tape was removed from the target, allowing the elliptical washer to be separated.

- Loose molybdenum powder was gently brushed from the target and elliptical washer into the Petri dish using a gloved finger.

- Balance was zeroed.

- Target was placed onto the balance and its mass recorded.

- Target was removed from the balance and stored in a safe location. 


\subsubsection{Loss of Molybdenum during Production}

Typically, the mass of the copper blank added to the mass of the molybdenum dispensed onto the blank, equaled the mass of the target plus the recovered residual powder, to within $4 \%$. Table 2 shows results from manufacturing four elliptical ${ }^{100}$ Mo targets.

Table 2: Summary of data for elliptical ${ }^{100}$ Mo targets

\begin{tabular}{|cccccc|}
\hline $\begin{array}{c}\text { Target } \\
\text { Number }\end{array}$ & $\begin{array}{c}\text { Mass Cu } \\
\text { Blank (g) }\end{array}$ & $\begin{array}{c}\text { Mass Mo } \\
\text { Initial (g) }\end{array}$ & $\begin{array}{c}\text { Final Mass } \\
\text { Target (g) }\end{array}$ & $\begin{array}{c}\text { Mass Mo on } \\
\text { Target (g) }\end{array}$ & $\begin{array}{c}\text { Applied Force } \\
\text { (kN) }\end{array}$ \\
GP-1 & 50.6130 & 0.2220 & 50.8282 & 0.2152 & 400 \\
GP-2 & 50.2804 & 0.2201 & 50.4931 & 0.2127 & 400 \\
GP-3 & 50.3370 & 0.2208 & 50.5528 & 0.2158 & 400 \\
GP-4 & 50.4050 & 0.2212 & 50.6187 & 0.2137 & 400 \\
\hline
\end{tabular}

Mass of the vial containing the ${ }^{100}$ Mo powder was recorded before $(11.7769 \mathrm{~g})$ and after $(10.8863 \mathrm{~g})$ target manufacture. Summation of masses of ${ }^{100}$ Mo on the four targets was compared with the difference in vial mass to determine that $33 \mathrm{mg}$ of ${ }^{100} \mathrm{Mo}$ were lost during manufacture of the four elliptical targets.

\subsubsection{Post-Press Machining}

Machining of the targets was conducted at the Science Technology Centre; refer to Appendix B for machining set-up sheets that include tool specifications, speeds, and feeds. Post-press machining was necessary so that the final dimensions of the targets were as close to the given specification as possible and so the targets would mate with the target holders. Jigs to align and clamp targets during machining were cut in-situ so the 
highest accuracy could be achieved. A batch of targets would undergo each machining operation before the machine was set to complete the next operation. Coolant was not used during machining and only a small amount of vegetable based oil was smeared onto the target when cutting the thickness and water-side O-ring groove. Cutting oil was not used on the beam side of the targets.

The first operation that each target underwent was to have its length and width cut to size. A three-pin jig, shown below as Figure 14, was used to align the target in the CNC milling machine. The target was clamped into place using a step clamp. The pin was removed from the short side of the jig, allowing for three out of four sides of the target to be machined with a $12.7 \mathrm{~mm}(1 / 2 ")$ end mill.

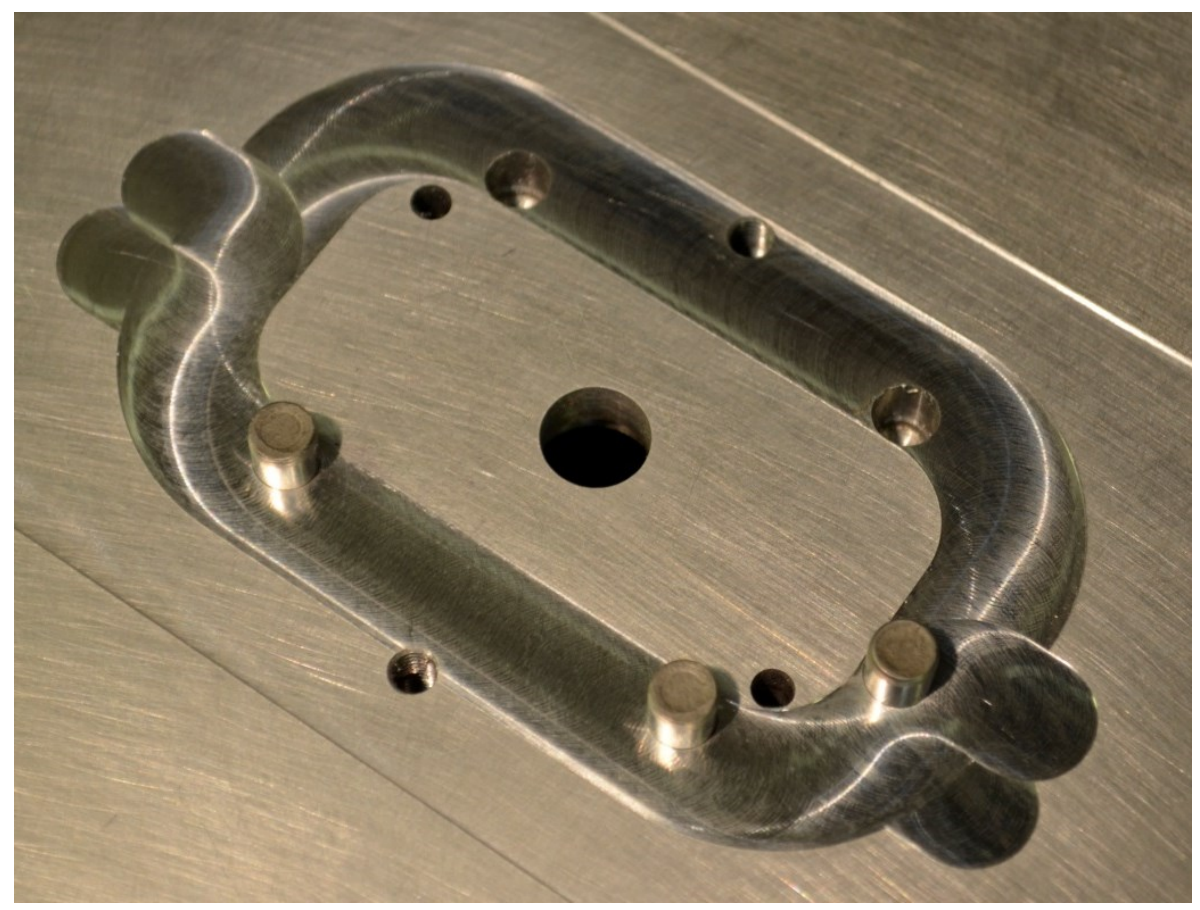

Figure 14: Three-pin jig for cutting outer dimensions of elliptical targets. 
Once the three sides had been cut to size, a second clamp held the target while the first clamp was removed. With the first clamp removed and the second clamp in place, the fourth side of the target was accessible, and was cut to size using the same end mill. A target and clamps are shown in Figure 15. The target's dimensions were verified with a vernier caliper before the target was removed from the milling machine. If the length and width of the target were satisfactory, the target was removed, and its edges de-burred with a fine file.
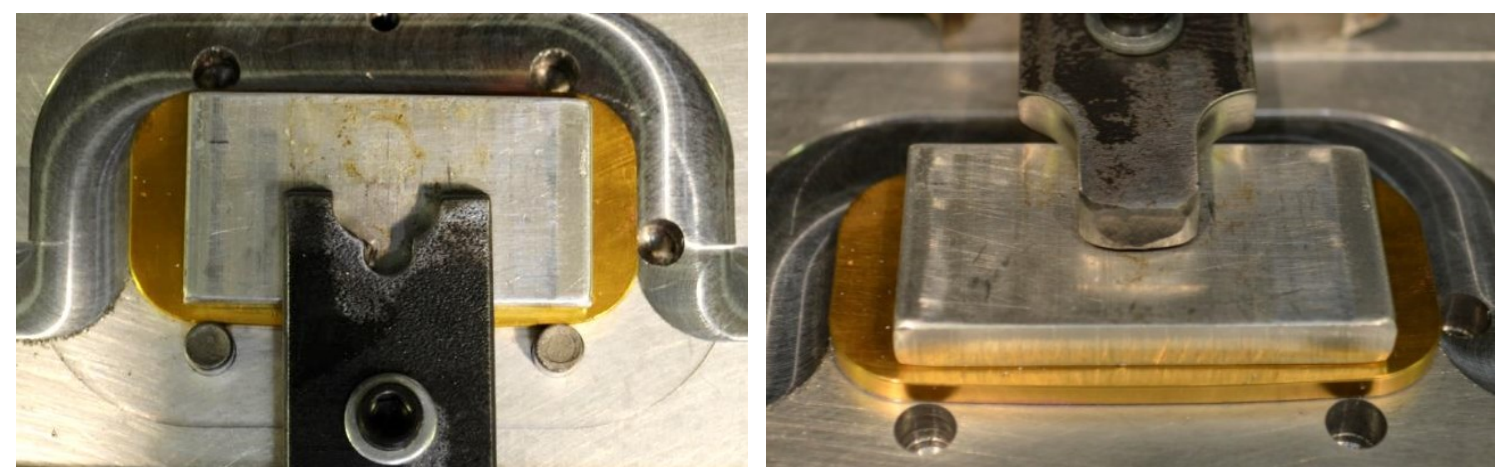

Figure 15: Clamping sequence for machining outer dimensions of an elliptical target. Three sides can be machined while clamped in the left configuration; the final side is machined with the configuration shown on the right.

The batch of targets was then subjected to the next operations, which required a different jig. The jig, shown in Figure 16, consisted of a target-shaped pocket cut into two aluminum halves. The halves were bolted to the jaws of a vice, which was mounted to the mill table. When the vice was closed, the aluminum halves would move together, and clamp a target in place. 

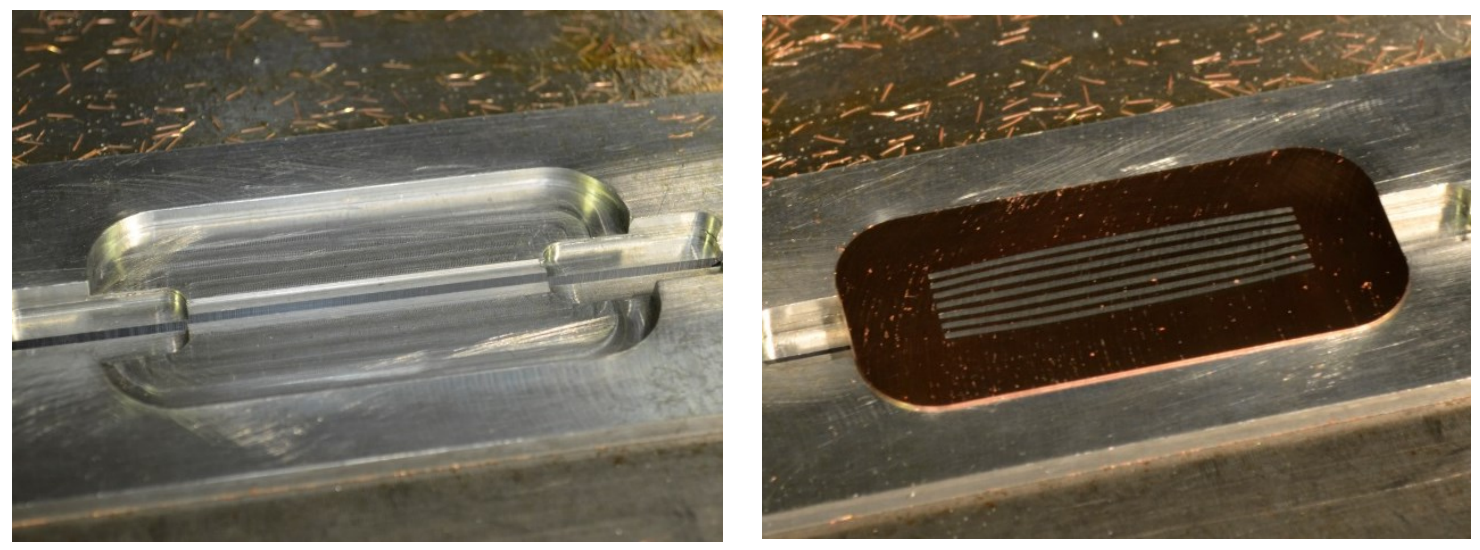

Figure 16: Two-piece jig attached to vice jaws, used to clamp a target.

Once a target was gently secured in the jig, the thickness was cut to specification with a single pass of a fly cutter. Without removing the target from the jig, the next operation began. The O-ring groove was roughed-in using a flat end mill, ramped down to avoid excessive force on the target. The drop hole for the dovetail cutter was also machined using the flat end mill. The dovetail cutter entered the O-ring groove via the drop hole and made a pass along the centre of the roughed-in groove. Following the first pass, the dovetail cutter made a pass $0.076 \mathrm{~mm}(0.003$ ") towards the inside of the groove and a pass $0.076 \mathrm{~mm}(0.003$ ") towards the outside of the groove. Additional passes by the dovetail cutter widened the groove, and cut rounds on the neck of the groove. A finished O-ring groove on the water side of a target is shown in Figure 17. Copper chips and debris were brushed from the target and jig before the target was removed. Once the target was out of the jig, and safely put aside, compressed air was used to finish cleaning the jig. Care was taken not to expose the molybdenum to oil or high pressured air. 


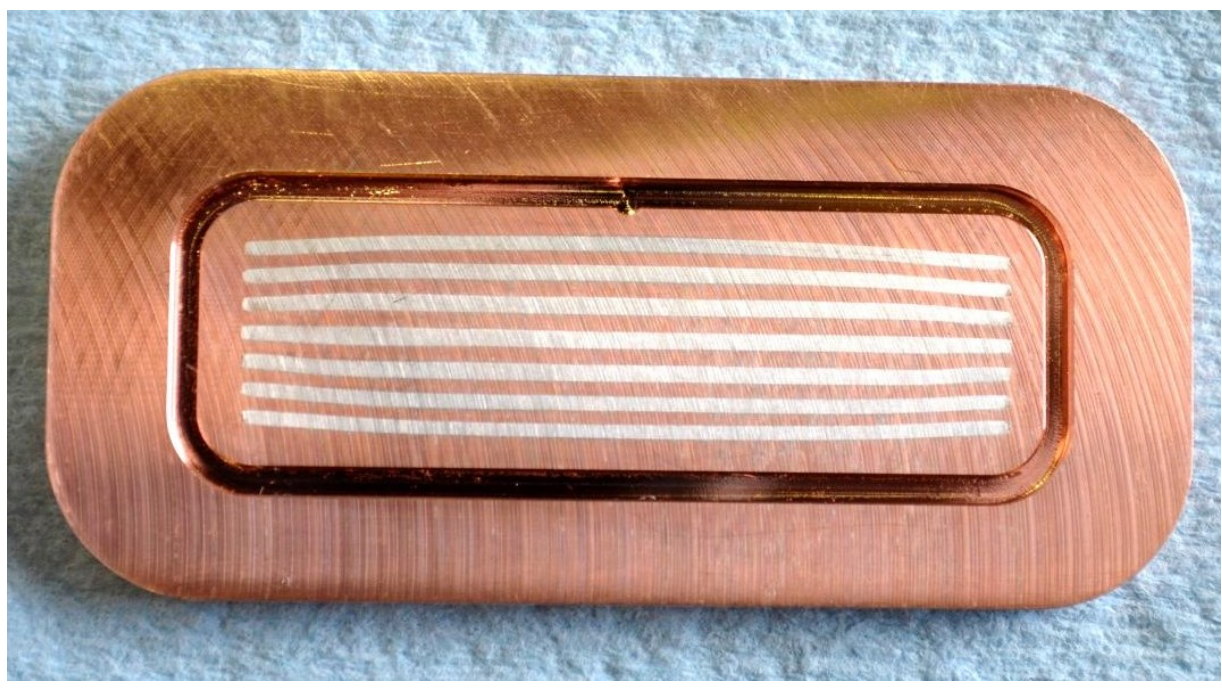

Figure 17: Finished O-ring groove on water side of an elliptical target.

Preparation for cutting the beam side O-ring groove involved taping a protective shim over the molybdenum ellipse. With the shim in place, the target was gently secured in the two-piece jig, beam side up, as shown in Figure 18.

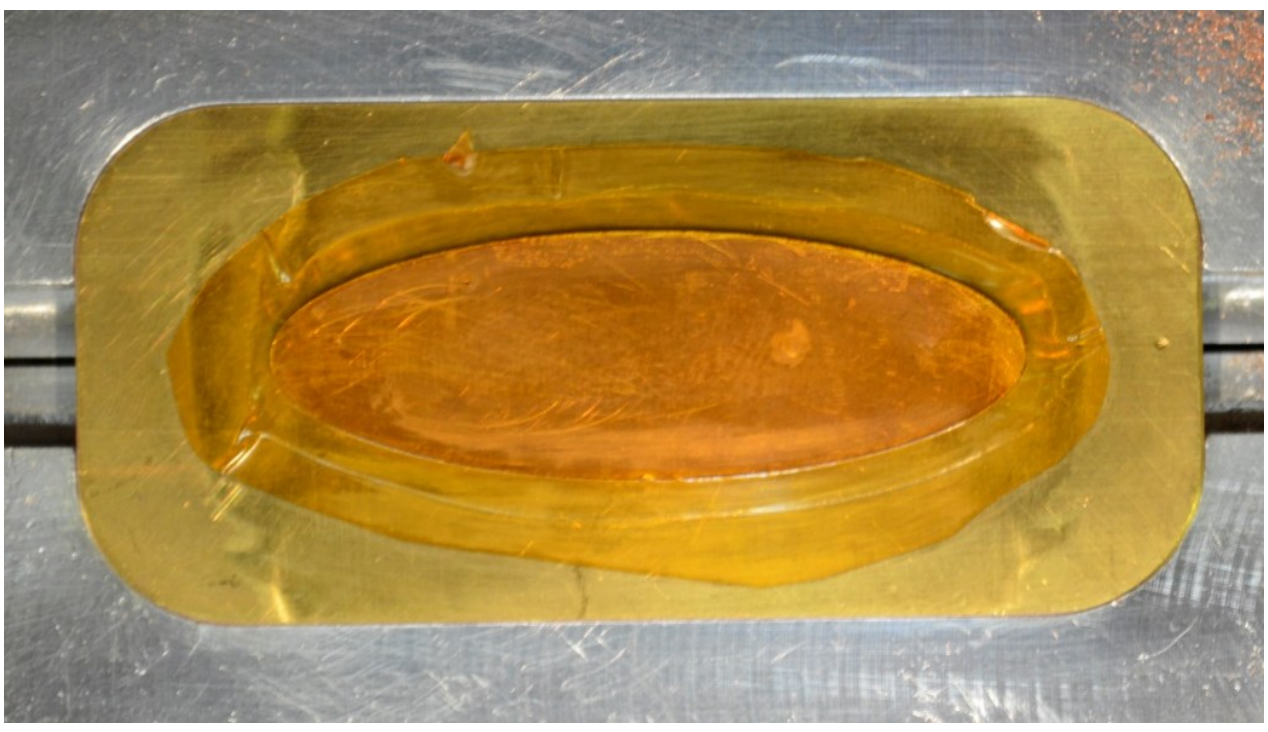

Figure 18: An elliptical target with molybdenum covered, awaiting beam side O-ring groove. 
The beam side O-ring groove was cut in a similar fashion to the water side groove; rough cut groove and drop hole were machined with a flat end mill, followed by three passes with the dovetail cutter. The target was brushed free of debris, and removed from the jig. Both O-ring grooves were cleaned using alcohol and a cotton cloth. The protective covering was kept on the target while the O-ring grooves were cleaned and during the removal of the cooling channel supports.

\subsubsection{Dissolving Cooling Channel Supports}

Hydrochloric acid (12 M) was used to dissolve the cooling channel supports out of the targets. Targets were suspended in a bath of $\mathrm{HCl}$, such that the acid could interact with the aluminum cooling channel supports, but not flood over the target and onto the protective covering, see Figure 19.

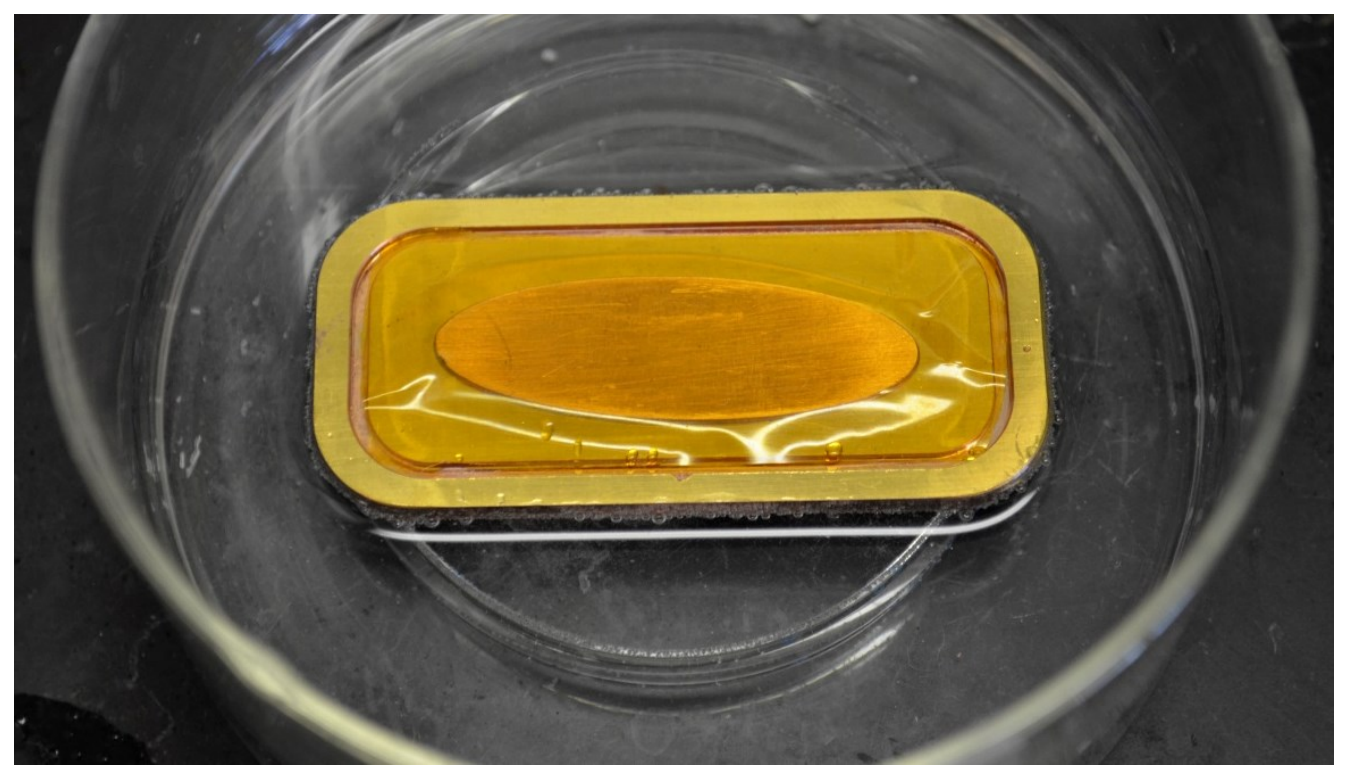

Figure 19: Dissolving cooling channel supports from an elliptical target supported in beaker. 
Forceps were used to lift the target off its support, and excess acid was allowed to drip off before the target was rinsed. A fine jet of water from a spray bottle was used to flush the cooling channels and O-ring grooves, with care taken not to get any water underneath the protective covering and onto the molybdenum. The beam side of a finished target is Figure 20, and the water side is Figure 21.

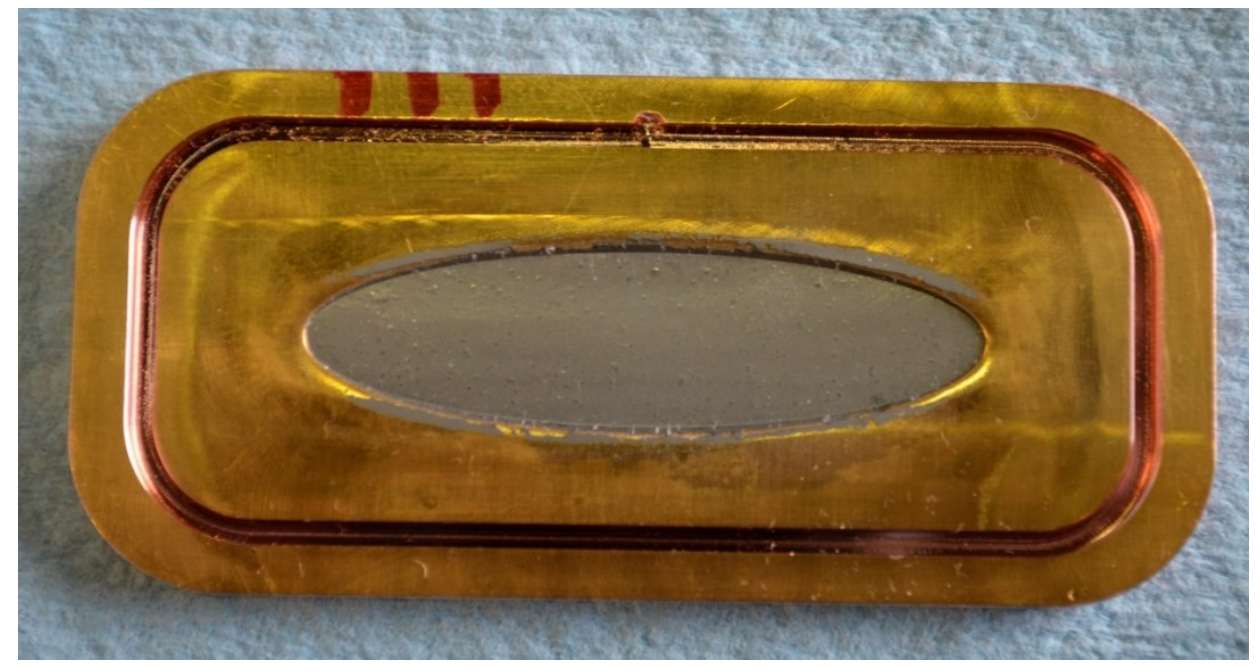

Figure 20: Beam side of a finished elliptical ${ }^{100}$ Mo target.

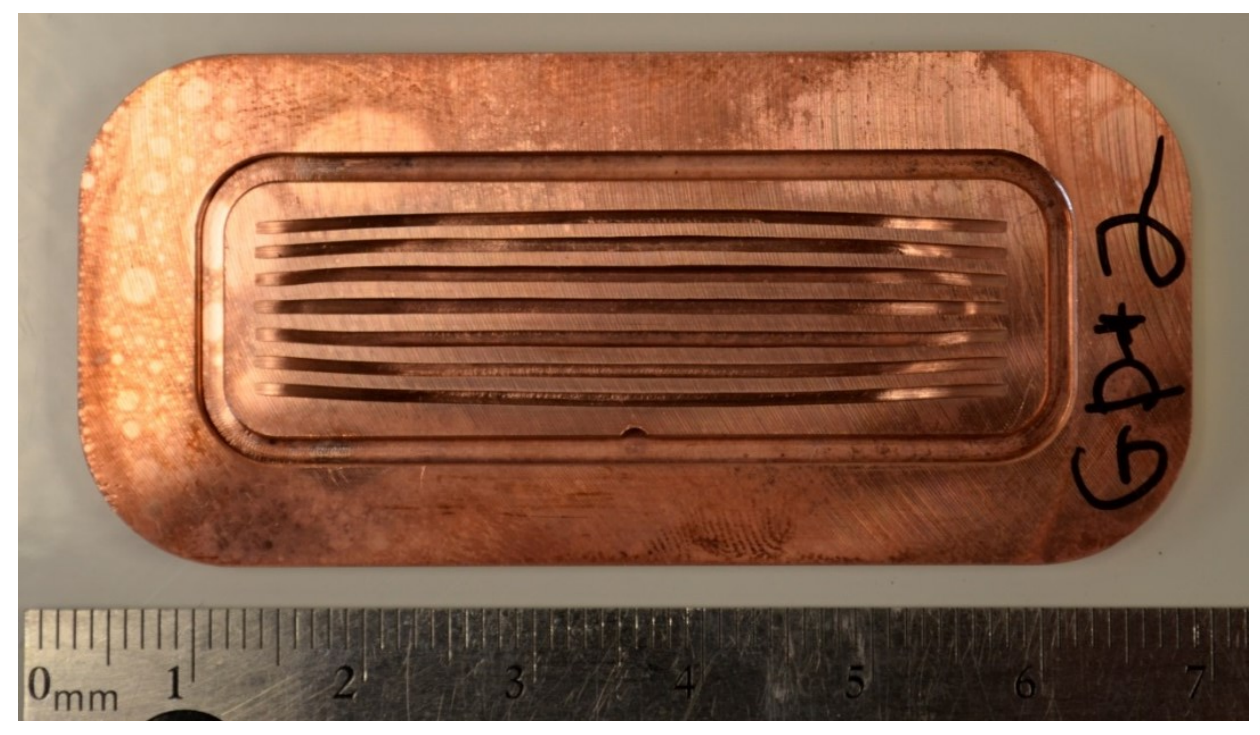

Figure 21: Water side of a finished elliptical ${ }^{100}$ Mo target. 


\subsection{Packaging for Shipping}

Once acid was rinsed from the targets, they were wiped dry with a soft cloth, and the protective coverings over the molybdenum were removed. The molybdenum on each target was inspected for any damage, such as: cracks, bubbles, or chips. If the target appeared sound and free from defects it was deemed suitable for use in a cyclotron. The protective shim was re-placed over the molybdenum, and secured with new tape. Each target was fitted with two EPDM O-rings: the beam side being size \#029 and the water side being size \#027. O-ring grease such as Apiezon grease, compatible with EPDM materials, is recommended. Installation began by spreading a small amount of the grease onto the O-ring. The O-ring was pushed into the groove at one corner, and then pushed into rest of the groove. The grooves have a dovetailed shape, so getting the O-ring past the neck of the groove was made easier by applying a bit of tension on the O-ring, while pushing into the groove. Once the O-ring was placed into the groove, it was important to ensure the O-ring had been pushed down completely and is evenly seated. Once both Orings were properly installed, the targets were individually wrapped in soft cloths, and placed into a box with packing material.

\subsection{Pre-Irradiation Target Qualification}

Outer dimensions of elliptical targets were within the given tolerance of $\pm 0.1 \mathrm{~mm}$ (0.004"); however, thickness had greater deviation than the specified tolerance of \pm 25 microns (0.001"). Despite having a thickness of $2.8 \mathrm{~mm} \pm 150$ microns (0.006"), elliptical targets, with ${ }^{100} \mathrm{Mo}$, have been placed in the cyclotron's target holder, and have been shown to hold a vacuum of $10^{-7} \mathrm{~atm}$. 
Natural molybdenum targets were taken off the press and drop-tested onto concrete from $1.5 \mathrm{~m}$ without cracking. If a crack or bubble in the molybdenum was present, the target would not be suitable for irradiation, as fragments of molybdenum could move throughout the cyclotron and contaminate the system. 


\section{Chapter: Testing and Irradiation of Circular Targets}

This chapter presents the experiments used to demonstrate the viability of producing

${ }^{99 \mathrm{~m}} \mathrm{Tc}$ from circular ${ }^{100} \mathrm{Mo}$ targets manufactured according to the procedures described in this thesis. Natural and enriched molybdenum targets were supplied to Best Theratronics Ltd., so that irradiation and post-irradiation processing could be conducted. Sodium pertechnetate solution $\left(\mathrm{Na}^{99 \mathrm{~m}} \mathrm{TcO}_{4}\right.$, Cardinal Health, $>99 \%$ radiochemical purity) with a known activity level was placed on a circular target and evaporated to dryness with a hot plate to create a 'spiked' natMo target, which was processed as described by Matei et al., in the 15th International Workshop on Targetry and Target Chemistry conference proceedings [21]. Tests with the 'spiked' targets formed the basis for processing targets irradiated in a cyclotron.

\subsection{Irradiation of ${ }^{100} \mathrm{Mo}$ Targets}

After the successful completion of processing a 'spiked' target, a circular ${ }^{100} \mathrm{Mo}$ target was irradiated by a cyclotron in Romania and processed in 2014 by Matei et al. [21]. Figure 22 shows the circular ${ }^{100} \mathrm{Mo}$ target before and after irradiation. 

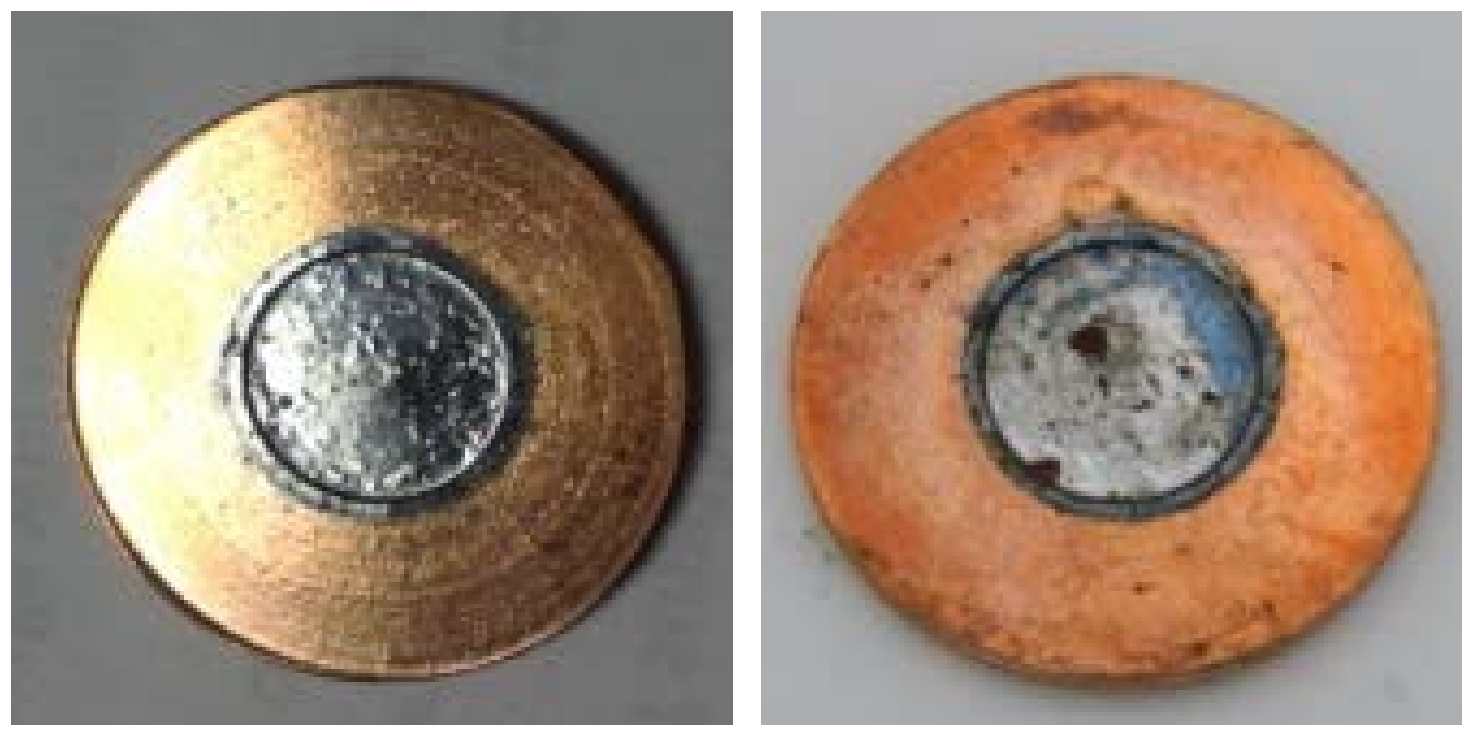

Figure 22: Circular ${ }^{100} \mathrm{Mo}$ target (24 mm diameter) before (left) and after (right) irradiation [21].

A proton beam of $15 \mathrm{MeV}$ and $50 \mu \mathrm{A}$ was used to irradiate the ${ }^{100} \mathrm{Mo}$ target for one hour. The target was found to have $6.6 \mathrm{GBq}(0.18 \mathrm{Ci})$, end of bombardment corrected [21]. After irradiation, the target was dissolved in $30 \% \mathrm{H}_{2} \mathrm{O}_{2}$ (Fischer), and transferred to a quartz tube for separation of the isotopes via thermal chromatography. Approximately $70 \%$ of the activity was recovered following separation, and gamma spectroscopy was performed on a sample of the purified product. The gamma spectrum, shown in Figure 23, revealed only technetium isotopes remained in the product purified by thermal chromatography [21]. 


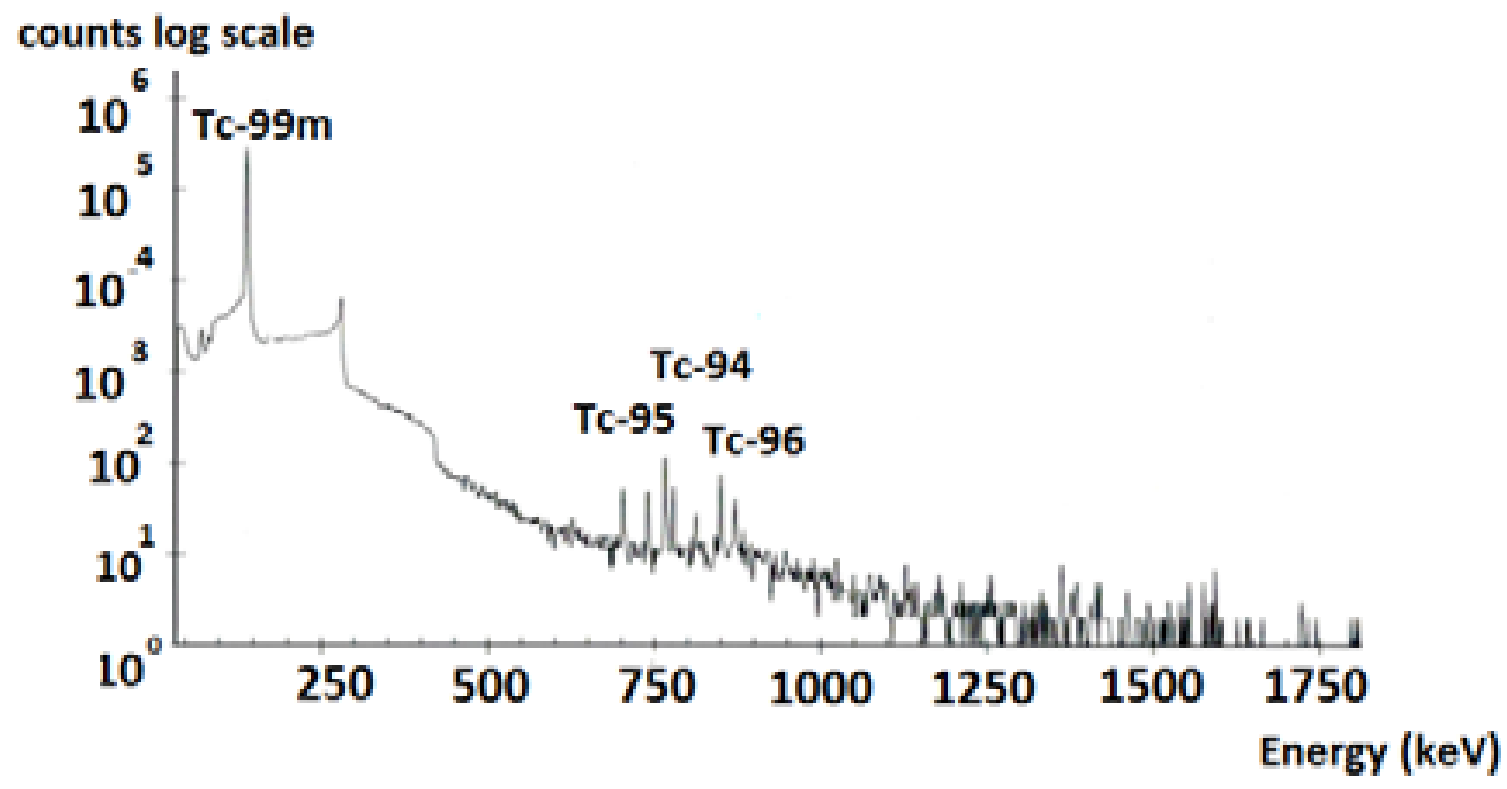

Figure 23: Gamma spectrum from irradiated ${ }^{100}$ Mo target [21].

In addition to the circular ${ }^{100}$ Mo targets described above, two more circular ${ }^{100}$ Mo targets were manufactured and sent for irradiation during April 22-28, 2015. A circular ${ }^{100} \mathrm{Mo}$ target was processed by a team of radiochemists, physicists, and scientists in Bucharest, Romania. The information below was provided by Dr. L. Matei, who was present on behalf of BTL. The team gathered at the National Institute for Physics and Nuclear Engineering (NIPNE), and used a TR-19 cyclotron and a Thermal Separation Unit (TSU) provided by Advanced Systems Designs Inc. (ASD-Inc.) to irradiate and process the ${ }^{100}$ Mo target. Unfortunately, the molybdenum layer detached from the copper disk during irradiation because of insufficient heat dissipation, but the team was able to contain the ${ }^{99 \mathrm{~m}} \mathrm{Tc}$, and meet their objectives. 
The objectives, with respect to the ${ }^{100}$ Mo target, were to:

- Determine radioisotope profile of ${ }^{99 \mathrm{~m}} \mathrm{Tc}$ produced by direct irradiation of ${ }^{100} \mathrm{Mo}$ target material deposited on copper discs, at the energy of $15 \mathrm{MeV}$.

- Separate produced ${ }^{99 \mathrm{~m}} \mathrm{Tc}$ as $\mathrm{Na}^{99 \mathrm{~m}} \mathrm{TcO}_{4}$, by thermal chromatography, using the Thermal Separation Unit designed and built by Advanced Systems Designs Inc.

- Assess the behaviour of ${ }^{100}$ Mo targets manufactured at Carleton University.

The ${ }^{100}$ Mo powder pressed onto the target, supplied by ISOFLEX USA, had the isotopic distribution shown in Table 3. The circular target had $0.1929 \mathrm{~g}$ of the ${ }^{100}$ Mo powder present.

Table 3: Isotopic distribution of Mo-100 target material.

\begin{tabular}{|c|c|c|c|c|c|c|c|}
\hline Isotope & Mo-92 & Mo-94 & Mo-95 & Mo-96 & Mo-97 & Mo-98 & Mo-100 \\
\hline Content \% & 0.08 & 0.07 & 0.09 & 0.11 & 0.08 & 0.54 & 99.03 \\
\hline
\end{tabular}

Before irradiation, a $40 \mu \mathrm{m}$ aluminum foil (GoodFellow, $99.99 \%$ purity) was attached to the copper disk as a protective covering for the ${ }^{100} \mathrm{Mo}$. In the event that the ${ }^{100} \mathrm{Mo}$ separated from the copper during irradiation, the aluminum would contain the radioactive material and prevent its distribution throughout the cyclotron. The target was irradiated by a proton beam at normal incidence with energy of $15.6 \mathrm{MeV}$ and current of $65.3 \mu \mathrm{A}$ for 30 minutes. The power density was $1.25 \mathrm{~kW} / \mathrm{cm}^{2}$, so the target required water cooling. After irradiation, it was found that a portion of the ${ }^{100}$ Mo had flaked from the 
copper, suggesting that the $4 \mathrm{~L} / \mathrm{min}$ rate of cooling water was insufficient for dissipating heat deposited on the target.

Activity on the target was $34.5 \mathrm{GBq}(0.93 \mathrm{Ci})$ counted 90 minutes after end of bombardment (EOB). The activity drastically decreased in the first two hours from EOB,

suggesting the presence of short half-life isotopes such as: ${ }^{94 \mathrm{~m}} \mathrm{Tc}\left(\mathrm{T}_{1 / 2}=52 \mathrm{~min}\right),{ }^{96 \mathrm{~m}} \mathrm{Tc}$ $\left(\mathrm{T}_{1 / 2}=52 \mathrm{~min}\right)$ and ${ }^{97} \mathrm{Nb}\left(\mathrm{T}^{1 / 2}=72 \mathrm{~min}\right)$.

\subsection{Thermal Separation of ${ }^{99 \mathrm{~m}} \mathrm{Tc}$}

Approximately two hours elapsed between end of bombardment and dissolution of the target to allow activity on the target to reduce to safer levels. The portion of the molybdenum that flaked from the copper was transferred into a beaker, placed on a hot plate, and dissolved with $5 \mathrm{~mL}$ of $30 \% \mathrm{H}_{2} \mathrm{O}_{2}$ (Sigma). In parallel, the target was transferred to the fume hood, and the molybdenum which remained attached was dissolved with $1.5 \mathrm{~mL}$ of $30 \% \mathrm{H}_{2} \mathrm{O}_{2}$. Both the solutions were collected and allowed to evaporate until $2 \mathrm{~mL}$ of the mixture remained. The Thermal Separation Unit (TSU) and mixture are shown in Figure 24. 


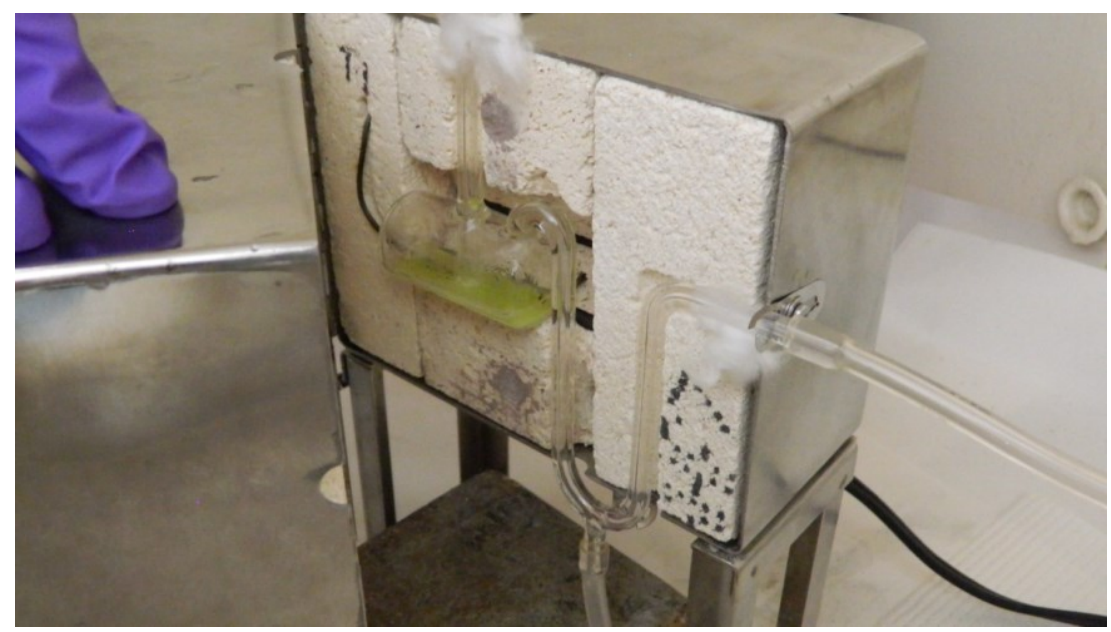

Figure 24: Thermal Separation Unit with mixture of $\mathrm{H}_{2} \mathrm{O}_{2}$ and dissolved target.

The mixture had an activity of $4.6 \mathrm{GBq}(0.12 \mathrm{Ci})$ when it was put into the TSU. The TSU was used to oxidize the isotopic mixture at $700^{\circ} \mathrm{C}$ while oxygen was pumped through at 16 cubic centimeters per minute. After 30 minutes, the TSU was allowed to cool, and was carefully washed with $0.1 \mathrm{M} \mathrm{NaOH}$ in two fractions of $1.5 \mathrm{~mL}$ to collect the pertechnetate. The recovered activity was $1.5 \mathrm{GBq}(0.04 \mathrm{Ci})$, EOB corrected.

This recovery demonstrated the viability of ${ }^{100}$ Mo targets, from start to finish. Starting with molybdenum powder, and using the procedures outlined in this thesis, circular ${ }^{100} \mathrm{Mo}$ targets were manufactured, shipped across the world for irradiation in a cyclotron, and processed to yield ${ }^{99 \mathrm{~m}} \mathrm{Tc}$. 


\section{Chapter: Large Scale Production and Future Considerations}

Large scale production is necessary to meet the Canadian requirements for ${ }^{99 \mathrm{~m}} \mathrm{Tc}$. This chapter discusses procedural improvements to enable production of at least 30 targets per day. Each target has the potential to produce $296 \mathrm{GBq}(8 \mathrm{Ci})$ of ${ }^{99 \mathrm{~m}} \mathrm{Tc}$, based on irradiation of a target for four hours with a $15 \mathrm{MeV}$ and $400 \mu \mathrm{A}$ proton beam, and 185 $\mathrm{MBq} / \mu \mathrm{Ah}(5 \mathrm{mCi} / \mu \mathrm{Ah})$ [28]. Currently, $8 \mathrm{TBq}(220 \mathrm{Ci})$ are needed at the start of each day, Section 1.3, hence the requirement of 30 targets per day. Four elliptical targets manufactured with the procedures presented in this thesis took eight hours to produce. Methods to increase the production rate of targets are presented in this chapter.

\subsection{Dispensing Powder}

Elimination of manually massing and spreading the molybdenum onto the copper blank would increase the rate of target production. Natural molybdenum powder was used to improve the dispensing and dispersing system. The density of the natural molybdenum powder was estimated by massing consistently compressed volumes of the as received powder. It was estimated that $0.13 \mathrm{~cm}^{3}$ of consistently compressed powder would provide $220 \mathrm{mg}$ of molybdenum, and various measuring spoons were tested by massing the contents of a level spoon. Measuring by volume provided close to the desired mass, but consistency was outside the given tolerance of molybdenum required per target.

Another method tested for dispensing the powder was a hopper and auger system. A funnel shaped hopper was made of mild steel and a mild steel tube was attached to the bottom of the hopper. Various screws were tested inside of the system; when the screw 
was turned, the threads would pull powder from the hopper and push it towards an opening at the end of the tube. The hopper and auger system worked in terms of moving powder when the screw was turned, and a mass balance was used for quality control. An improved screw thread design, coupled with an automated system for revolving the auger until the desired mass is dispensed should be investigated for larger scale production of targets.

\subsection{Dispersing Powder}

The molybdenum powder is deposited and spread onto the target manually. A small spatula is used to disperse the powder evenly on the surface of the copper blank. If the Mo was not spread evenly on the copper blank, the resulting molybdenum sheet pressed onto the target would have a non-uniform thickness. Two alternative methods of dispersing the powder were explored: a vibrating table and a slurry of molybdenum powder mixed with ethyl alcohol.

A copper blank and an elliptical washer were taped together and placed on the vibrating table. Molybdenum powder was placed on the copper blank, and the table was turned on. The molybdenum tended to form a pile in the centre of the washer, and did not spread evenly across the copper as intended.

The next experiment was to create a slurry comprised of ethyl alcohol and molybdenum powder, which was then poured onto the copper blank through the opening of the elliptical washer. The slurry tended to level itself and cover the desired area. The slurry 
was ignited to burn off excess alcohol, and no residue was noticed. After pressing, the molybdenum sheets on the targets were similar to those of targets that had the powder spread manually. Advantages to dispersing the molybdenum in slurry form include: massing via volume of slurry, and self-leveling onto the copper blank. Although the slurry method proved useful, two disadvantages were perceived. One disadvantage occurs when dealing with recycled target material that could be radioactive: igniting the alcohol could cause radioactive particles to become airborne. The second disadvantage is that the slurry was able to move outside of the elliptical opening in the washer and lie between the elliptical washer and the copper blank during pressing. Molybdenum pressed outside of the desired elliptical shape would not be irradiated, and therefore wasteful of the expensive ${ }^{100} \mathrm{Mo}$.

\subsection{Reduction in Machining Time}

Suggestions for reducing the machining time of copper blanks and targets are discussed in this section. Copper blanks for both circular and elliptical targets are machined by a $\mathrm{CNC}$ milling machine, however, it was demonstrated that circular copper blanks could be punched from copper sheet, and elliptical blanks could also be punched from a sheet, with appropriate tooling.

Cooling channels are cut into the blanks with a single slitting saw, and supported by aluminum strips. Alternative methods of supporting the channels were investigated, but abandoned due to failure, Section 2.4. Additional lower molds to support the cooling channels could be developed, as both installation and removal of aluminum channel 
supports is time intensive, and tedious. In addition to developing better cooling channel supports, multiple channels could be cut simultaneously if multiple saws were used in parallel.

Post-press machining could be improved by machining more than one target simultaneously. Targets are machined one at a time, and each undergoes one machining process before the batch undergoes the next process. A pallet of targets could be assembled so multiple targets are machined at the same time. The targets would be disassembled from the pallet, and placed on different pallets designed for each machining operation. This would reduce the handling and set-up time required for each target.

With further investigation and implementation of the methods proposed for an increase in target production, it is reasonable to expect that thirty targets could be manufactured daily, with an automated hydraulic press and a CNC milling machine. 


\section{Chapter: Conclusions}

This chapter discusses to what extent the primary objectives from Section 1.4, and the additional requirements from Section 3.1 were met. Each objective and requirement is listed, and followed by a description of the results.

- Demonstrate a target produces ${ }^{99 \mathrm{~m}} \mathrm{Tc}$ when irradiated in a cyclotron with protons and is commercially viable.

- Achieved: Circular ${ }^{100}$ Mo targets were irradiated, and produced ${ }^{99 \mathrm{~m}} \mathrm{Tc}$, Section 4. Methods for increasing rate of target production were provided, Section 5.

- Target must be capable of withstanding irradiation induced heat (6 kW) for up to six hours. In the event that the target fails during irradiation, radioactive material could move throughout the cyclotron, and expensive downtime and decontamination of the cyclotron required.

- Partially Achieved: Thermal simulation, completed by ASD-Inc. [23], has shown that during irradiation with $6 \mathrm{~kW}$, the molybdenum will not exceed $260^{\circ} \mathrm{C}$, which is below the temperatures at which any oxides inadvertently generated in situ could volatilize and contaminate the target holder and cyclotron, Section 2.1 [21]. In a test of a circular target, a thin aluminum foil covered the molybdenum and prevented loss of radioactive material and contamination of the cyclotron. This objective was only partially achieved because a target was not irradiated at $6 \mathrm{~kW}$. 
- Loss of ${ }^{100} \mathrm{Mo}$ was to be less than $5 \%$ during production. The ${ }^{100}$ Mo costs about $\$ 2000 / \mathrm{g}$ (ISOFLEX, USA), so waste must be minimal, and all of the material accounted for.

- Achieved: Loss of molybdenum during manufacturing is $4 \%$, Section

\subsubsection{3.}

- O-rings for the target were to be specified; one to seal the proton beam side and hold a medium vacuum $\left(10^{-7} \mathrm{~atm}\right)$, the other to seal the cooling channels through which water is pumped.

○ Achieved: Dovetail O-ring grooves are used, and firmly hold standardsized O-rings in place. An elliptical target was tested in the target holder, and withheld a medium vacuum, Section 3.4.

- The molybdenum layer was to be greater than $95 \%$ of the theoretical density, with a thickness of about $60 \mu \mathrm{m}$.

○ Achieved: Molybdenum layers with thicknesses of $60 \mu \mathrm{m}$ were produced and approached full density, Figure 8.

- Geometric tolerances on the target needed to be consistent with the tolerances of the target holder on the cyclotron.

○ Achieved: Targets fit within their respective target holders. Circular targets were irradiated, Section 4.1; elliptical targets fit in the holder and held a medium vacuum, Section 3.4.

- The cooling channels needed to have the full depth of $2.1 \mathrm{~mm}(0.083$ "). Both the Oring grooves and the cooling channels were allowed to have small radii at the bottom. 
- Achieved: Cooling channels have full depth, Section 2.4. Radii in the grooves and channels correspond to the radius on the cutters used.

- Target thickness tolerance was specified to be \pm 25 microns (0.001"). Outside dimensions were to be $\pm 0.1 \mathrm{~mm}(0.004 ")$.

- Partially Achieved: Tolerance on the thickness of a target is \pm 150 microns (0.006"), which was greater than specified, but did not affect the ability of the target to hold a medium vacuum. Outside dimensions were within the specified tolerance, Section 3.4.

- The O-ring materials known as EPDM or Ethylene-propylene rubber were recommended.

- Achieved: Elliptical targets use EPDM O-rings.

The next step with respect to testing targets is to refine the thermal separation process so that the system has a higher efficiency and can be used for processing the elliptical ${ }^{100} \mathrm{Mo}$ targets. Once the thermal separation process is improved, the elliptical targets will be irradiated by a beam of $15 \mathrm{MeV}$ protons at $400 \mu \mathrm{A}$. 


\section{Appendices}

\section{Appendix A Engineering Drawings of Components}

Below are engineering drawings of components to manufacture targets. Two Platens, presented in A.1, are held by the MTS during pressing and are common to all of the apparatus described below.

Pressing Apparatus \#1 is used for manufacturing circular targets. The components are: Circular Die, Circular Washer, and Circular Target Jig.

Pressing Apparatus \#2 is used for manufacturing elliptical targets. The components are: Elliptical Die and Elliptical Washer. This apparatus yielded the most robust targets and consistent results during manufacturing, and was used as the final apparatus for ${ }^{100} \mathrm{Mo}$ target production.

Pressing Apparatus \#3 is used for manufacturing elliptical targets. The components are: Elliptical Die \#2, Copper Blank \#3, Lower Mold \#3, Top Mold \#2, and Copper Blank with Dovetail Grooves \#3.

Pressing Apparatus \#4 is used for manufacturing elliptical targets. The components are: Cooling Channel Support \#2, Lower Mold \#4, Cu for Channel Support, Copper Blank with Dovetail Grooves \#4, and Copper Blank with Seven Cooling Channels. 


\section{A.1 Pressing Apparatus \#1}

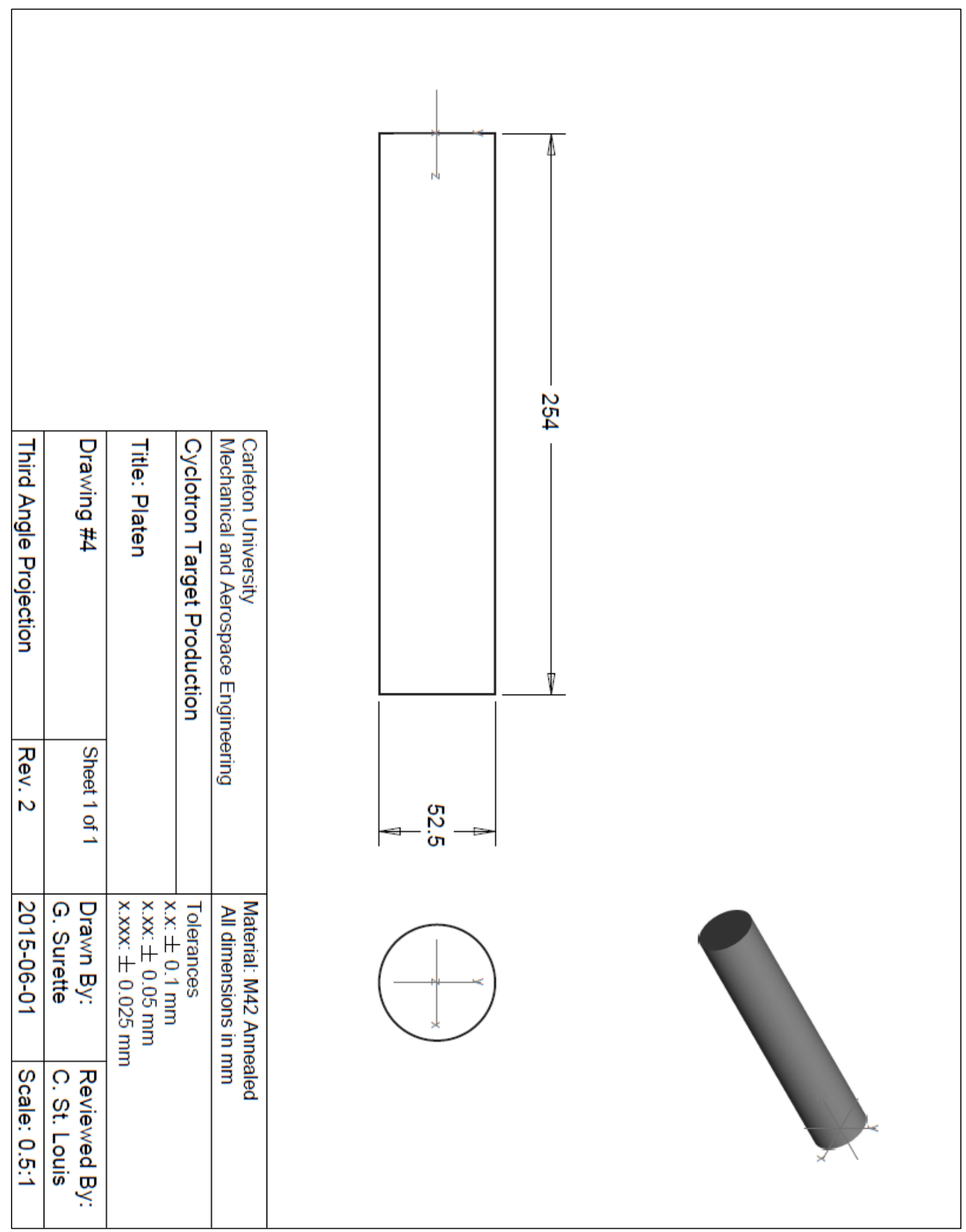




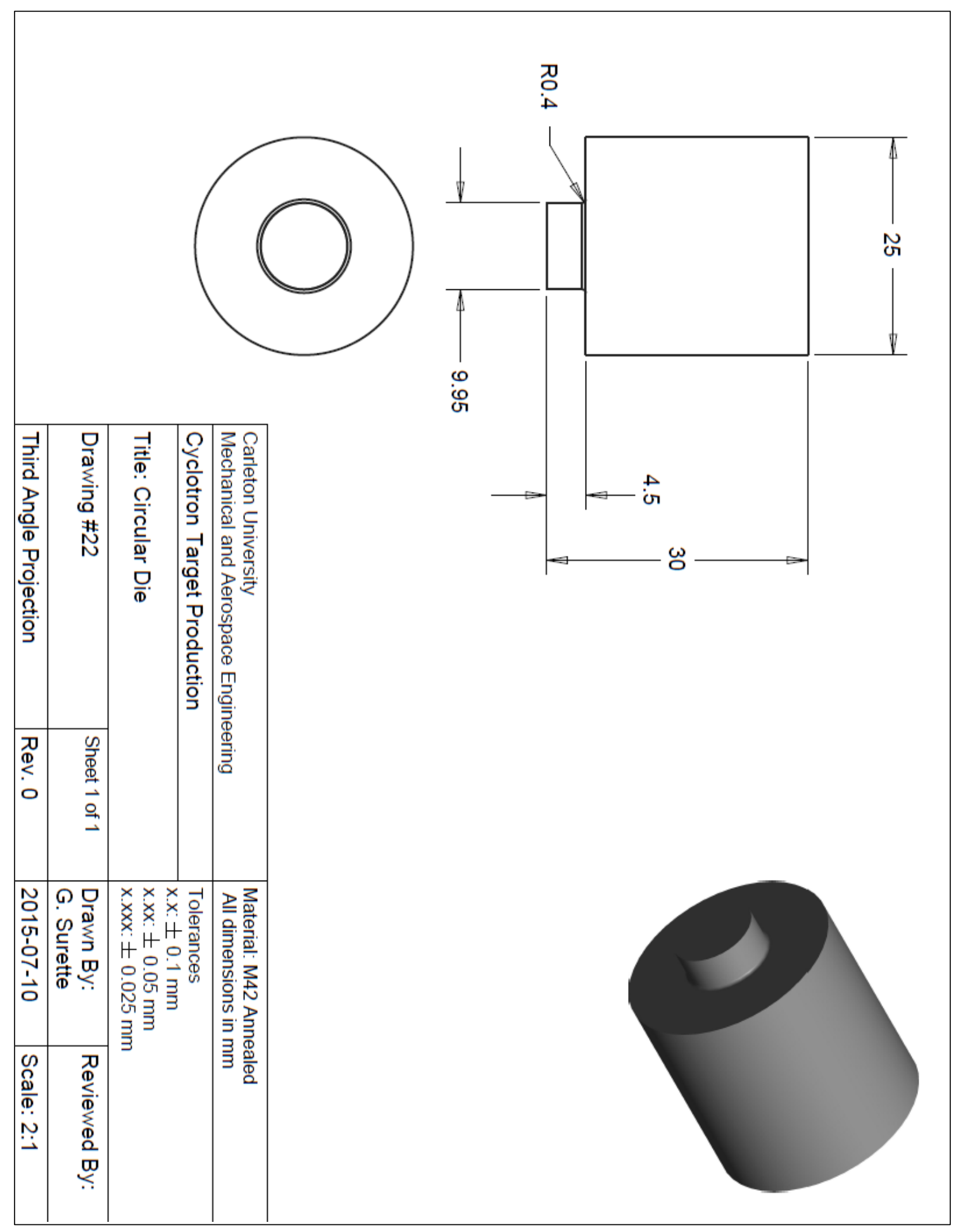



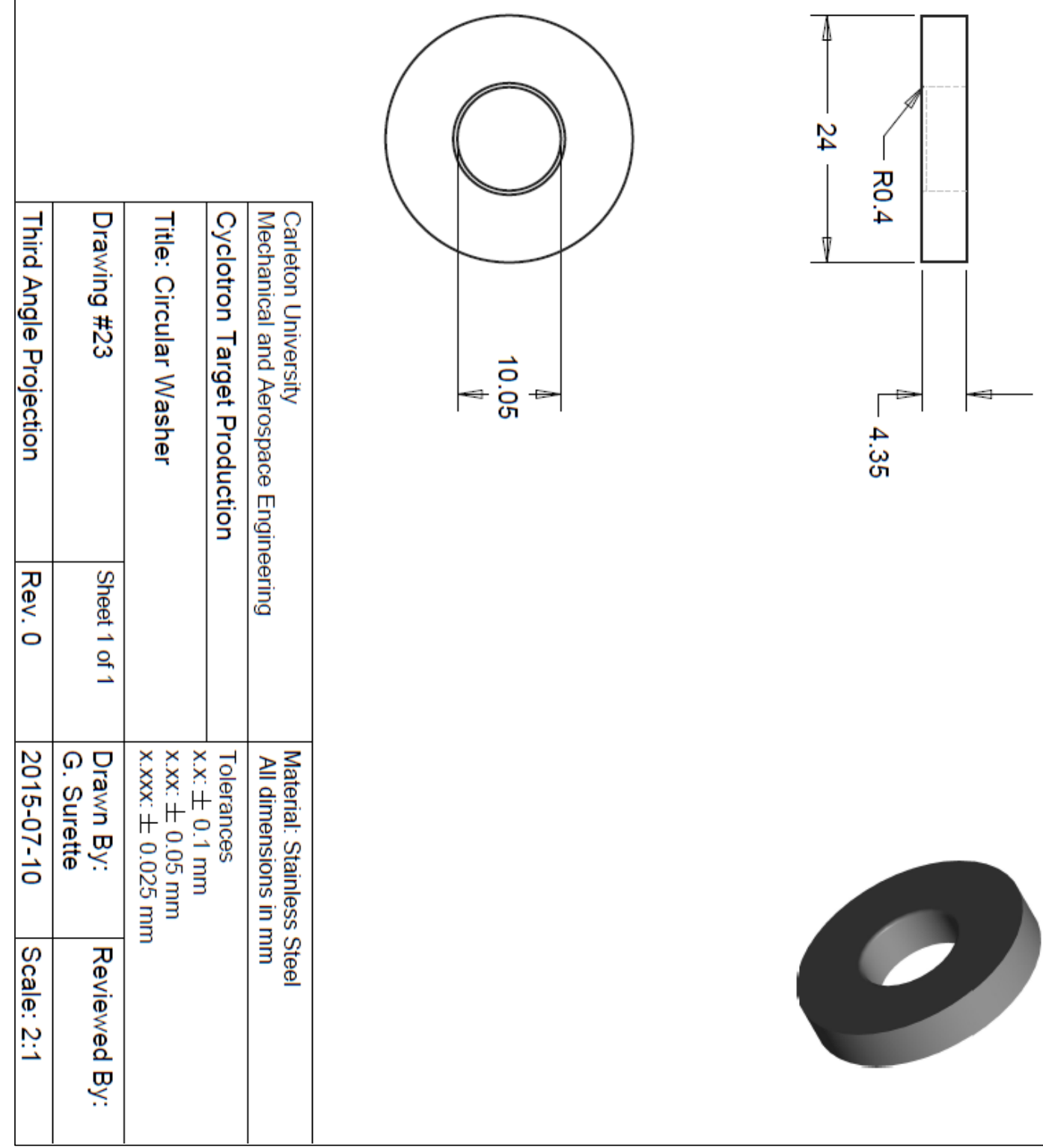


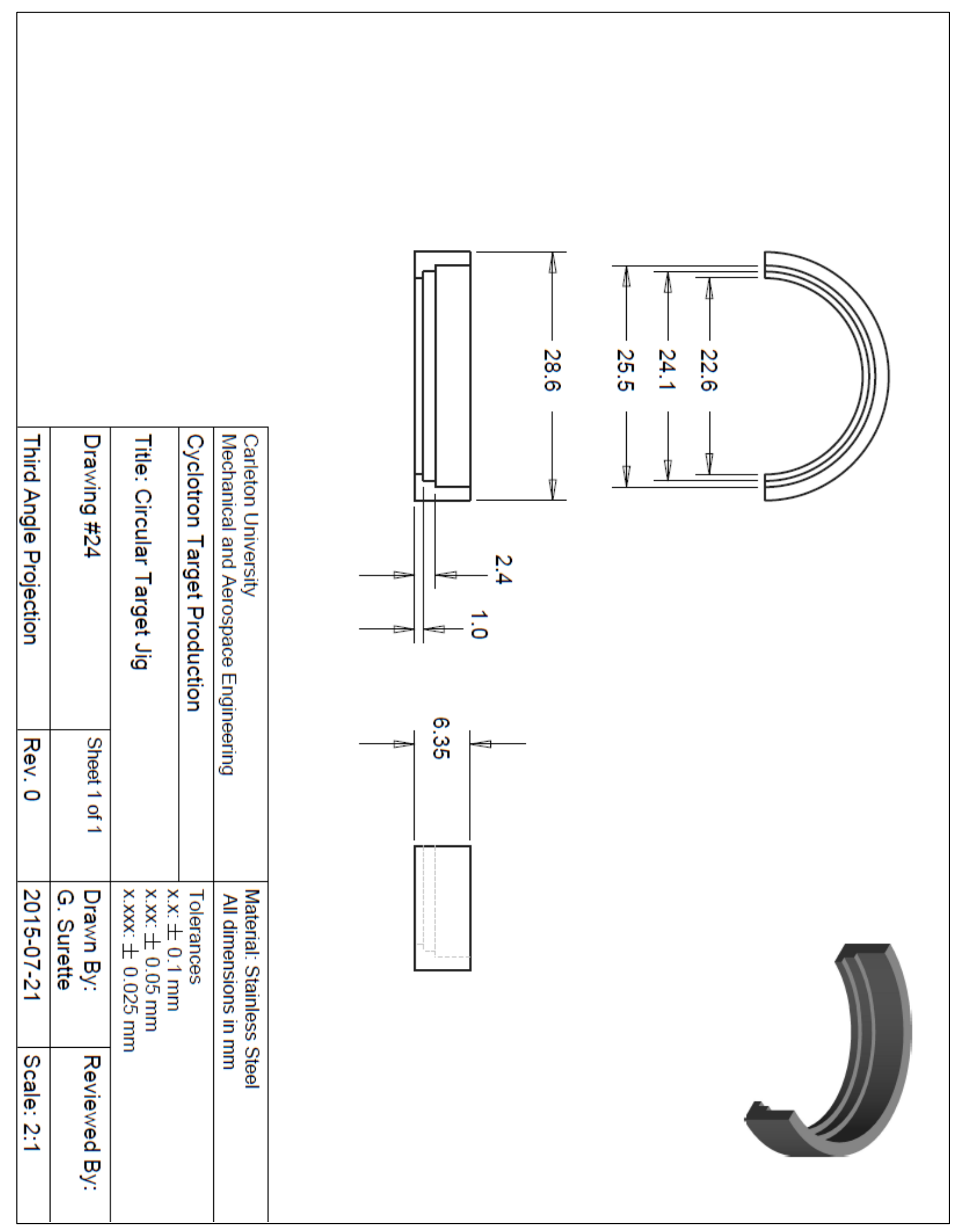




\section{A.2 Pressing Apparatus \#2}

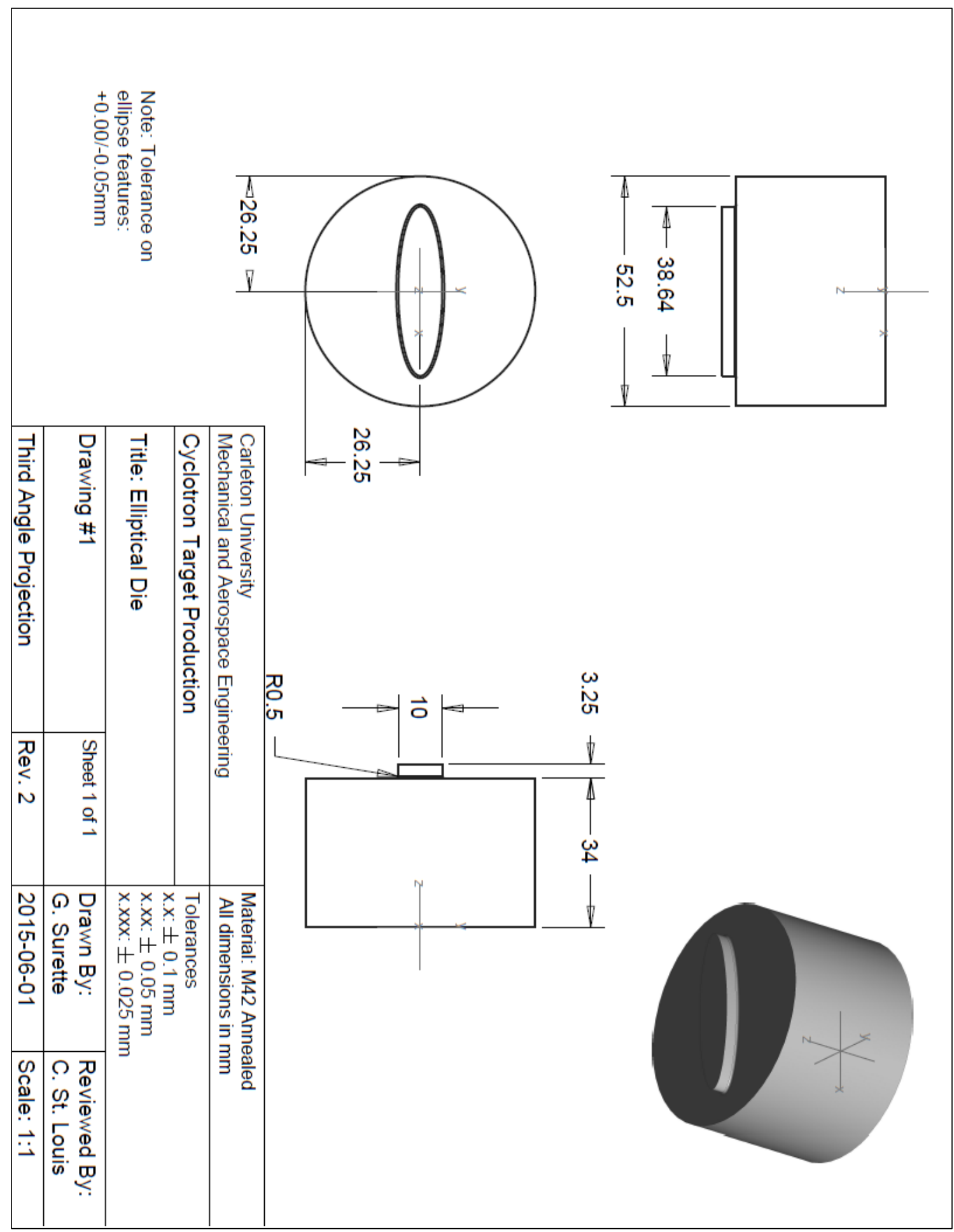




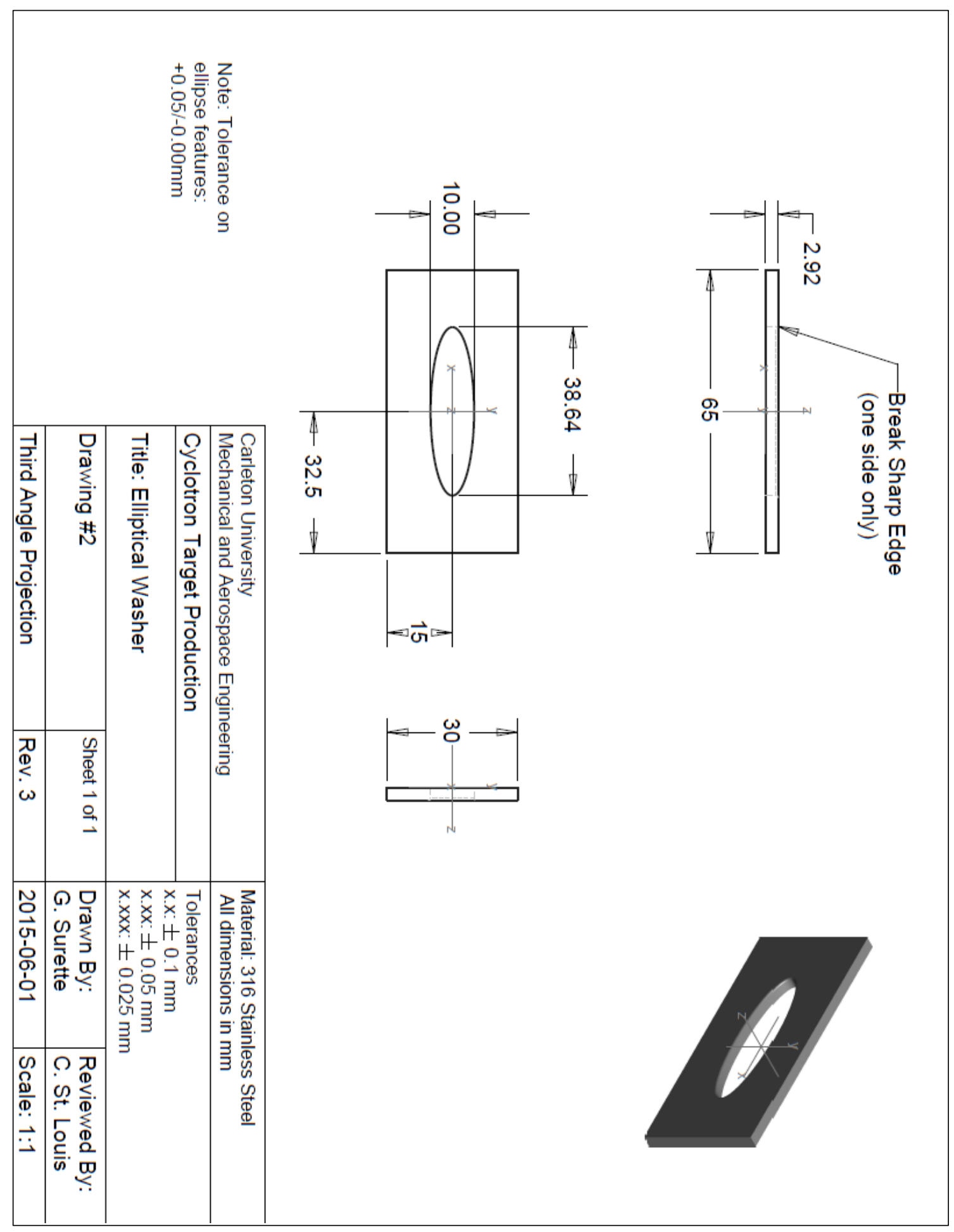




\section{A.3 Pressing Apparatus \#3}

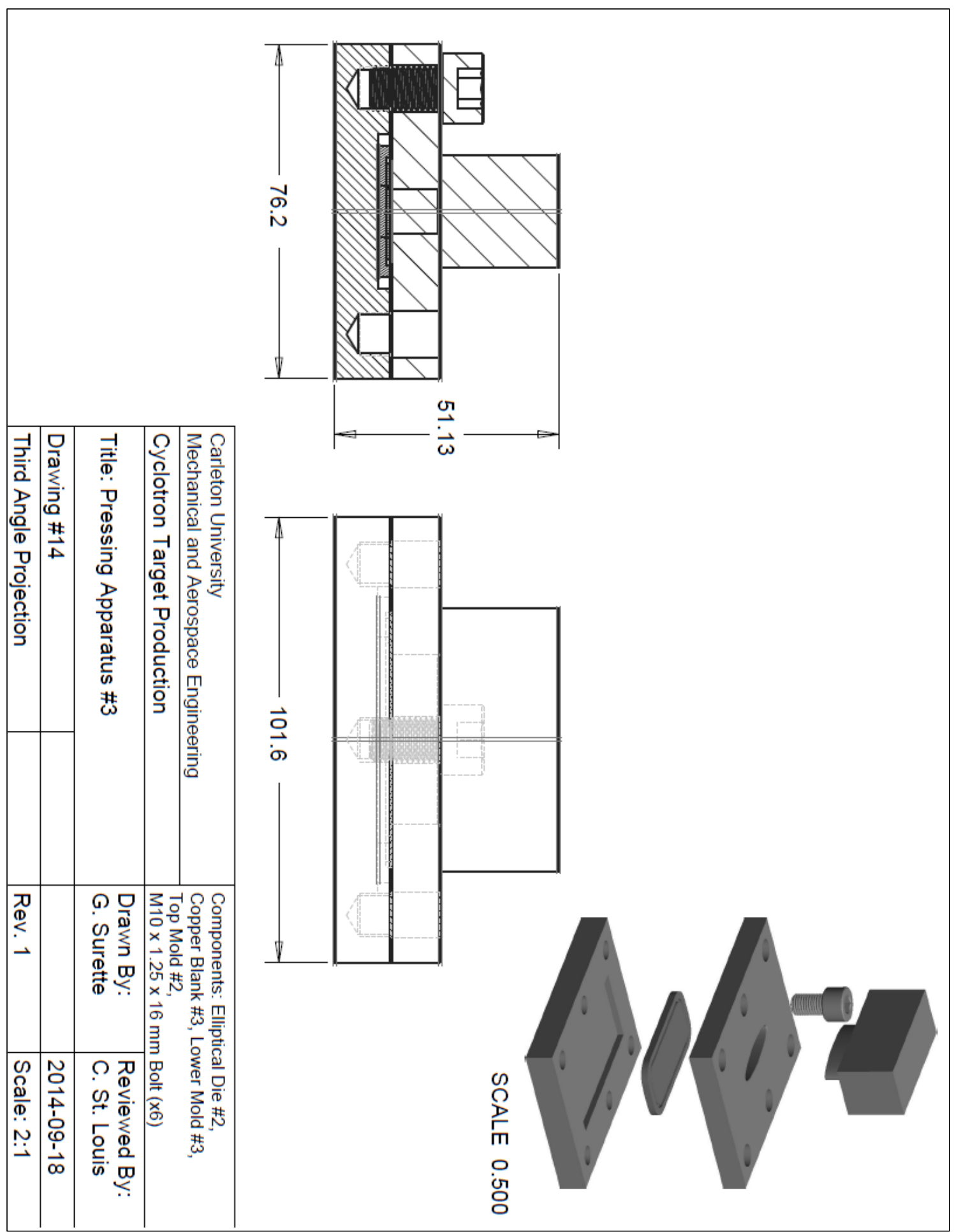




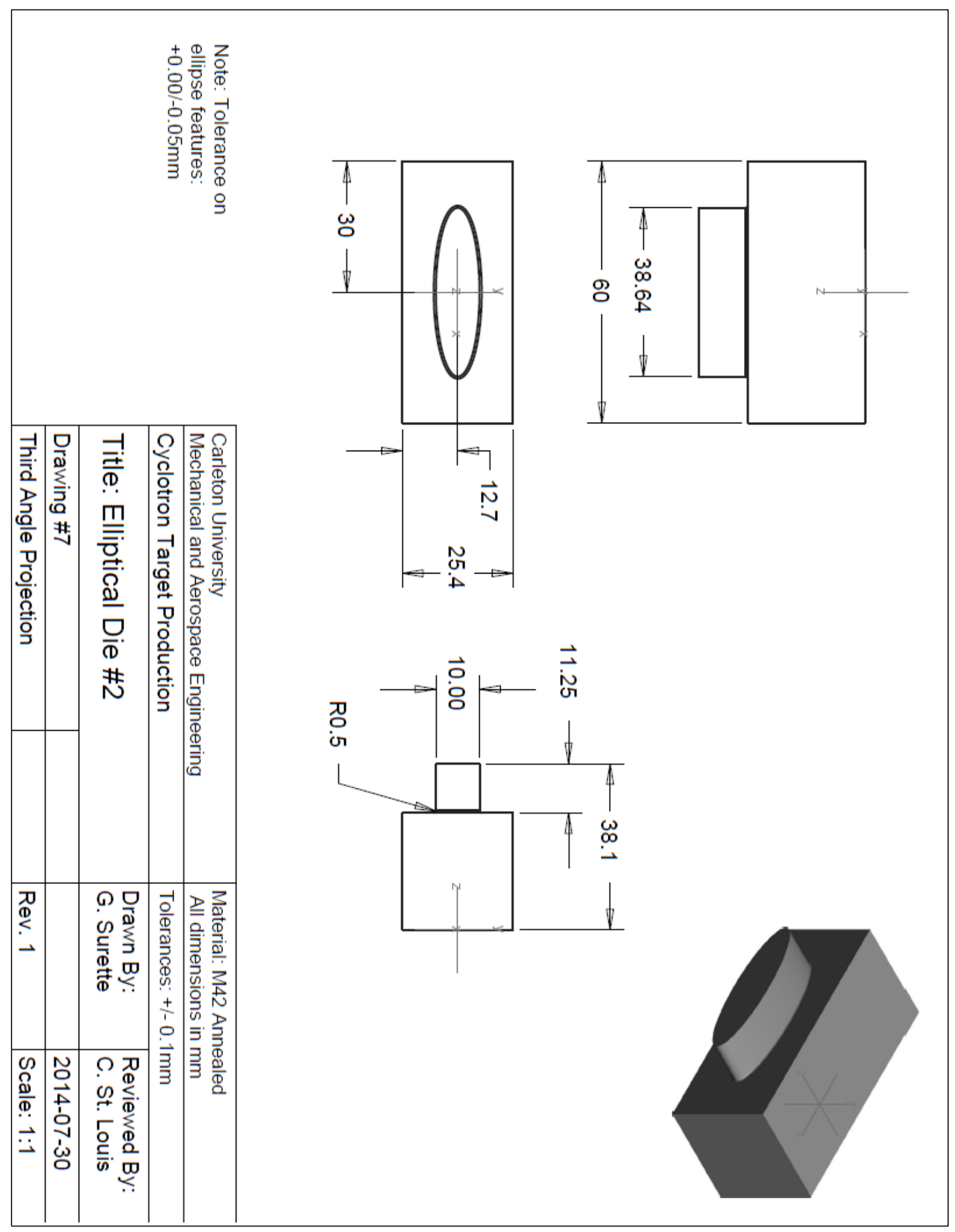




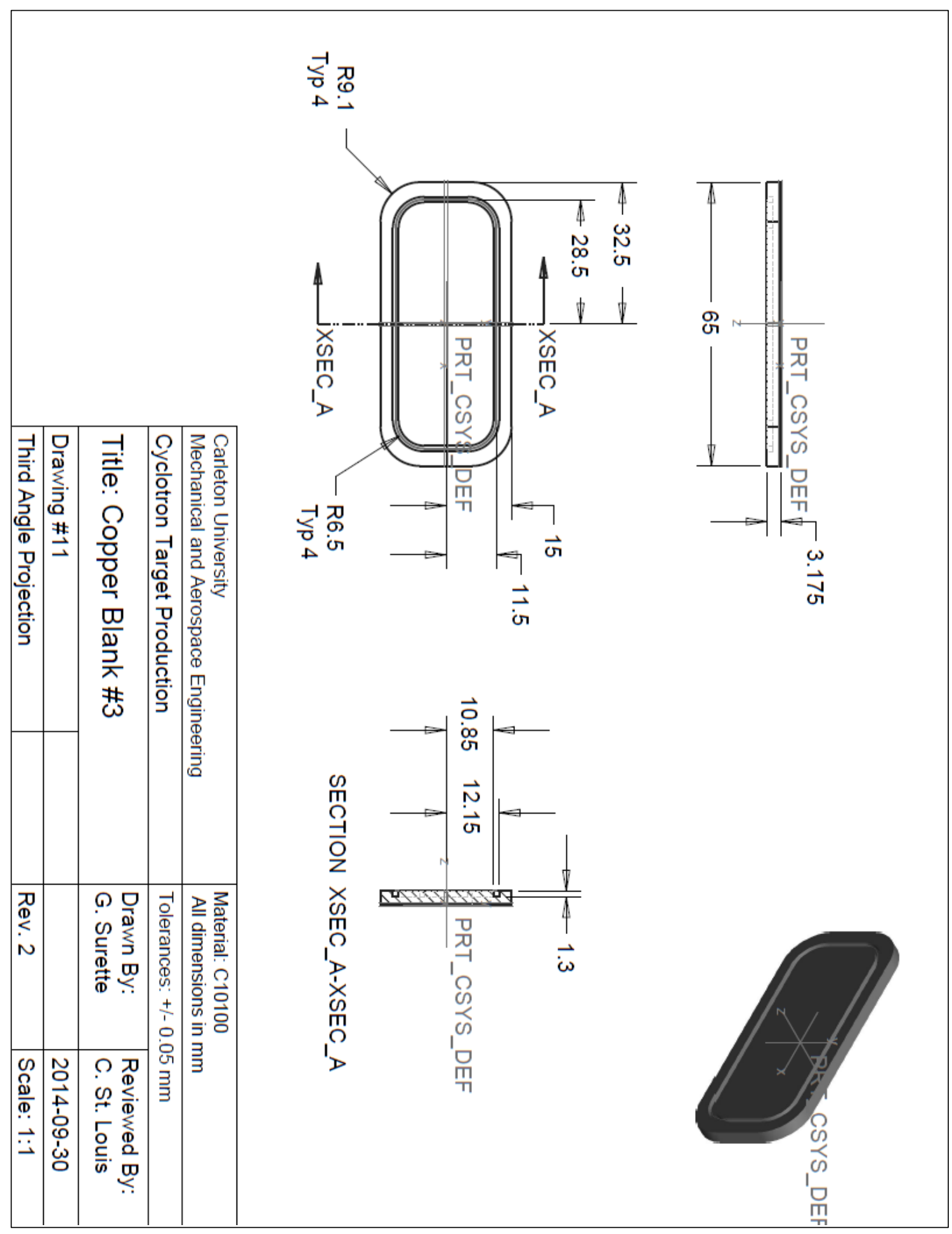




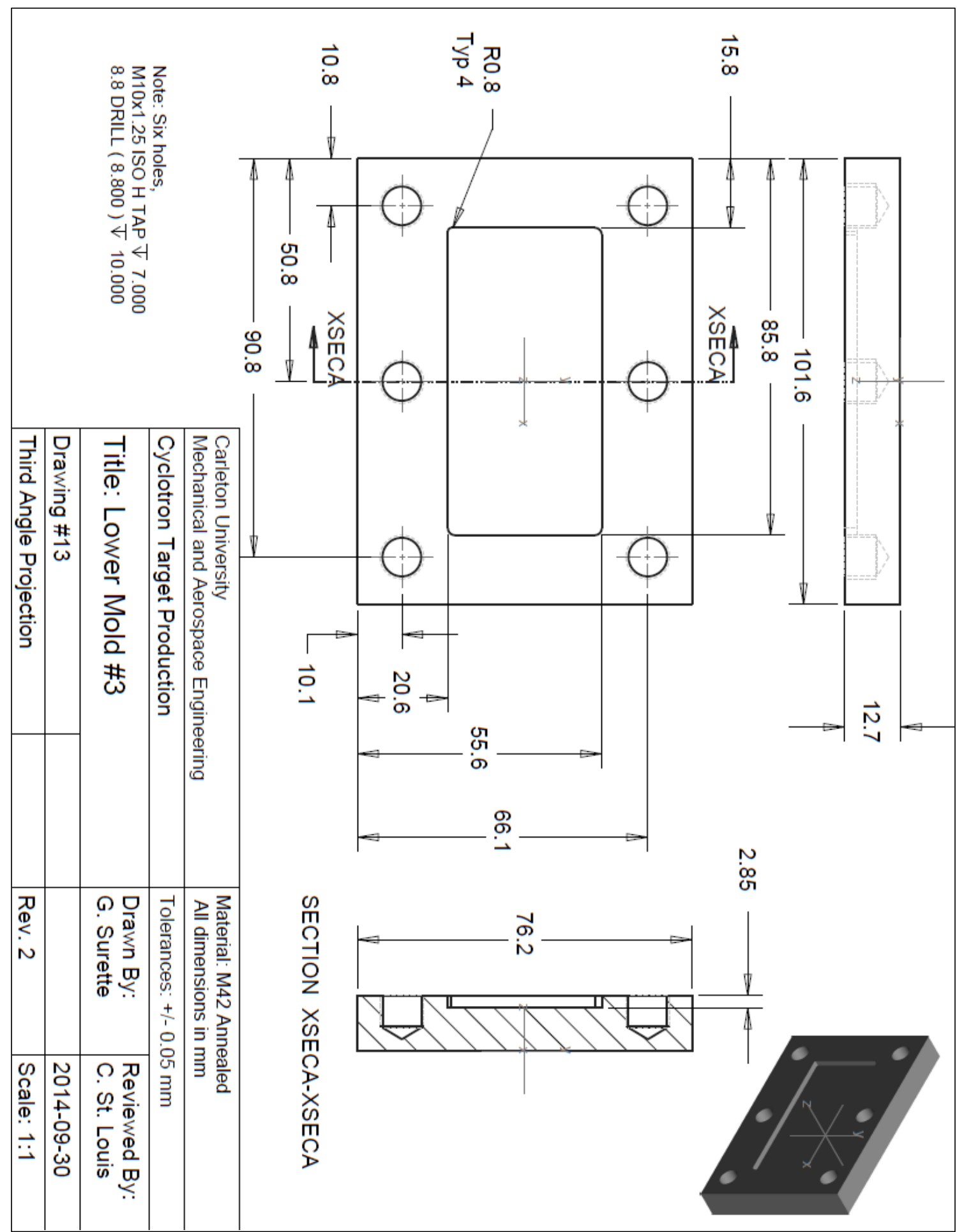




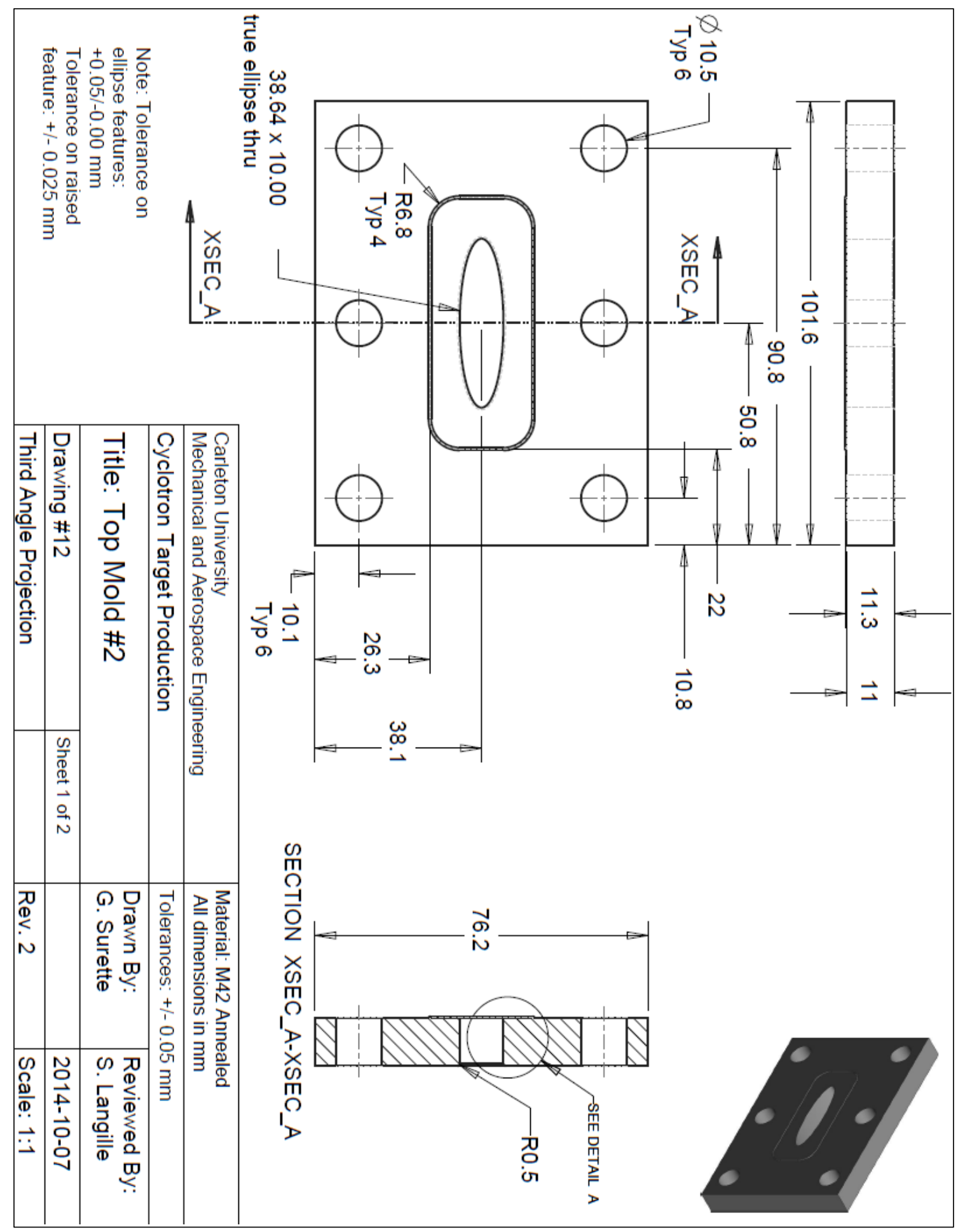




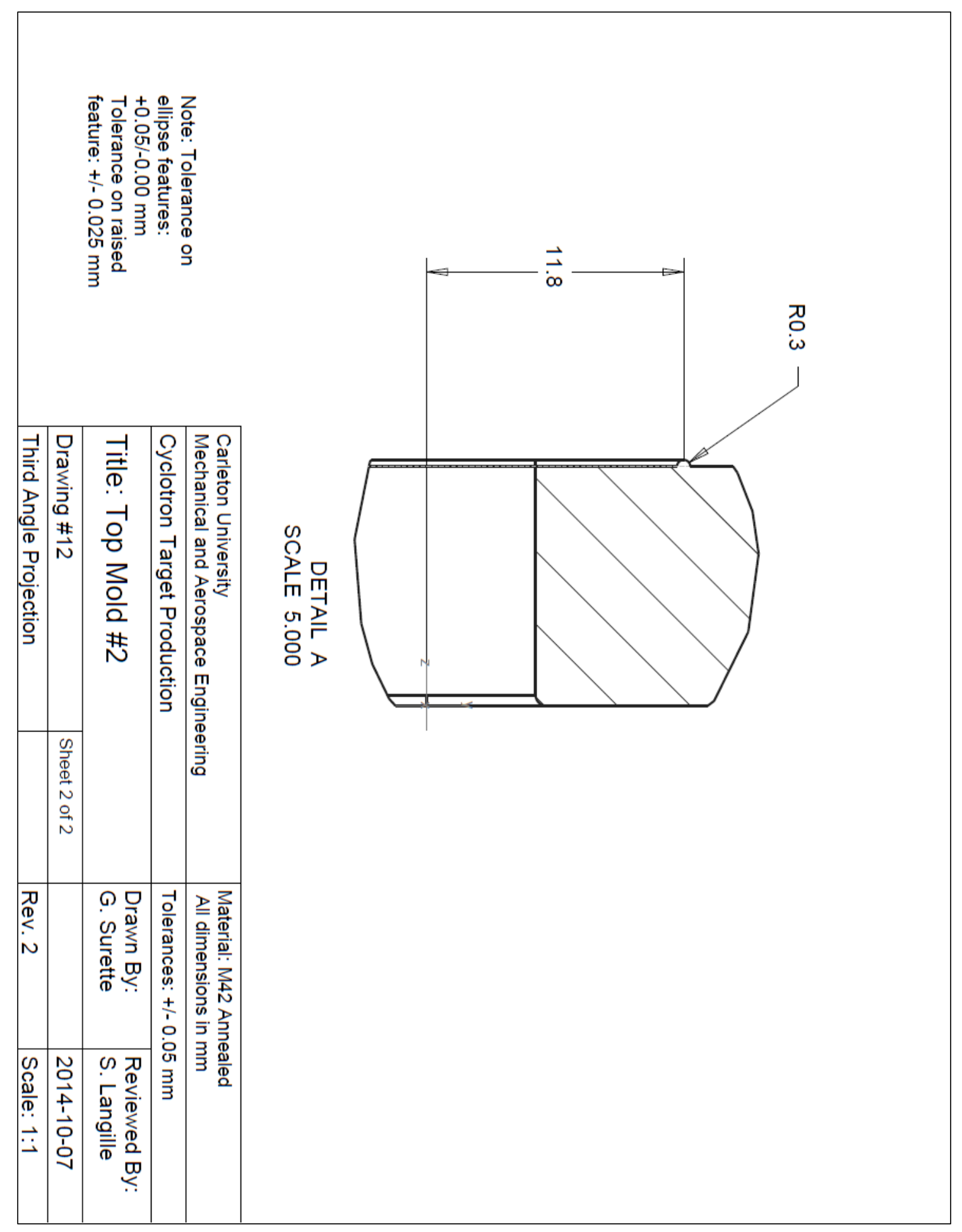




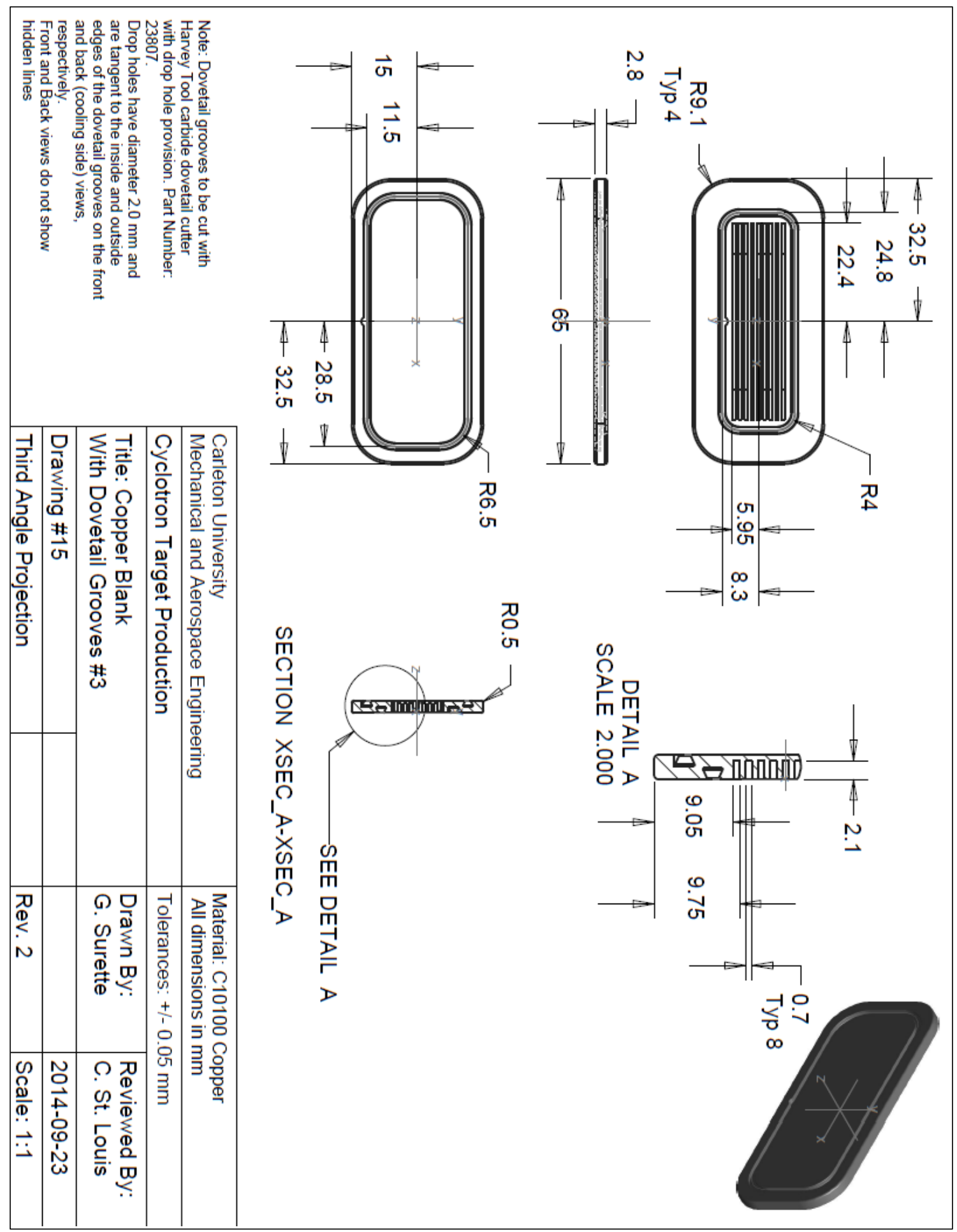




\section{A.4 Pressing Apparatus \#4}

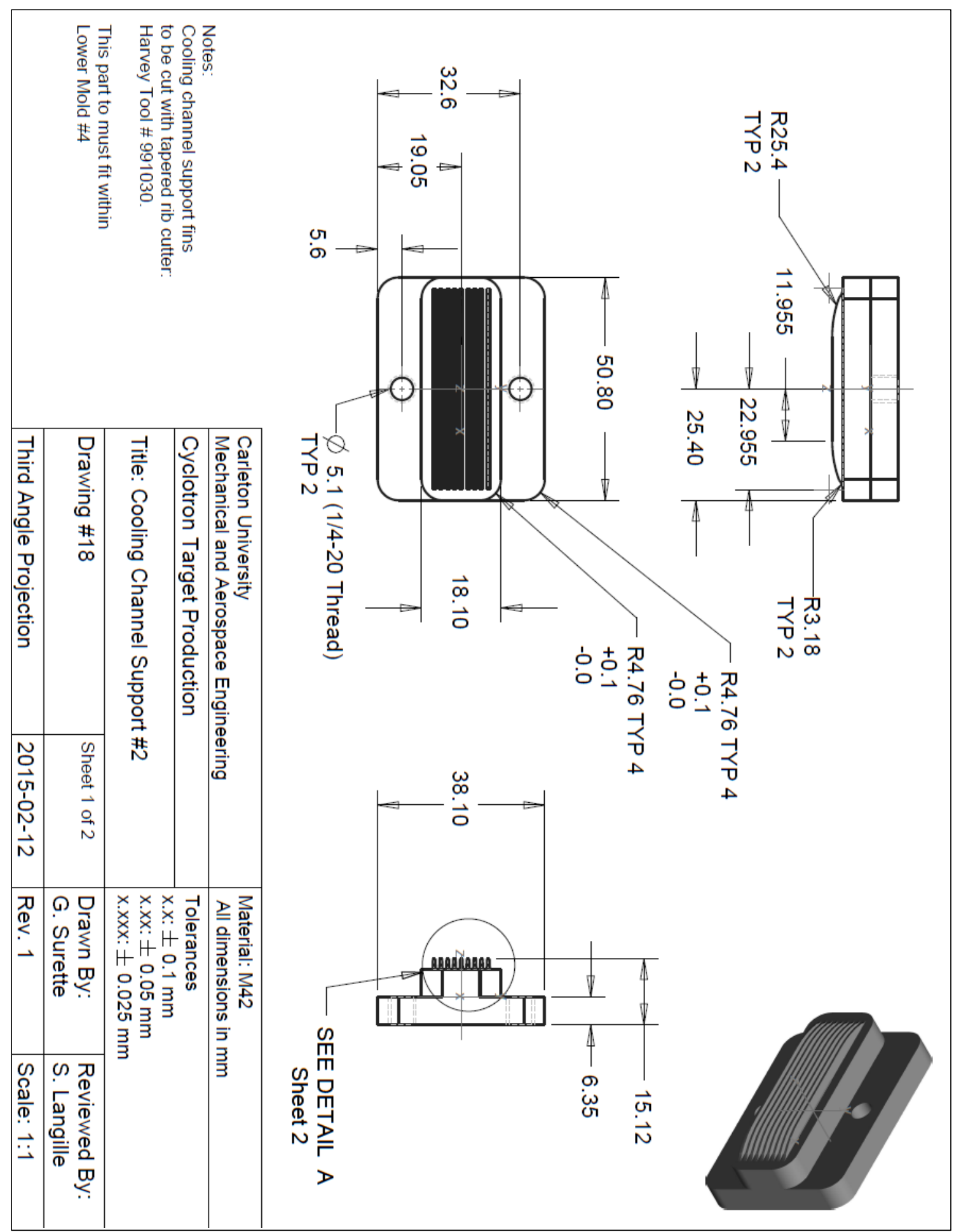




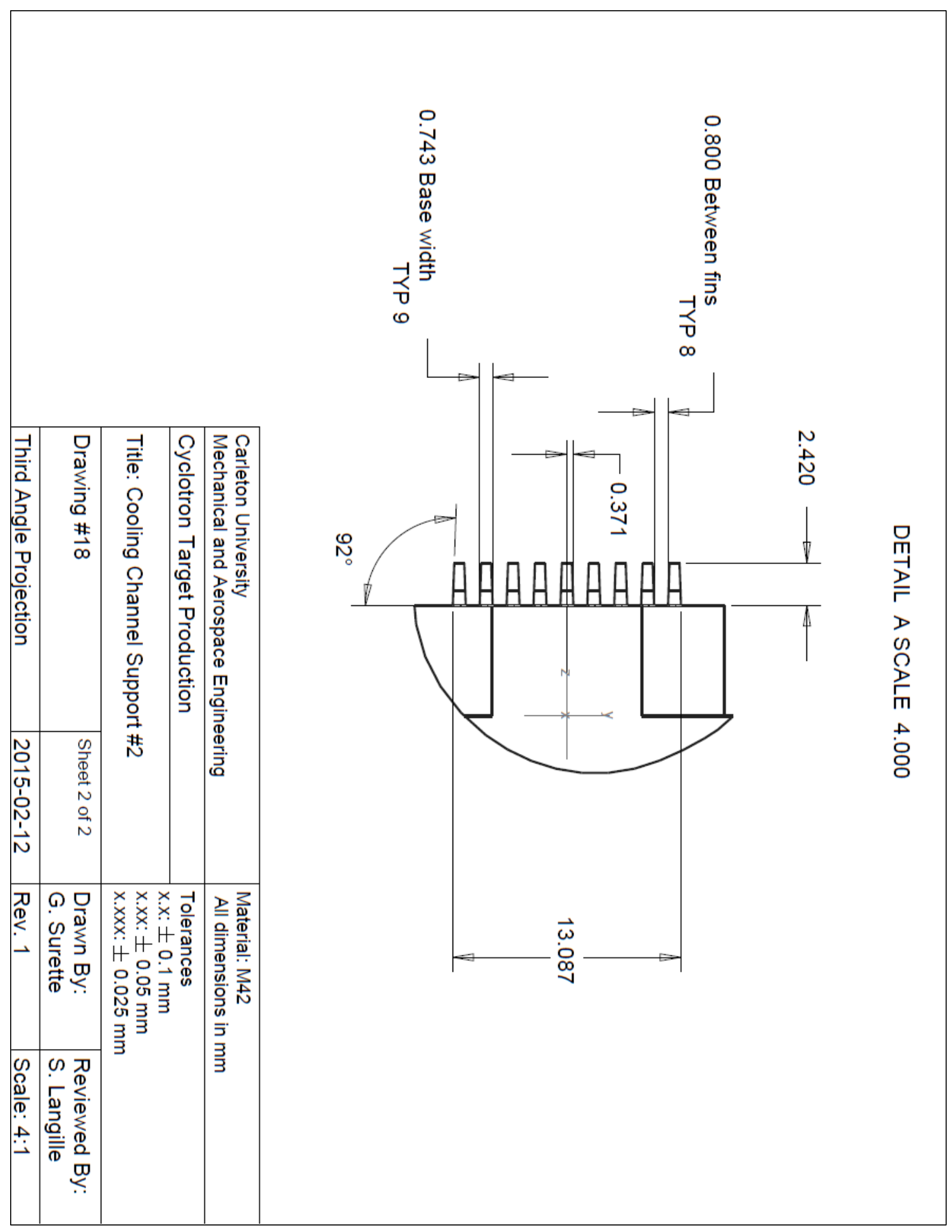




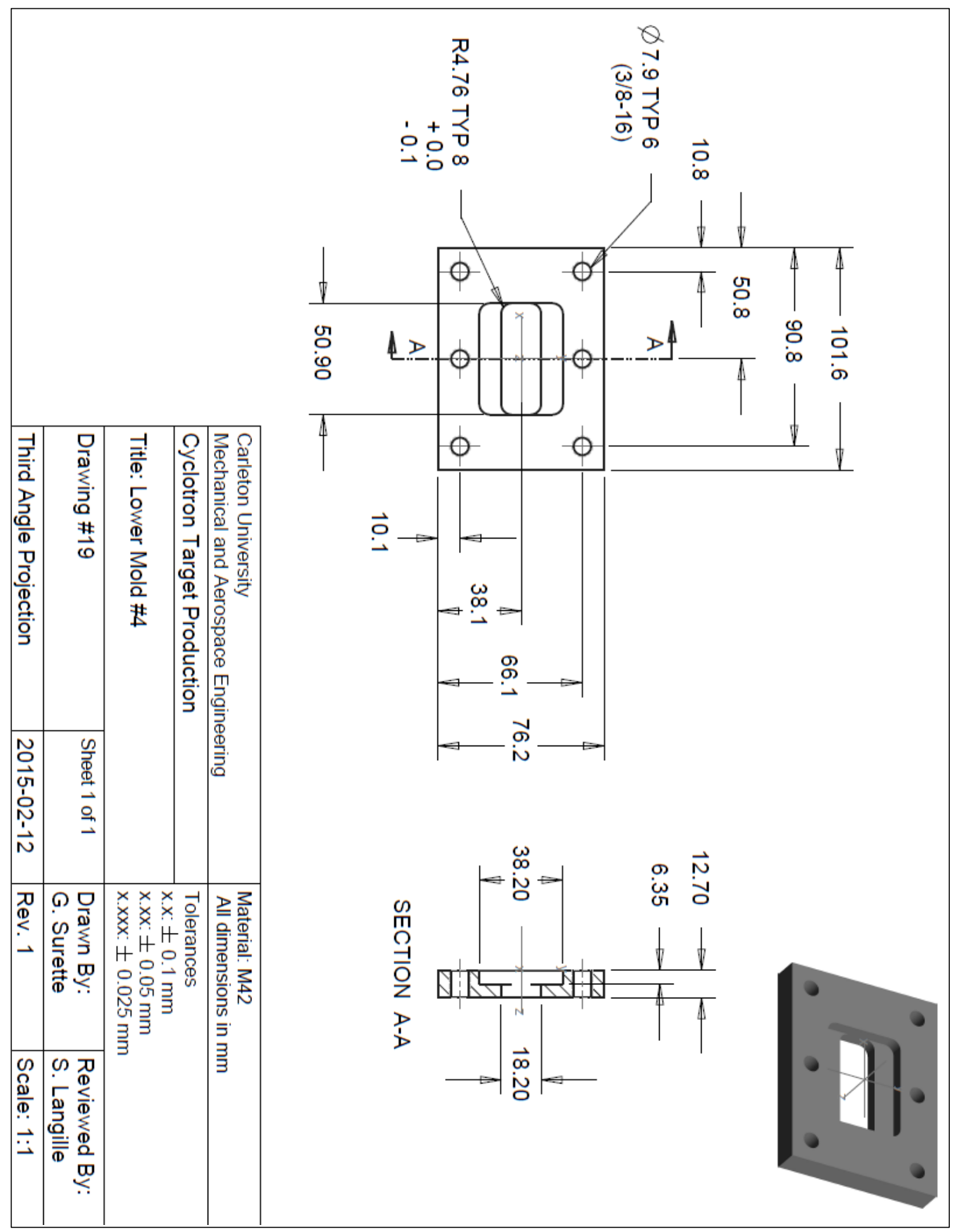




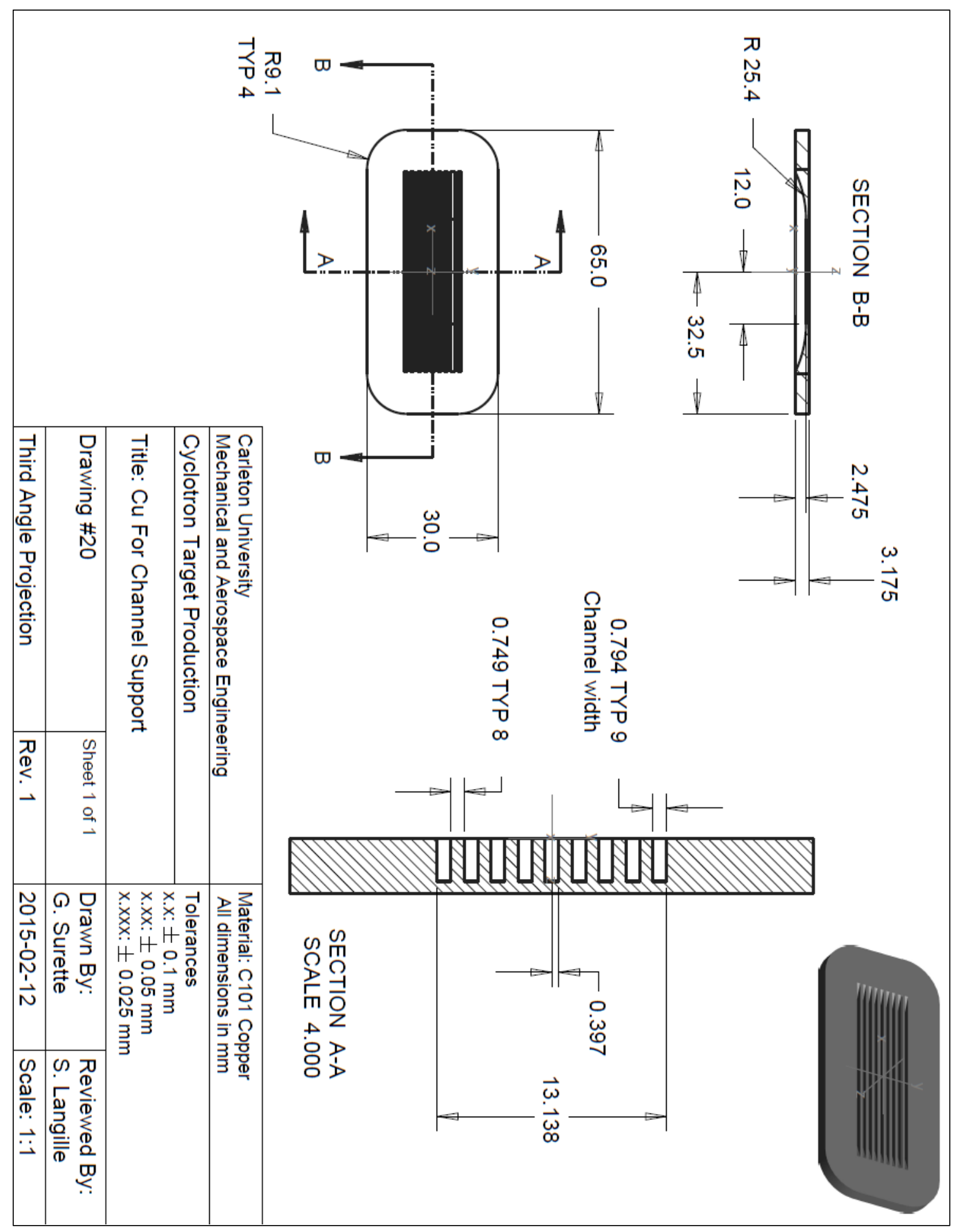




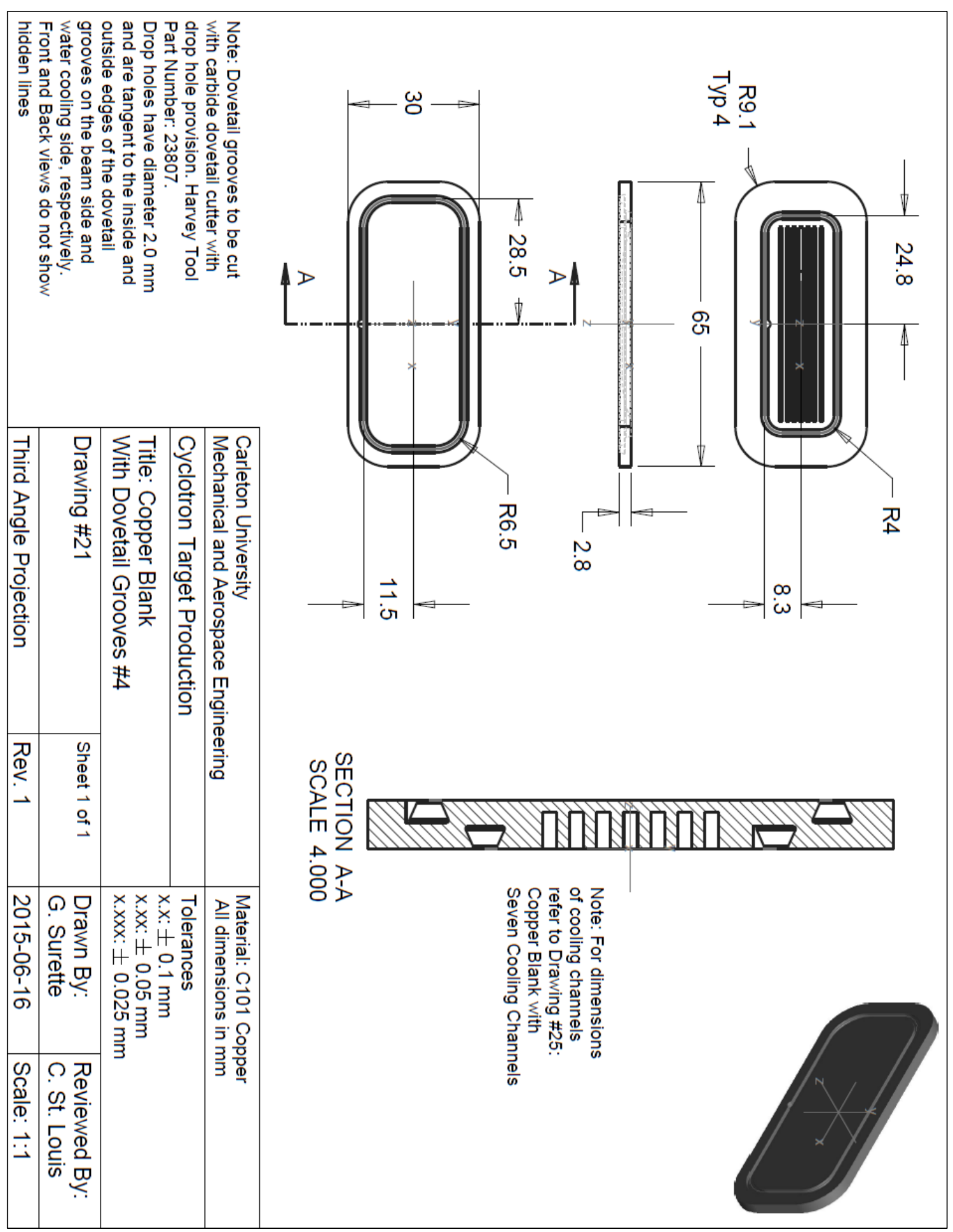




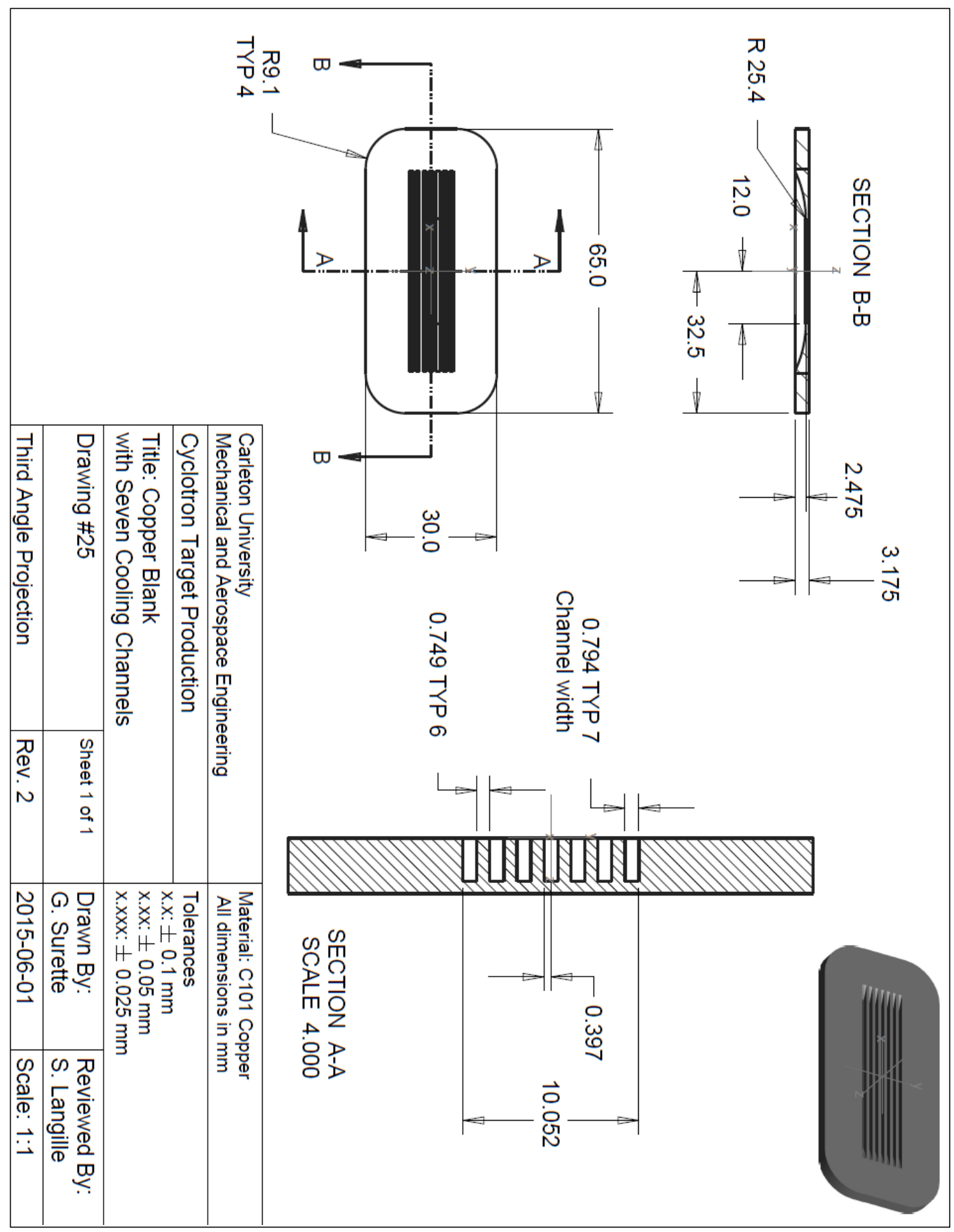




\section{Appendix B Setup Sheets for Machining Targets}

The tools, speeds, and feeds used on the CNC milling machine to post-machine elliptical targets are shown on the setup sheets below.

Appendix B.1 presents the setup sheet used for machining outer dimensions of elliptical targets. Three of the four sides are machined while the target is held in the three-pin jig, as shown in Figure 15, in Section 3.2.5.

Appendix B.2 presents the setup sheet used for machining outer dimensions of elliptical targets. The fourth side of a target is machined while the target is held in the three-pin jig, as shown in Figure 15, in Section 3.2.5.

Appendix B.3 presents the setup sheet used for machining the target to proper thickness, rough-cutting a groove, and cutting the dovetail O-ring groove on the water side, while held in the two piece jig shown in Figure 16, in Section 3.2.5.

Appendix B.4 presents the setup sheet used for rough-cutting a groove, and cutting the dovetail O-ring groove on the beam side, while held in the two piece jig, as shown in Figure 18, in Section 3.2.5. 


\section{B.1 Trimming Outer Dimensions (Three Sides)}

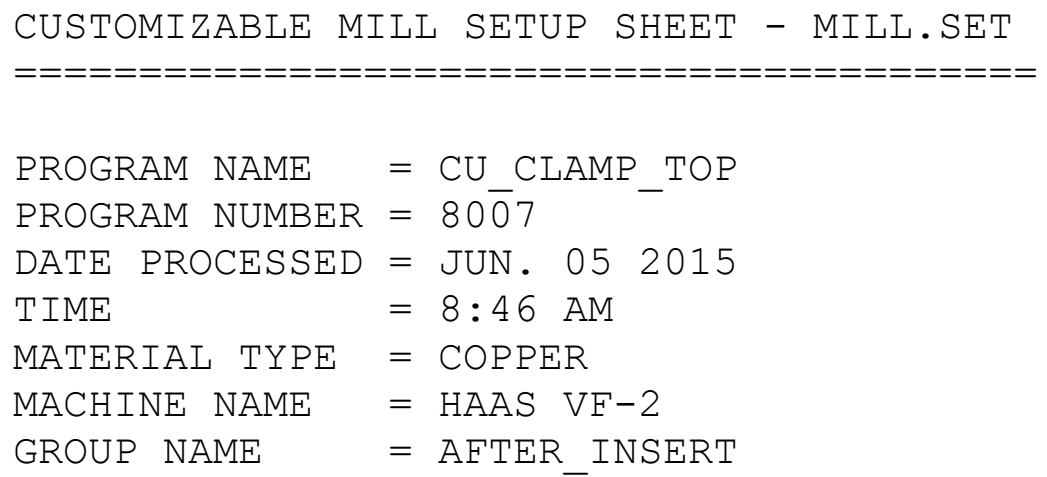




\section{B.2 Trimming Outer Dimensions (Fourth Side)}

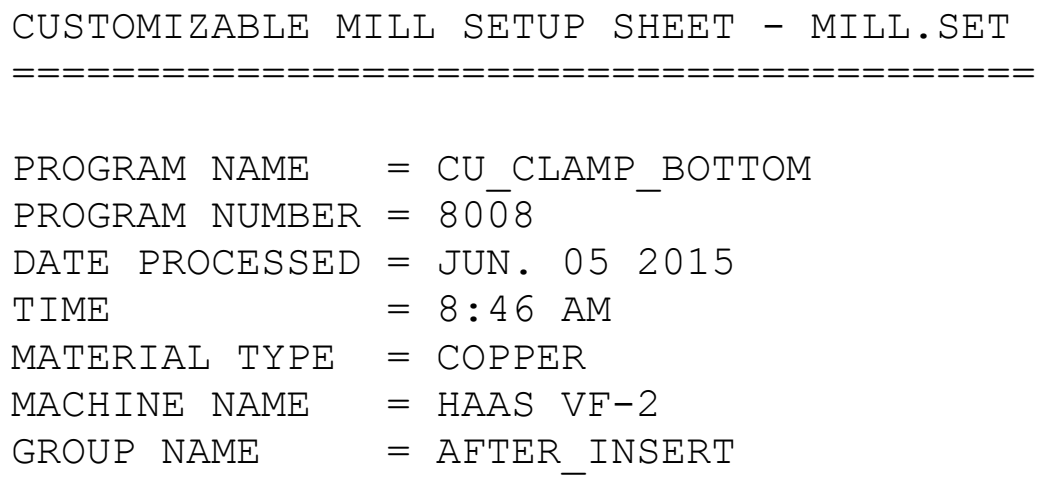




\section{B.3 Target Thickness and Water Side O-ring Groove}

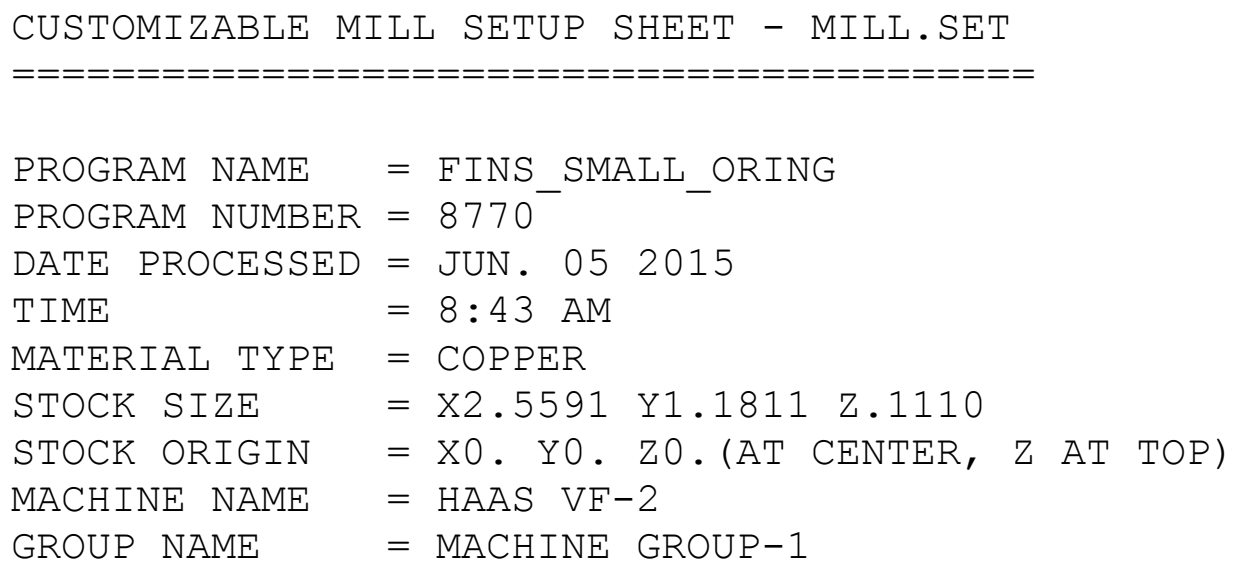




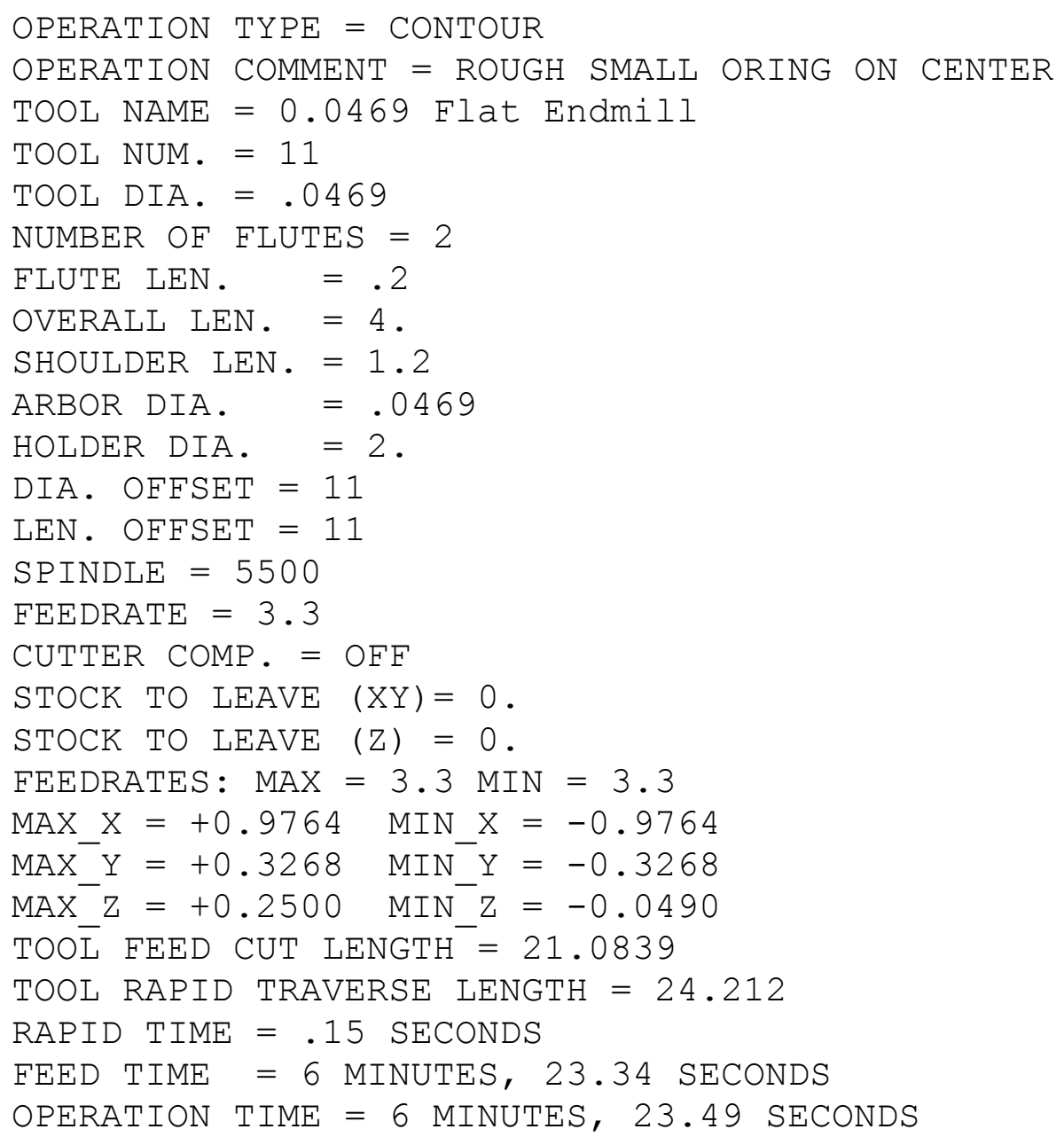




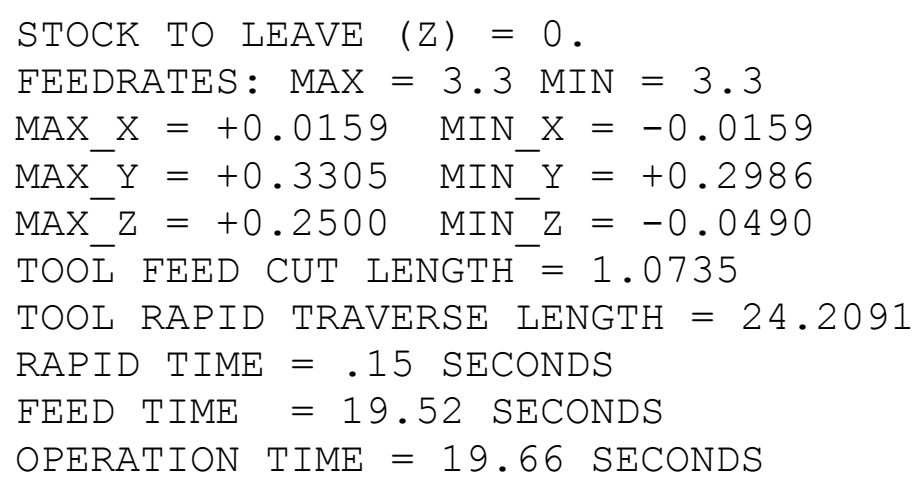


TOTAL RAPID TIME $=1.01$ SECONDS

TOTAL FEED TIME = 13 MINUTES, 23.97 SECONDS

CYCLE TIME: 14 MINUTES, 6.99 SECONDS 


\section{B.4 Beam Side O-ring Groove}

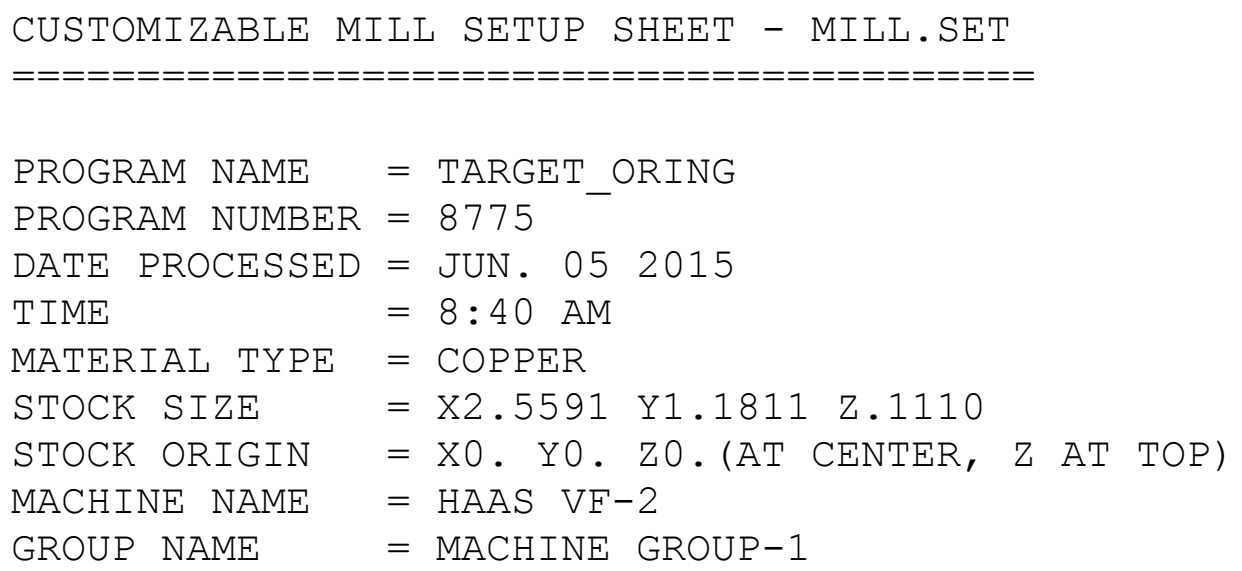




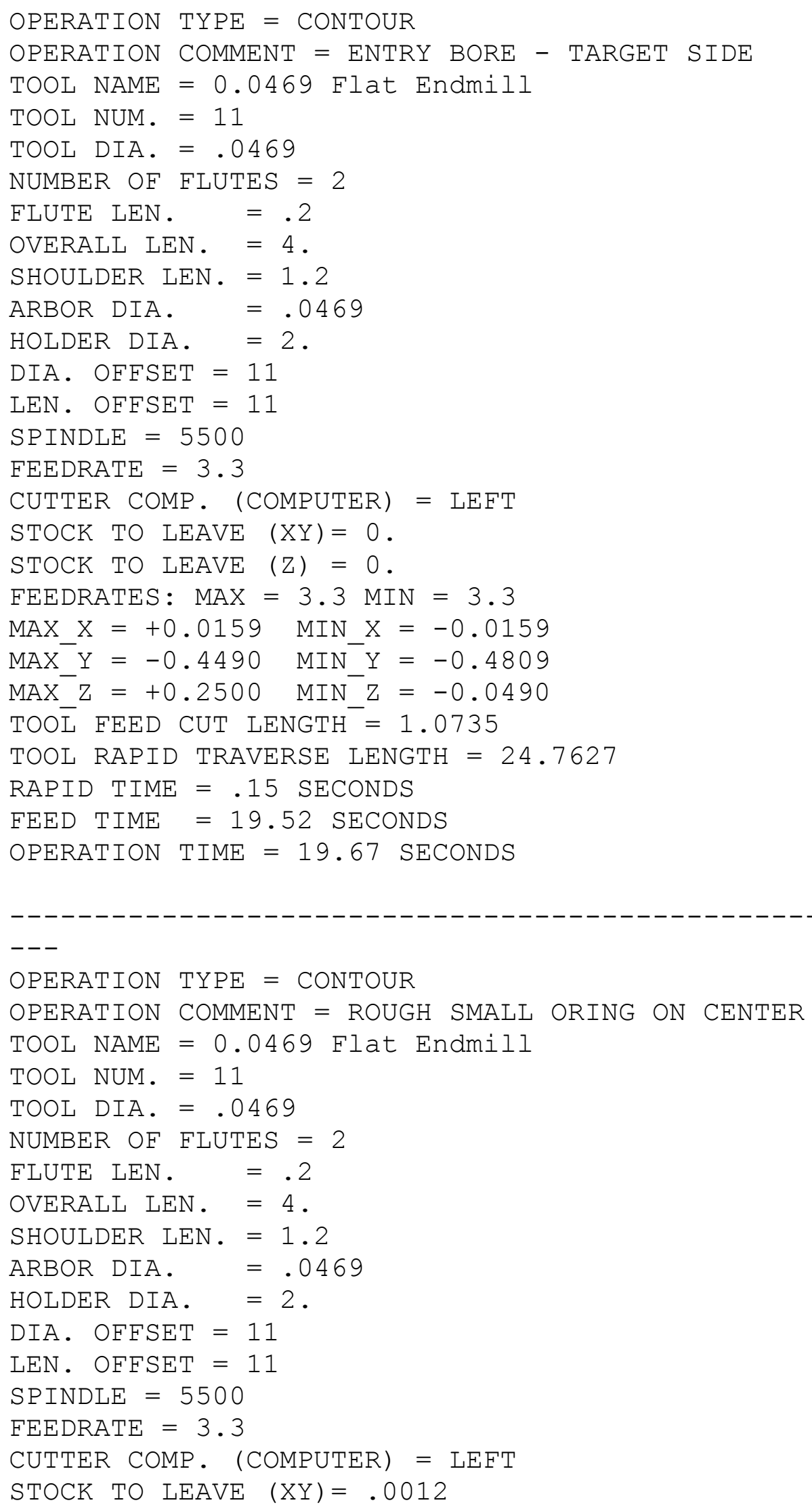




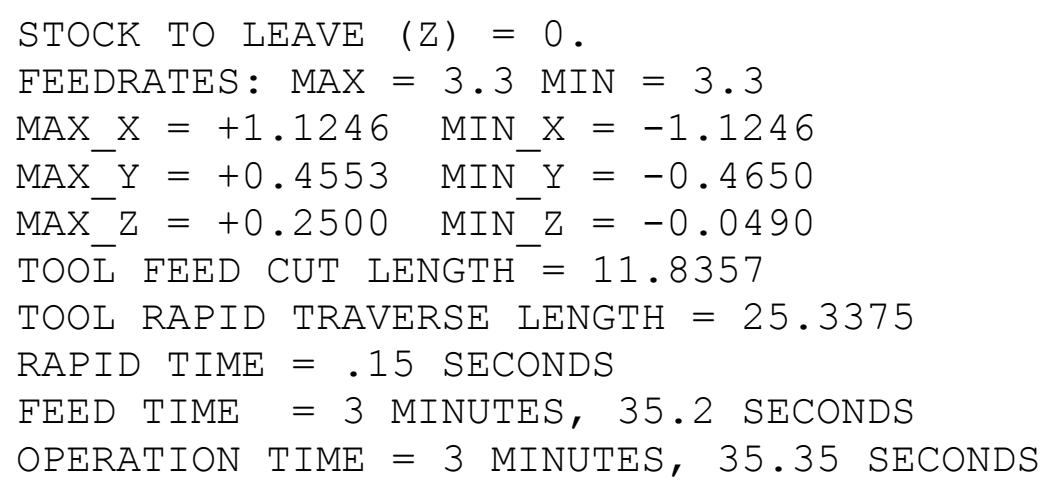




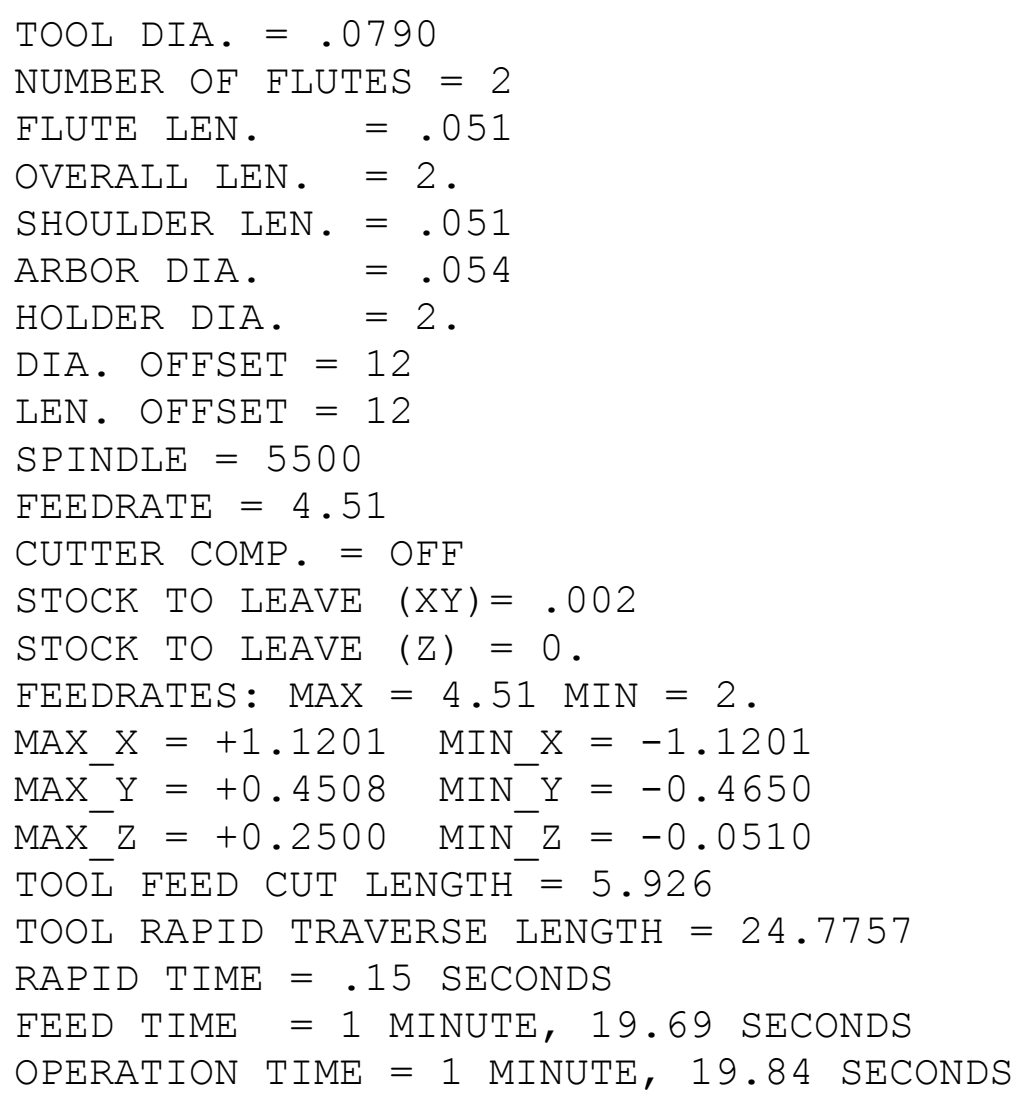




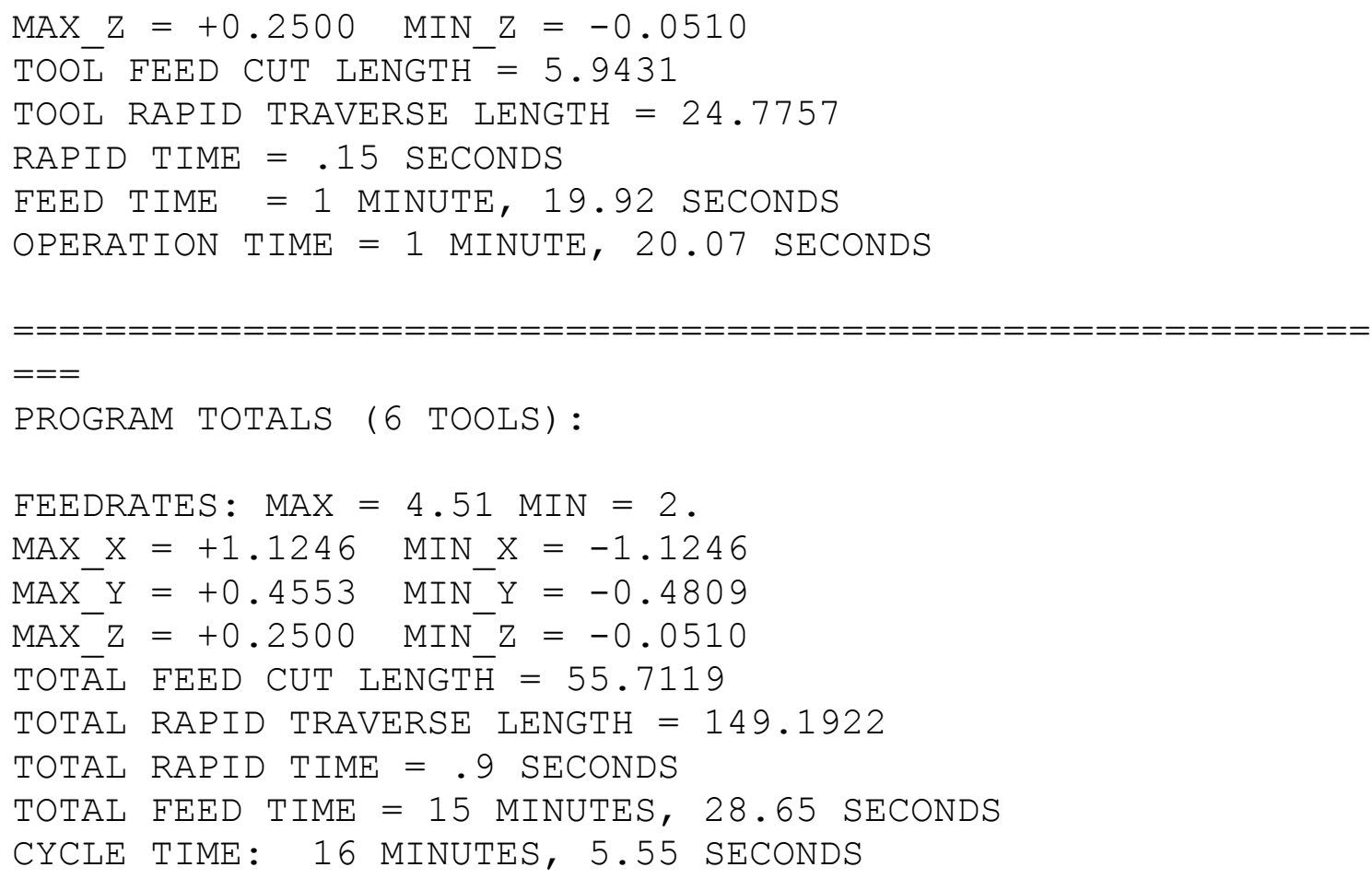




\section{References}

[1] Natural Resources Canada, "Tc-99m supply chain: From the NRU reactor to patients in Canada," 16 May 2013. [Online]. Available: https://www.nrcan.gc.ca/energy/uranium-nuclear/7799. [Accessed 24 June 2015].

[2] Natural Resources Canada, "Government of Canada Announces Extension of National Research Universal (NRU) Reactor," 6 February 2015. [Online]. Available: http://news.gc.ca/web/articleen.do?mthd=index\&crtr.page $=1 \&$ nid $=929189 \& \_g a=1.244450754 .654397081 .1376$ 485762. [Accessed 22 July 2015].

[3] H. L. Owen, J. Ballinger, J. Buscombe, R. Clarke, E. Denton, B. Ellis, G. Flux, L. Fraser, B. Neilly, A. Paterson, A. C. Perkins and A. Scarsbrook, "Options For UK Technetium-99m Production Using Accelerators," in International Particle Accelerator Conference, Dresden, Germany, 2014.

[4] M. E. Phelps, S. R. Cherry and J. A. Sorrenson, Physics in Nuclear Medicine. Third Edition., Pennsylvania, United States: Saunders, 2003.

[5] S. Vallabhajosula, Molecular Imaging: Radiopharmaceuticals for PET and SPECT, Berlin, Germany: Springer-Verlag Berlin Heidelberg, 2009.

[6] P. Goodhand, R. Drouin, T. Mason and E. Turcotte, "Report of the Expert Review Panel on Medical Isotope Production," Ottawa, Ontario, November 2009.

[7] K. V. Kotegov, O. N. Pavlov and V. P. Shvedov, "Technetium," Advances in Inorganic Chemistry and Radiochemistry, vol. 11, pp. 1-82, 1968. 
[8] C. Perrier and E. Segrè, "Some chemical properties of element 43," J. Chem. Phys., vol. 5, pp. 712-716, 1937.

[9] Los Alamos National Laboratory, "Periodic Table of the Elements," [Online]. Available: http://periodic.lanl.gov/43.shtml. [Accessed 18 June 2015].

[10] P. Richards, "Technetium-99m: The early days," in 3rd International Symposium on Technetium in Chemistry and Nuclear Medicine, Padua (Italy), 1989.

[11] K. Gagnon, "Cyclotron Production of Technetium-99m" Ph.D. dissertion, Dept. of Phys., Univ. of Alberta: Edmonton, 2012.

[12] C. K. Ross and W. T. Diamond, "Predictions regarding the supply of 99Mo and 99mTc when NRU ceases production in 2018," June 2015. [Online]. Available: http://arxiv.org/abs/1506.08065. [Accessed 22 July 2015].

[13] J. E. Beaver and H. B. Hupf, "Production of 99mTc on a Medical Cyclotron: A Feasibility Study," Nucl. Med., vol. 12, no. 11, pp. 739-741, 1971.

[14] P. Gould, "Medical isotope shortage reaches crisis level," Nature, vol. 460, pp. 312-313, 2009.

[15] Toronto Star, "Isotope shortage looms after reactor shutdown," 19 May 2009. [Online]. Available: http://www.thestar.com/news/canada/2009/05/19/isotope_shortage_looms_after_re actor_shutdown.html. [Accessed 27 July 2015]. 
[16] R. Trager, "Medical isotope shortage concerns in US," Royal Society of Chemistry, 25 November 2009. [Online]. Available:

http://www.rsc.org/chemistryworld/News/2009/November/25110902.asp. [Accessed 27 July 2015].

[17] Natural Resources Canada, "Request for Project Proposals for the Non-reactorbased Isotope Supply Contribution Program," 1605 2013. [Online]. Available: https://www.nrcan.gc.ca/energy/uranium-nuclear/7797. [Accessed 2707 2015].

[18] Natural Resources Canada, "Minister Oliver Invites Proposals for New Medical Isotopes Innovation Program," 22 June 2012. [Online]. Available: http://www.nrcan.gc.ca/media-room/news-release/2012/2077. [Accessed 23 June 2015].

[19] P. Schaffer, F. Benard, K. R. Buckley, V. Hanemaayer, C. H. Manuela, J. A. Klug, M. S. Kovacs, T. J. Morley, T. J. Ruth, J. Valliant, S. K. Zeisler and M. G. Dodd, "Processes, systems, and apparatus for cyclotron production of technetium-99m". Canada Patent CA 2871305 A1, 31 October 2013.

[20] A. Bell, G. A. McRae, R. Wassenaar, R. G. Wells and D. Faber, "nSPECT: A Radioisotope-Free Approach to Nuclear Medicine Imaging," IEEE Transactions on Nuclear Science, vol. 62, no. 3, pp. 791-798, June 2015. 
[21] L. Matei, G. McRae, R. Galea, K. Moore, D. Niculae, L. Craciun, G. Surette, S. Langille, P. Keeping, C. St. Louis, W. Gelbart, B. Abeysekera and R. R. Johnson, "A new approach for manufacturing and processing targets used to produce $99 \mathrm{mTc}$ with cyclotrons," in 15th International Workshop on Targetry and Target Chemistry, Prague, Czech Republic, 2014.

[22] J. F. Ziegler, M. D. Ziegler and J. P. Biersack, "The stopping and range of ions in matter (SRIM code, version 2013.00)," [Online]. Available: http://www.srim.org/. [Accessed 2015].

[23] Advanced Systems Designs Inc., [Online]. Available: http://www.asd-inc.ca/.

[24] J. Lilley, Nuclear Physics: Principles and Applications, West Sussex, UK: John Wiley \& Sons, 2001.

[25] Bohler Uddeholm Thermo-Tech , 2645 Meadowvale Blvd, Mississauga, ON L5N $8 C 2$.

[26] Marco Rubber and Plastic Products Inc., "Groove Design Assistance," [Online]. Available: http://www.marcorubber.com/gd-directory.htm.

[27] Y. W. Lee, "Water soluble ceramic core for use in die casting, gravity and investment casting of aluminum alloys". United States of America Patent US6024787A, 15 February 2000.

[28] B. Scholten, R. M. Lambrecht, M. Cogneau, H. Vera Ruiz and S. M. Qaim, "Excitation functions for the cyclotron production of 99mTc and 99Mo," Applied Radiation and Isotopes, no. 51, pp. 69-80, 1999. 
[29] L. Matei, "Thermal separation of 99mTc from Molybdenum Targets, presentation," in 15th Int. Workshop on Targetry and Target Chemistry WTTC15, Prague, Czech Republic, August 18-21, 2014. 